\title{
THE MICROPOLITICS OF EDUCATIONAL CHANGE EXPERIENCED BY NOVICE PUBLIC MIDDLE SCHOOL PRINCIPALS
}

\author{
By LOUIS F. CARUSO
}

A dissertation submitted to

The Graduate School of Education

Rutgers-The State University of New Jersey

In partial fulfillment of the requirements

for the degree

Doctor of Education

Graduate Program in Educational Administration and Supervision

Approved by

Catherine A. Lugg, Ph.D., Chair

Bruce D. Baker, Ed.D.

Carol F. Karpinski, Ed.D.

New Brunswick, New Jersey

May, 2011 
Copyright 2011, Louis F. Caruso 


\section{ACKNOWLEDGMENTS}

I extend a sincere thank you to the principals, teachers and parents who dedicated time to offer their perspectives about a topic I passionately care about. The principals granted me full access to their routines and kept me informed through bi-monthly journals. The staff members provided me insight into their school cultures. Parents helped me gain an understanding into each school community. I am fortunate to have had the contributions these dedicated professionals made to this project.

My research would not have been successful without the contributions from my committee. I wish to thank my committee chair, Dr. Catherine Lugg, for her continuous encouragement, support and guidance throughout my time at Rutgers University. She dedicated her own time to read countless pages of my work, provide critical feedback that shaped the evolution of my study and point me to critical studies to encapsulate my findings within a historical and social context. I wish to thank Dr. Bruce Baker and Dr. Carol Karpinski for their influences. Dr. Baker's writings regarding the implications of national rhetoric on public education policy led me to inquire more about macro factors. Dr. Karpinski’s feedback on several installments of my study made me feel I was on target.

I am most grateful to my wife, Stephanie, for the sacrifices she made to support me throughout the doctoral program. She was a pillar of strength for our family, as I was busy reading, writing and thinking. Although too young to realize, my son Christian has taught me, everyday, the importance of curiosity and the new discoveries it will lead to. I also thank my parents who instilled in me the value of work ethic and the importance of education, and my brother, Leo, who always supported me throughout the process. Finally, I thank my colleague, Mark Mongon, who gave me substantial feedback on this study. 


\begin{abstract}
OF THE DISSERTATION
The Micropolitics of Educational Change Experienced by Novice Public Middle School Principals

\author{
By Louis F. Caruso
}

Dissertation Chairperson: Catherine A. Lugg, Ph.D.
\end{abstract}

Every public school displays its own life, social climate, organizational culture, and subsystems (Iannaccone, 1991). First or second year middle school principals often find themselves contributing to and navigating through one element of these social systems known as the micropolitics of education. Consequently, novice public middle school principals face the challenge of identifying key micropolitical structures and landscapes within their public schools, and have the daunting task of navigating internal micropolitical structures and interactions in relationship to external macropolitical structures, while negotiating educational change (Bacharach \& Mundell, 1993; Hargreaves \& Goodson, 2006; Willower, 1991). This year-long qualitative study detailed the lived experiences of two suburban novice middle school principals and documented their attempts to identify their micropolitical landscapes through seemingly open approaches, and lead within their environments to negotiate holistic educational change (Blase \& Anderson, 1995).

However, both novice middle school principals were unprepared to manage a period of decline in public education (Boyd, 1982). The principals relied on closed and conflictive leadership approaches, as typically peripheral macropolitical elements became central actors in their micropolitical landscapes (Marshall, Mitchell \& Wirt, 1989). Consequently, formal hierarchies and structural vertical leadership styles were enforced through mandates, rewards and sanctions to ensure efficiency and compliance during implementation of school and district 
initiatives (Bolman \& Deal, 2003; Scribner, Hager, \& Warne, 2002). During periods of macropolitical ambiguity and uncertainty, each principal relied on coercive tactics to limit and control teachers' social interactions during grade-level team meetings, and access to micropolitical structures, which decided who got what, when and how. As communicative networks became inaccessible, teachers grew apathetic and disengaged from administrative decisions and requests to promote holistic educational change.

During current budgetary and economic decline, suburban novice middle school principals need to understand how their decisions impact existing micropolitical social structures. Novice principals also must be much more attuned to macropolitical policies and mandates, and be more sophisticated at conceptual thinking, and transforming the organization through people and teams (Fullan, 2007). 


\section{TABLE OF CONTENTS}

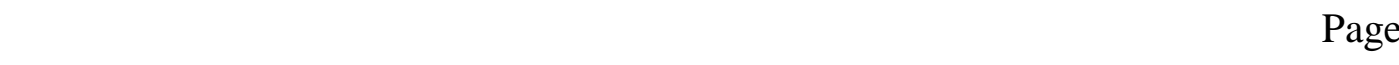

$\begin{array}{ll}\text { ACKNOWLEDGEMENTS } & \text { ii }\end{array}$

ABSTRACT

LIST OF TABLES vii

Chapter

$\begin{array}{lll}\text { I INTRODUCTION } & 1\end{array}$

Introduction to the Problem 1

Methods 4

Plan of Dissertation $\quad 6$

Limitations $\quad 8$

Significance of Study $\quad 11$

$\begin{array}{ll}\text { Summary } & 12\end{array}$

$\begin{array}{lll}\text { II } & \text { REVIEW OF LITERATURE } & 14\end{array}$

Micropolitics of Education $\quad 14$

Understanding the Micropolitical Landscape $\quad 18$

$\begin{array}{ll}\text { Leading within Micropolitical Landscapes } & 23\end{array}$

Politics of Educational Change $\quad 29$

Rational, Conceptual Framework and Research Questions 32

Summary $\quad 35$

$\begin{array}{ll}\text { III } & 37\end{array}$

Method 37

Sample Selection $\quad 38$

Methods of Data Collection $\quad 44$

Role of the Researcher $\quad 47$

Interviews and Observations $\quad 49$

Review of Documents 51

Inclusion of School Community Voices $\quad 52$

Review of Documents Timeline $\quad 53$

Data Analysis $\quad 56$

$\begin{array}{ll}\text { Summary } & 58\end{array}$ 
IV UNDERSTANDING THE MICROPOLITICAL LANDSCAPE 61

Macropolitical Budget Crisis and Culture of Shock 63

Getting to Know Each Other 66

Building Relationships with Superiors and Colleagues $\quad 74$

Understanding Previous Administrative Culture $\quad 78$

V LEADING WITHIN THE LANDSCAPE 82

Forging an Administrative Culture $\quad 84$

Implementing District and School Initiatives 91

Addressing Parent and Teacher Concerns 101

Leading through Decisions $\quad 112$

VI THE POLITICS OF EDUCATIONAL CHANGE 119

Surviving Budget Cuts 120

Staff Movement amidst Budget Crisis 127

Enhancing Initiatives through the Hiring Process 130

Creating Change through Initiatives $\quad 135$

The Politics of Change amid Decline 155

$\begin{array}{ll}\text { VII DISCUSSION } & 165\end{array}$

Revisiting Research Questions 166

Findings in Light of Existing Research 176

Implications for Future Research and Current Practices $\quad 181$

Limitations 183

$\begin{array}{ll}\text { Conclusion } & 184\end{array}$

$\begin{array}{ll}\text { REFERENCES } & 186\end{array}$

$\begin{array}{ll}\text { APPENDICES } & 195\end{array}$

Data Collection Instruments for Principals 195

Data Collection Instruments for School Community Voices 204

IRB Review Approval Notice 207 


\section{LIST OF TABLES}

Table

1. Overview of Eligible Participants

2. Overview of Selected Districts

3. Overview of Schools

4. Overview of Principals

5. Overview of School Community Voices

6. Data Collection Calendar and Matrix
Page 


\section{CHAPTER I}

\section{INTRODUCTION}

\section{Introduction to the Problem}

According to Iannaccone (1991), every public school displays its own life, social climate, organizational culture, and subsystems. School community members often find themselves contributing to and navigating through one element of these social systems known as the micropolitics of education. The study of micropolitics is concerned with social interactions and political ideologies of teachers, administrators and pupils to decide who gets what, when and how. These interactions often deal with the displacement of conflicts, as members pursue their own legitimate interests within the organization (Iannaccone, 1991; Marshall \& Scribner, 1991). Subsequently, decision making in schools cannot be explained without understanding political power and the strategies used by individuals and groups to gain such power (Mawhinney, 1999). Consequently, new members, specifically school leaders, entering a school community for the first time, often frame their practice as political, as their goals and decisions emerge from negotiating scarce resources among different stakeholders (Bolman \& Deal, 2003; Lindle \& Mawhinney, 2003). Novice middle school principals often find themselves contributing to and navigating through micropolitics to decide who gets access to scarce resources. Subsequently, school administrators face micropolitical elements, such as power, divergent organizational goals, ideological disputes and control of resources (Ball, 1987; Lindle \& Mawhinney, 2003). Micropolitical perspectives imply that order in organizations is constantly being negotiated and renegotiated (Bacharach \& Mundell, 1993). As a result, interest groups and individuals emerge and attempt to influence decision making (Bacharach \& Mundell, 1993). 
Additionally, public school principals often find themselves balancing macropolitical elements, such as declining state public school funding, waning public confidence in schools and federal mandates to improve student achievement (Boyd, 1982, 1983). Strikingly, today's macropolitical environment closely resembles the "politics of decline" of the 1970s, as public school principals face retrenchment, which includes slashed public school budgets, contracted student programs, teacher cutbacks and larger class sizes (Boyd, 1982, 1983). Even during decline, middle school principals still faced the fundamental educational responsibility to provide quality student-centered educational programs that addressed children socially, physically, emotionally and academically (Hickcox \& Ryan, 1979; Hoy \& Hannum, 1997). Consequently, public middle school principals do not work in a vacuum nor are they immune from macropolitical pressures. Instead, each principal's micropolitical landscape is influenced, and depends on, the macropolitical environment (Bacharach \& Mundell, 1993).

The interaction of interest groups or individuals can happen both within and outside of the organization. In an effort for educational administrators to create lasting and holistic educational change, rather than islands or pockets of change, novice principals confront the challenge of negotiating, both macro and micropolitically, individuals and groups seeking to pursue their own interests through the organization (Bacharach \& Mundell, 1993; Hargreaves \& Goodson, 2006). Ideally, novice principals cannot rely solely on their formal authority and hierarchical power. Instead, they must learn how to bring people and organizational structures together to create a union focused on educational change (Ball, 1987). Moreover, novice public middle school principals must find ways to successfully implement district and school goals and develop positive partnerships with teachers, parents, colleagues, superiors and board of education members in the midst of state and local budgetary crises. 
Educational change is intrinsically political and conflict-ridden in origin. Groups organize and contest other groups in the politics of education to express their values and to secure their interests in public schools (Tyack \& Cuban, 1995). These actions are heightened when schools face macropolitical pressures, such as No Child Left Behind (NCLB) mandates, slashed local budgets and retrenchment. Consequently, influential actors have the potential to derail or support principals' goals and initiatives. Despite previous researchers (Bacharach \& Mundell, 1993; Bjork \& Blase, 2009; Blase, 1991; Blase \& Bjork, 2009; Boyd, 1982, 1983; Darling-Hammond, 1992; Hickcox \& Doris, 1979; Mawhinney, 1999) confirming that macro level factors significantly influence the micropolitical character of schools, the nature and processes in which novice middle school principals negotiate the micropolitics of education, within their macropolitical environment, to create holistic educational change is not concretely understood.

This qualitative study discusses how first and second year middle school principals navigated micropolitical landscapes in their public school environments to create holistic educational change. The following questions guided my plan to capture the lived experiences of two novice public middle school principals:

How do novice middle school principals navigate micropolitical landscapes in their public schools to create educational change? From this large research question flow three smaller questions:

a. How do new middle school principals identify key micropolitical power structures and individual power brokers in their school community?

b. How do new middle school principals situate themselves within the micropolitical structures of their schools? 
c. How do new middle school principals navigate micropolitical structures and conflicts in schools to create educational change?

\section{Methods}

The study documents and analyzes the lived experiences of two (2) first or second year public middle school principals and explores how each navigated their micropolitical landscape. The study describes how novice principals navigated and negotiated internal micropolitical pressures in relationship to external macropolitcal pressures to negotiate holistic educational change. The subjects' participation began January, 2010 and concluded December, 2010. Both participants were first or second year principals in suburban New Jersey public middle schools. The principals were leaders in schools containing 300-600 students. The two school districts involved were rated within the same District Factor Group and had similar demographics within the school and community.

Both principals received their Masters of Education in Administration through a New Jersey state approved preparation program. One participant, Lisa Miller, was considered an 'outsider' since she was externally hired from another district. The second participant, Robert Wilson, was considered an 'insider' because he assumed his principalship through promotion within the district. At the conclusion of the study, Wilson had completed two full years in the principalship, while Miller finished one full year as a principal. The study also included seven school community voices from each school, which consisted of active and influential parents and teachers. These participants provided topics, issues and concerns that faced each principal within his or her respective micropolitical landscape.

The principals participated in seven in-depth interviews during the months of January, March, May, August, September, October and December. These months were selected since they 
were designated as active months within the principalship (Wolcott, 1984). The principals also participated in bi-monthly email logs, which focused on key interactions and responses to concerns and issues that each principal faced within his or her micropolitical environment, and also documented their responses to various situations. All of the interviews were digitally recorded, transcribed and coded. All journal entries were also coded. Analysis of the data yielded themes and patterns that were pursued in each subsequent contact, which helped provide richer and fuller analysis in the two cases. Themes included building positive relationships with school community members, responding to parent and teacher concerns, implementing district goals and initiatives, surviving budget crisis, school climate and culture, gaining efficacy within the school community and navigating micropolitical landscapes to create educational change through negotiation. The study specifically sought to explore the lived experiences of first or second year principals and how they navigated their micropolitical landscapes to create educational change.

School community voices were also included to help identify key topics, issues and concerns that faced each principal within their micropolitical landscape. These members included lead teachers and influential parents. Each participant participated in three in-depth interviews during the months of January, June and November. All of the interviews were digitally recorded, transcribed and coded. Each interview yielded common themes and patterns, which provided both consistencies and gaps between the principals' responses. Consistent responses solidified the occurrence of events in each case and gaps were followed up in subsequent interviews with all participants.

In the first four months of the study, the interview questions and email log prompts focused on how each principal understood their micropolitical landscapes. This portion yielded themes, such as building positive relationships through communication, understanding the 
micropolitical landscape and balancing middle school needs. During the next three months, the questions and prompts focused on how each principal led within his or her micropolitical landscape, while facing a macropolitical budget crisis. The data revealed how principals identified and navigated school community concerns, how first and second year principals created their own administrative culture and how they forged relationships with their colleagues, superiors and staff members. Finally, during the last three months, the questions and logs targeted how principals navigated their landscapes to create educational change, as the principals and their school communities survived the loss of state aid funding. These months produced themes, such as pushing through resistance to achieve school goals and initiatives and negotiating with colleagues and superiors for dwindling resources. Despite varying responses, both principals shared common experiences within each theme and returned to the themes repeatedly. Data was shaped by the themes and presented in a way that highlighted the commonalities of each subject's experiences.

\section{Plan of this Dissertation}

Chapter I provided an introduction and brief overview to this study. Novice public middle school principals confront the challenge of balancing their responsibilities to implement school and district goals, while developing relationships with colleagues, teachers and parents to create educational change within their schools. The process of how novice public middle school principals learn, understand and lead within their landscapes requires clear communication, visibility and positive partnerships with school community members, including superiors and colleagues. However, New Jersey novice public middle school principals have been challenged when faced with macropolitical pressures of losing staff members and academic programs to a 
budget crisis, which reinforces the culture of shock in which the novice middle school principal finds him or herself negotiating.

Chapter II explores and reviews literature related to the underlying strands of micropolitics of education and how it relates to novice public middle school principals. The fields of understanding the micropolitical landscape, leading within the micropolitical landscape and negotiating with the micropolitical landscape to create holistic educational change are all important facets within this study and provide a foundation for the present study.

Chapter III outlines the method of the dissertation and details the sample selection, data collection, analysis techniques and the evolution of the findings. This chapter explains the purpose and development of the study. In all the study describes the lived experiences of two first or second year public middle school principals during one year. It also includes the perceptions of school community voices to create a clear perspective of each micropolitical landscape.

Chapter IV illustrates the processes, including getting to know school community members, understanding previous administrative cultures and establishing grapevine structures, the principals experienced while learning their micropolitical landscapes. This chapter also includes an ongoing analysis of how each principal understood his or her landscape during the first six months of entry.

Chapter V presents the processes, including establishing an administrative culture, implementing school initiatives and addressing school community concerns, that enabled the principals to lead within their micropolitical landscape. The chapter also includes an ongoing analysis throughout the presentation of the data. 
Chapter VI describes the processes, including surviving a macropolitical crisis and negotiating with colleagues and superiors for resources to create holistic educational change. The chapter includes an ongoing analysis to illustrate how micropolitical structures were unveiled as the principals implemented school initiatives and goals.

Chapter VII summarizes the findings of the study and explores the implications of the findings within the context of practice and further research.

\section{Limitations}

This qualitative study explored the lived experiences of two novice public middle school principals. In many ways, both principals were different, as they were alike and brought a unique perspective to the study. However, it is difficult to generalize and transfer experiences of two novice principals, since each school setting represented a limited perspective of various micropolitical landscapes. The study also depended on each participant's realistic view of his or her work performance and micropolitical interactions since a review of annual observations and evaluations was not appropriate. However, the inclusion of influential school community voices created a clear perspective of each micropolitical landscape. What this sample lacked was breadth, since each principal was followed for one year, which spanned two academic years. The study did not document subsequent years, which could have provided a wider perspective of their movement and leadership approaches within the micropolitical landscapes in their schools in contrast to their macropolitical realities. The use of two first or second year middle school principals in a specific socioeconomic group also limited the transferability and scientific generalization, as this study did not examine urban or lower socioeconomic suburban settings, which may contain differing micropolitical landscapes. 
Perspectives and reactions were gained from each principal during a time where he or she entered a stage of survival and culture of shock. The novice principals offered substantial perspectives; however, each could have easily omitted important details or accounts merely because he or she was overwhelmed by his or her numerous roles and responsibilities. To complicate matters, each novice principal operated under an extremely stressful and uncertain macropolitical environment, which directly impacted his or her micropolitical interactions. Each principal confronted and managed the realities and consequences of retrenchment or cutbacks, while trying to promote trust and communication within his or her landscape. However, each principal also managed potential contraction of academic programs and personnel in school communities that voted to pass their fiscal budgets. Novice principals living the effects of a defeated school budget vote may have faced different micropolitical implications.

During stressful periods of decline, both participants also had to manage their obligations to me. They completed bi-monthly email logs and in-depth interviews. My presence, as a researcher during field visits, served as yet another audience the novice principals instinctively felt compelled to manage. Consequently, time demands posed a concern, which could have affected the amount of information each principal shared during each email log or interview. The principals also could have felt a heightened sense of anxiety since they were being observed in the midst of a tumultuous macropolitcal environment.

The macropolitical budgetary climate clearly amplified micropolitical interactions in each school landscape (Anderson, 1999). Hidden agendas suddenly became overt, as school community members scrounged for scarce resources. Each school contained members that responded differently to macro and micropolitical pressures and dilemmas. This presented a difficult task of determining which perspectives and details were shared out of anger or 
resentment to the budgetary crisis and which comments were genuine concerns that would exist in any micropolitical environment. Although numerous individual responses were divergent and school-specific, common themes did emerge between both schools, which confirmed the emergence of authentic micropolitical issues and processes that each principal tackled. However, the political uncertainty made participants hesitant about sharing complete accounts of their micropolitical realities. They may have withheld mentioning a negative experience or conflict. One principal communicated apprehension about sharing 'everything' out of concern for confidentiality with colleagues and superiors once the study was published. For the majority of interactions, the participants spoke freely. However, the question persisted, throughout the study, whether all significant micropolitical events and realities were revealed.

Wolcott (1984) discussed within the limitations of his study that his portrayal of Ed Bell might discourage people from considering a career in the principalship. Similarly to Wolcott's concerns, this study could capture an individual holding a principalship for whom the assignment is inappropriate in terms of his or her talents and personalities. Validity and accuracy of each principal's view of his or her work and understanding of what was really going on was vital. The study depended on each participant's realistic view of his or her work. The realization that one does not belong in the principalship may bring little solace to someone who recognizes that his or her only option for the foreseeable future is to hold on to the position anyway (Wolcott, 1984).

The inclusion of additional participants, such as influential teachers, parents and staff members gave me a sense of each micropolitical landscape. This helped me put the principals' micropolitical perceptions in perspective. The use of these members added significant opportunities for extensive analysis. Subsequently, interview questions and email log prompts were refined as the focus of the study narrowed. The case study itself, however, could have 
shifted its orientation and nature if too much attention was given to these school community voices (Yin, 2009). The selection of these informants, and further inquiry into their experiences, had to be navigated carefully to avoid political hostility and personal conflict between the principals and me (Patton, 1987).

\section{Significance of Study}

The examination of two novice suburban public middle school principals and their experiences offered insight into multiple arenas of educational politics and communities. Each novice principal was exposed to divergent and complex macro and micropolitical environments. Each political environment was comprised of the culture and subcultures that existed within the public school community. These facets included school, district, and state political arenas. This study captured the lived experiences of novice middle school principals as they journeyed through a stage of survival. This state of survival was exacerbated by New Jersey's state budget crisis that reached every public school district in the state. Middle school principals already face the challenge of addressing the whole child in terms of social development, while surpassing academic standards. However, these principals encountered the often unclear task of maintaining structures that supported a child-centered educational experience, while school budgets and programs were slashed (Hoy \& Hannum, 1997).

This study also observed novice principals across two academic school years, which described the principals' development within the first two career stages - survival and control (Parkay, Currie \& Rhodes, 1992). The rich data and information presented in this proposed study may help principals and would-be principals assess the experiences of the middle school principalship in terms of navigating through the micropolitics of education and the politics of decline (Boyd, 1982, 1983). Finally, novice and experienced principals might better understand 
the relationship between schools and their broader social context, as this study described the highly conflictive and layered arenas that exist within the macropolitics of education.

\section{Summary}

Novice middle school principals face the challenge of identifying key micropolitical structures and landscapes within their public schools. They also have the daunting task of navigating internal micropolitical structures and interactions in relationship to external macropolitical structures while negotiating educational change (Bacharach \& Mundell, 1993; Hargreaves \& Goodson, 2006; Willower, 1991). It is also imperative for novice principals to understand how organizations work within daily interactions and tasks to identify micropolitical structures (Achinstein, 2002). The process of how administrators navigate and understand daily managerial tasks is well documented (Bridges, 1965; Parkay, Currie \& Rhodes, 1992; Wolcott, 1984). This proposed research will attempt to describe the navigation and negotiation of the micropolitics of education for novice middle school principals in relationship to promoting educational change.

A principal's potential to lead within the micropolitics of education depends on his or her ability to identify cognitive politics, which are formed through cultural values of a social organization and are shared between all members of the school community (Marshall \& Scribner, 1991). These values of subsystems exist within the political ideologies of social systems comprised of teachers, administrators and students (Marshall \& Scribner, 1991). A principal's ability to navigate through cognitive politics will help develop and maintain integrated communities with his or her school (Kardos et al, 2001).

Finally, the research, studying two novice first-year middle school principals, built a complex and holistic picture of how they perceive the micropolitical landscapes in their schools. 
The year-long study will potentially help aspiring and established principals better understand the relationship between the micropolitics of education and their work within the school community. 


\section{CHAPTER II}

\section{REVIEW OF LITERATURE}

\section{Micropolitics of Education}

Since the 1970s, concern for scarce federal resources, declining state public school funding, lack of public confidence in schools, and a barrage of reports demanding public school excellence have caused educators to focus more closely on the classroom and to the politics in and around schools (Boyd, 1982, 1983; Marshall \& Scribner, 1991). Out of these concerns, the study of the micropolitics of education was born. Micropolitical studies focus on the "interaction and political ideologies of social systems of teachers, administrators, and pupils within school buildings" (Iannaccone, 1975, p. 43). These interactions revolve around the authoritative allocation of scarce and valued resources (Johnson, 2001). They also focus on the decisions that allocate resources for a social organization and apply notions about deciding who gets what, when and how amongst actors, coalitions and interest groups that exist within the school community (Marshall \& Scribner, 1991). These efforts are typically conflict-ridden (Johnson, 2001). Often, these vested interests will be a matter of contention between individuals and groups, within the mircopolitical landscape, resulting in conflict (Ball, 1987). According to Ball (1987), the systems and structures that form micropolitics, or the unseen everyday affairs, is the system-it is the organization.

According to Sergiovanni (1994), schools are understood as formal organizations; what goes on within schools is understood as organizational behavior. Educational administration borrows its fundamental frames for thinking about how schools should be structured and coordinated from traditional organizational theory (Sergiovanni, 1994). Traditionally, organizations are viewed as the primary vehicle by which systemically the areas of our lives are 
planned, articulated, made more efficient and managed by experts (Scott, 2002). According to Weber (1946), organizations exist under specific assumptions. These assumptions include: that hierarchies exist where a firmly ordered vertical system is created; organizational members follow general rules, which are stable and can be learned by all members; organizations are also seen as the vehicle to get things done - to achieve goals beyond the reach of the individual. The two primary aspects of bureaucratic organizations are formalization and centralization (Hoy \& Sweetland, 2001). Formalization is the degree to which the organization has written rules, regulations, procedures and policies. Centralization of authority is the locus of control for organizational decision making. High centralization means that decisions are concentrated at the top and decisions are made in the hands of the few. Low centralization indicates that the authority for making decisions is diffuse and shared among many (Hoy \& Sweetland, 2001). A principal's authority, within the hierarchy of the school structure, is legitimated once he or she has gained acceptance by those over whom they exercise control (Anderson, 1966).

Organizations are complex (Bolman \& Deal, 2003). They are populated by people, whose behavior is notoriously hard to understand and predict. Organizations, which house diverse members, are often comprised of members with common and divergent interests, even though organizational structures are created by individuals to support the collaborative pursuit of specified goals (Scott, 2002). Subsequently, the micropolitical perspective challenges traditionalrational theories of organizations that highlight clear and shared values and goals, formal power arrangements and an objective notion of organizational life (Achinstein, 2002). These traditional perspectives of organizations do not account for everyday lived experiences of those inside the organization. Micropolitical theories instead spotlight individual differences, goals, diversity, 
conflict, uses of informal power and the negotiated and interpretive nature of organizations (Achinstein, 2002).

Both management and leadership are very important in public schools, which are understood as organizations (Sergiovanni, 1994). School leaders are expected to monitor the interactions and behaviors of the members, where inevitably, leadership takes the form of bartering. Here, principals and teachers strike bargains, where principals give to teachers needed resources in exchange for compliance (Sergiovanni, 1994). Since public schools as organizations are open systems with constant interactions between school community members, the micropolitics of education show how interpersonal relationships are structured in terms of rules, norms, lines of communications and decision making structures.

Ball (1987) proposed that the realm of micropolitics includes struggles over control of organizations, goals and the ideological content of policy-making and decision-making in schools. Blase (1991) also noted that micropolitics refers to the use of formal and informal power by individuals and groups to achieve their goals in organizations. Bacharach and Mundell (1993) noted that much of the political action that occurs in organizations takes place in groups. Individuals have neither political personalities nor access to power because of the roles they occupy. To engage in any political activity, individuals also may need protection afforded by groups (Bacharach \& Mundell, 1993). These interest groups emerge when individuals realize that they have common objectives that may collectively exert enough influence to sway a decision that they could not sway individually. According to Johnson (2001), micropolitics entails a social interaction or exchange in the political sphere. Within micropolitics, individuals or groups seek to maximize the benefits, material or nonmaterial, derived from exchanges with others. The result of micropolitics involves strategies used by organizational participants to 
influence decisions that allocate scarce and valued resources within the organization (Johnson, 2001). The politics of public schools is thus a power game involving external and internal interest groups that attempt to influence the organization to negotiate and enact specific interests (Bacharach \& Mundell, 1993).

These members and groups, who are negotiating for resources, including power, exist within the public school. They also work externally within the larger school community (Willower, 1991). Macropolitically, public schools are not insulated organizations and are expected to reflect the goals, values and culture of a broader society (Bacharach \& Mundell, 1993). Novice principals face the task of balancing federal, state and local interest groups that seek to influence local public schools (Bacharach \& Mundell, 1993). Micropolitically, first-year building principals face the challenge of identifying key social structures, such as major actors and players, within their public schools, while balancing macropolitical pressures to create educational change. They also have the daunting task of managing and negotiating within internal micropolitical structures, interactions and decision-making processes which include various teachers groups, individual teachers and the union, and parents. During these interactions, novice principals are expected to act as protectors of their organizations against macropolitical external interest groups that seek resources (Willower, 1991). Conflict emerges as internal and external groups, with competing values or priorities, seek to have their priorities prevail (Marshall \& Scribner, 1991). Macropolitical pressures, such as slashed public school funding, also have the potential to erode teacher morale, stifle school climate and derail the success of school initiatives and holistic educational change (Boyd, 1982, 1983). As a result, the administrator faces the task of negotiating these processes and structures to arrive at decisions and policies that emanate from power relationships and conflicts (Marshall \& Scribner, 1991). 
Novice principals are also entering a stage of survival, where experiences shock the individual. Here, the individual has a concern with sorting out challenges and tasks and also has personal concerns with professional security. Through this, the novice principal enters a culture of shock where the change to an administrative position is traumatic. However, he or she has to appear calm, competent and in control (Marshall, 1985). Principals learn that they must not display this shock and must present a united front with other administrators. They are expected to make sound decisions, while staying loyal to the administrative group (Marshall, 1985).

Overreactions by novice principals are likely during this stage (Parkay, Currie \& Rhodes, 1992). As principals gain experience, they enter Stage Two - control. During this stage, the primary concern is with setting priorities and getting on top of situations. Parkay, Currie and Rhodes's (1992) study of first year high school principals found that novice principals were unsuccessful in identifying micropolitical landscapes, within their schools, during their first year. The principals were unable to develop a strategy for survival and also could not handle the political dimensions of the principalship. Both principals noted that they did not realize politics played a large part of the role. However, Tooms, Kretovics and Smialek (2007) found that principals view politics as a 'necessary evil' to carry forth a vision that enhances or maintains the school. It is important for principals to be politically savvy in order to ensure successful leadership. Subsequently, it is imperative for novice principals to understand how daily interactions and exchanges influence the existing micropolitical structures within their organization.

Understanding the Micropolitical Landscape

Achinstein (2002) states "schools cannot be understood without understanding the environment or larger social contexts in which they operate" (p. 427). Micropolitics is a critical aspect of many organizational structures and processes through which major organizational 
outcomes related to change are produced (Blase \& Blase, 2002). It is essential for principals to understand actual or potential conflicts that exist naturally in schools (Ball, 1987). Principals, who understand their schools as organizations, or arenas of struggle, will also determine parties that have access to and control of resources (Ball, 1987). These resources include time, materials, personnel, and territory. These interests will create a sense of conflict between individuals and groups, as they jockey for control over these resources (Ball, 1987).

Understanding how principals identify and navigate micropolitical landscapes in a new school environment is critical because it will help them identify key micropolitical concepts, such as power, conflict, ideological disputation and control of resources. Principals can start understanding their micropolitical environments through daily interactions. Wolcott (1984) described the daily experiences of a seasoned elementary school principal—Ed Bell. The researcher found that principals generally face daily issues, tasks and problems through formal and informal encounters. Formal encounters are defined as pre-arranged meetings, telephone contacts and deliberate or casual interactions. Wolcott (1984) found that the majority of a principal's formal encounters were spent listening to others. Here, the principal can accurately assess the needs and areas of concerns within the school community and develop key partnerships with parents and staff members.

Ed Bell's time spent in formal, prearranged meetings restricted the time available in his total day at school for handling other routines (Wolcott, 1984). These routines presented themselves as informal encounters and included receiving requests, handling problems, orienting and greeting visitors and taking care of the building. Here, the principal faced unanticipated tasks, such as handling telephone calls, addressing staff requests and needs, managing pupil conduct, handling lunchroom problems, and communicating messages or announcements 
(Wolcott, 1984). Similarly, Martin and Willower (1981) indicated that the managerial work of a principal and the wide variety of tasks were often brief in duration and frequently interrupted. Furthermore, the variation of the principal's job situations was also high when one considers the kind of tasks, participant types, locations, activity purposes and initiation situations that collectively defined the principal's behavior (Martin \& Willower, 1981).

Licata and Hack (1980) defined informal communications and encounters principals face as a structural feature of the informal organization. The researchers described these communications as a "grapevine structure" (p. 91). Additionally, Licata and Hack (1980) found that principals perceived themselves as working in a verbal culture, which made the "grapevine structure" a critical component of that culture. However, the principals in the study seemed unaware of the effect that their informal interaction with peers had on the total grapevine network within that culture. The principals also did not seem conscious of the consequences of such networking for their everyday lives (Licata \& Hack, 1980). Subsequently, novice principals also need to form relationships with superordinates and peers to identify the web of values, expectations and influences within the bureaucratic role of the principalship (Bridges, 1965). Forming relationships with superordinates.

Bridges (1965) found that formally established systems of rules and regulations govern officials' decisions and actions. The principal, in the enactment of his or her bureaucratic role, receives constant pressure from the bureaucratic structure to be disciplined and methodical when making decisions. People at the top of a school district's administrative hierarchy do not sit idly in their offices waiting for emergencies. Instead, they take many opportunities to remind novice principals of their obligation to keep them informed of real and potential sources of trouble. 
In Wolcott's (1984) study, constant communication with a superior or superiors working directly over a principal was essential. Administrative meetings and discussions often served to emphasize the formal hierarchical nature of the school district's organization. Principals were constantly reminded of their status within the professional hierarchy. The policies, directives, regulations and traditions, which the school district develops, were designed to clarify lines of authority and responsibility. Principals were expected to uphold all policies and directives and comply with all decisions made by superiors. Ultimatums, which were commonly handed down or requested by superiors, were expected to be followed. These types of procedures reminded principals of the restraints on the power invested in the principalship (Wolcott, 1984).

Various studies (Blase \& Blase, 1999; Martin \&Willower, 1981; Wolcott, 1984) have described the managerial tasks and experiences that principals face. Principals' attempts to successfully identify and work within the environment of their schools were found to be dependent on their leadership styles (Anderson, 1991; Blase, 1990; Blase \& Anderson, 1995; Scribner, Hager, \& Warne, 2002). Licata and Hack (1980) also stressed the informal learning process of principals through the formation of a verbal culture known as a grapevine structure. However, these studies have not described the processes novice principals undergo to identify micropolitical landscapes within their school communities.

Understanding the middle school landscape.

Middle schools, consisting of grades six through eight, typically have different programs and different philosophies than elementary or high schools. They strive for school programs with interdisciplinary team structures, a child-centered philosophy, heterogenous groupings for most subjects, specialization of subjects, an appropriate curriculum, time and flexibility for exploration, and activities structured around a team or unit concept. The task of addressing the 
whole child, in terms of development while surpassing academic standards, is a challenge new middle school principals face. Novice principals entering a middle school environment must orient themselves to the environment, set and implement goals, maintain a cohesive system and create and preserve a distinctive culture. Within the middle school team philosophy, teachers have the primary responsibility to collectively solve problems associated with teaching and learning. However, both teachers and principals need backing if they are to perform their respective responsibilities without undue pressure from individuals and groups within the school community (Hoy \& Hannum, 1997). Principals also are expected to find ways to develop maintain a connection between the school and the community, while coordinating internal school needs, such as allocating resources and developing teacher commitment to school goals and trust. A principal's ability to meet goals and successfully cope with disruptive internal and external forces, while upholding the organization's mission, is a challenge within micropolitics of education (Hoy \& Hannum, 1997).

Hoy and Hannum (1997) noted that middle school principals must also acclimate to the environment, set and implement goals, maintain a cohesive system and create and preserve a distinct climate and culture. In their study of 86 middle schools, the researchers pointed to resource support and principal influence as two factors that attributed to successful schools. These two factors also enabled the organization to maintain integrity, as the school coped with its environment in a way that maintained the integrity of educational programs and protected staff from unreasonable community and parental demands. Here resource support and influence were behaviors that maintained a healthy school environment in which the principal was able to furnish teachers with adequate supplies and additional instructional materials to do their jobs. The principals also had the ability to influence the actions of superiors and proceed relatively 
unimpeded by the hierarchy. Novice principals, however, might find difficulty in identifying and influencing school community voices within the micropolitical landscape.

\section{Leading within Micropolitical Landscapes}

Principals have become increasingly viewed as leaders who work at the center of public schools to strengthen the web of social and professional relations (Scribner, Hager, \&Warne, 2002). This is a shift from the perception of principals being viewed as leaders of organizational hierarchies. Subsequently, through informal and formal encounters, principals can help build a professional community (Scribner, Hager, \& Warne, 2002). Scribner, Hager and Warne (2002) used a micropolitical lens to examine the relationship between school leadership and professional communities. They found the principal, of North High School, had difficulty building a shared identity within a school, rather than a collective identity. The pitfall that the principal faced was to establish informal network or grapevine structures because teachers were reluctant to discuss or learn new skills and participate in professional development activities. The teachers seemed passive and led the principal to believe that all content and direction of teacher learning should be defined externally by the district and state reform policies. Consequently, informal and formal discussions did not take place; instead, clashes among teachers and the principal occurred over the organization and content of the professional learning. In this case, boundary and turf battles erupted where groups may have felt their rights and responsibilities were being limited or infringed upon by other groups (Hanson, 1979).

However, Scribner, Hager and Warne (2002) also studied Central High School, where the principal conducted formal and informal discussions with the staff that focused on ideologies and values. Here, the staff and administration discussed and agreed on shared understandings of the students' needs. All of the discussions about teacher learning and work were anchored in a 
commitment to students' academic, social and emotional learning needs. The principal was also seen as supporting individual and organizational learning. Her active leadership demonstrated a belief that her teachers were not only professionals who deserved autonomy, but were professionals expected to work towards shared goals. The teachers also gained a level of trust with the principal, since they were active participants in open decision making and genuinely valued teacher involvement in decisions surrounding teaching and learning. Within the micropolitical landscape, Central High School's principal was seen as minimizing external threats to teacher and school autonomy (Scribner, Hager, \& Warne, 2002). Hoy and Sweetland's (2001) study found that enabling schools encouraged trusting relationships between teachers and the principal. Trust, truthfulness and limited role conflicts were the hallmark of functional school climates (Hoy \& Sweetland, 2001). As these studies demonstrated (Anderson, 1991; Blase, 1987, 1998; Blase \& Blase, 1994; Hoy \& Sweetland, 2001; Scribner, Hager, \& Warne, 2002), enabling school structures are characterized by principals who help teachers solve problems, encourage openness and support teachers in performing their jobs without concern for conflict and punishment. The studies also noted that principal leadership, within the micropolitical context, influences the climate and culture of the school community. The principal's role in defining the micropolitical landscape.

The case studies of Blase and Anderson (1995) are grounded on the assumption that formal leaders have a strong influence on the micropolitical interactions that develop in a given school. The conflict that emerges out of micropolitics of education, as stakeholders battle for control of resources, can be categorized into three means — cultural, ideological and symbolic (Anderson, 1991). These three means comprise what Anderson (1991) called cognitive politics. Cognitive politics are formed through cultural values or beliefs of a social organization that are 
shared between all members of the school community (Marshall \& Scribner, 1991). These values of subsystems exist within the political ideologies of social systems composed of teachers, administrators and students (Marshall \& Scribner, 1991). Often, within cognitive politics, there is a battle for ideological control between stakeholders that will identify and influence perception of reality. Smircich and Morgan (1982) described leadership as the process where individuals succeed in attempting to frame and define the reality of others. Ideological control ensures parent, teacher and student support of school norms and values (Anderson, 1991). Finally, symbolic control relies on how actors lead and act through actions and words to interpret and reinterpret experiences and reality (Bolman \& Deal, 2003).

Blase and Anderson (1995) provide several micropolitical leadership perspectives to analyze micropolitical leadership styles principals may exhibit. These leadership styles act as aids in the analysis of school micropolitics and leadership. Blase and Anderson (1995) framed one leadership style through a conflictive or closed approach, in which leaders sought to control others or elicit the compliance of others to the means and/or ends of education as determined by leaders. In this approach, principals often avoided or ignored teachers, suppressed dialogue and exercised control through formal structures, while reinforcing policies and rules (Blase, 1990, 1991). The behaviors and intentions of the principal were fairly clear to teachers. Interactions tended to be formalized and predictable. The principal kept negotiation minimal and utilized coercive tactics, such as sanctions, to gain teacher compliance. As a result, leaders, through a closed or coercive approach, maintained control over the organization's overarching goals and ideologies (Blase, 1990, 1991).

Blase and Anderson (1995) also described another leadership approach--the consensualbased or open approach. In this approach, the leader supported and empowered teachers toward 
shared accountability and power (Blase \& Blase, 1997). This approach was often the choice for current site-based management and restructuring movements (Anderson, 1991; Blase, 1991). Often, a more humane and professional climate existed, as there was increased opportunity for members to participate. Teachers and principals participated in a discourse of change and participation. Goals were achieved through the motivation of others. An open leadership approach engaged teachers in a larger mission of student and community empowerment (Blase, 1989, 1993; Blase \& Blase, 1994).

Blase (1990) also examined the politics in schools, through a conflictive approach, from the perspectives of teachers. Through control-oriented strategies, principals looked to manipulate teachers' concepts and perceptions to gain teachers' compliance. Blase (1990) found that teachers perceived principals' goals and ends as nonnegotiable. Teachers also defined principal control tactics as coercive, forceful, stressful and punishing. Out of 900 teachers, 106 teachers found principals using sanctions and rewards to achieve teacher control. Sanctions were associated with manipulation of resources, work factors in the classrooms, support and opportunities for input regarding decision making. Blase (1990) also found teachers viewed principals as leading using a protection strategy. A protection leadership strategy involved administrators working to uphold a positive image of themselves within the school community. As a result of these tactics, teachers indicated that they had low morale and were fearful of control-oriented principals.

Anderson (1991) studied cognitive politics through the leadership lens of a consensualbased approach in his study of Fairlawn principals. Fairlawn principals were described, by teachers, as having to mediate conflict and legitimate various organizational stakeholders to each other. They mediated between parents and teachers, teachers and teachers, teachers and central 
office and teachers and students. When resolving conflicts, Fairlawn principals often were aware of and upheld organizational values, norms and policies. When negotiating, the principal developed a keen sense of which norms and policies were negotiable and which were not (Anderson, 1991).

Anderson's (1991) study of Fairlawn found that the principals maintained cooperation and harmony in their school environment through symbolic meaning. Here, meaning was managed symbolically through language. Principals promoted a conflict-free vocabulary in the district and schools. One member in the study, Frank Bradley, stressed the importance of selecting administrators and teachers who personified this humanistic philosophy. This outlook was dubbed Fairlawnized, and required teachers and administrators to use a common language of harmony and consensus to project the reality of a world relatively free of real conflict of interest (Anderson, 1991).

However, Fairlawn staff members still managed daily conflicts of interests. In Anderson's (1991) study, the librarians worked through the conflict of not having access to aides. This dilemma put pressure on the librarians to work longer hours. The librarians, however, supported only working required contractual hours. Kathy, one librarian, convinced her colleagues to maintain their previous behaviors of dedicating long hours to the progress of the school. She framed this through an ideological approach. Kathy expressed a sense of betrayal at the librarians' lack of solidarity. She talked of getting things worked out through appealing to a sense of family solidarity. Through her use of terms, such as 'our building' and 'district mentality', she upheld an ideology of containment. This paralleled the meaning behind Fairlawnized. Here, established norms were reinforced, policies implemented and hierarchical 
control maintained largely through effective management of meaning (Anderson, 1991).

Established and agreed norms and values also made up the school as an organization.

New principals' priorities in negotiating micropolitical structures.

Within micropolitics, the principal is seen primarily as a maintenance manager, and is concerned with resource allocation and managing interpersonal relations. As a result, educational leadership can heavily influence a school's organizational culture. Micropolitical structures and processes are fundamental to change and innovation, as well as the stability and maintenance of school settings (Blase, 1998). During periods of stability, micropolitical processes and structures benefit some individuals and groups. In addition, the political power of individuals and groups is often taken for granted as it is embedded in organizational and cultural structures to preserve the status quo (Blase, 1998).

However during periods of change, micropolitical interaction tends to intensify and become more visible in both formal and informal arenas of school life. Changing and new structures include new stakeholders with different ideologies and interests, who use different strategies to pursue a wide range of issues (Blase, 1998). For example, Griffith (1999) found that public schools with new principals were perceived, by parents and students, as being less orderly and disciplined. Parents also reported lower levels of school empowerment and participation in school activities. Barnett and McCormick (2004) also found that school organization conditions, such as goals, structure, people and culture had a mediated effect on student learning outcomes. First-year principals face the challenge of instilling attitudes, values and beliefs to create a school community for adequate performance in the principal's role.

A principal's role in creating community. 
Organizational life and community life both differ in quality and kind. In communities, members create social lives with others who have intentions that are similar. In organizations, relationships are constructed for members by others and become codified into a system of hierarchies, roles and role expectations (Sergiovanni, 1994). Middle school principals have become viewed as leaders who work at the center of communities to strengthen the web of social and professional relations, especially within the emergence of teams and professional learning communities (Scribner, Hager, \& Warne, 2002). Bryk and Driscoll (1988) found that teachers in school with strong professional communities held higher expectations for student achievement and behavior than schools with weak professional communities. Kardos, Johnson, Peske, Kauffman and Liu (2001) found that principals were important in developing and maintaining integrated professional communities where particular needs of teachers were both recognized and addressed.

Additionally, communities are confronted with issues of control; however, instead of relying on external control, communities rely on norms, purposes, values, and collegiality. Communities, through the empowerment of teachers, students and other members, focus on commitments and obligations people feel towards each other and their school (Sergiovanni, 1994). Wolcott (1984) noted the difficulty a principal experienced in stabilizing the culture and community in a school. Principals are faced with the challenge of keeping the system intact. New principals are additionally faced with the challenge of becoming acquainted with the culture of a school. A novice principal will have to identify the general patterns, as well as the more specific patterns, of differentiating students, teachers and administrator subcultures.

Politics of Educational Change 
Micropolitical structures and processes are fundamental to change and innovation, as well as stability and maintenance of school settings (Blase, 1998). Educational change is the result of the influence of educational interests on specific policies and arenas and is political in origin (Johnson, 2001; Tyack \& Cuban, 1995). During periods of stability, micropolitical structures and processes benefit some individuals or groups rather than others. In addition, the political power of individuals or groups is often taken for granted because it is embedded in micropolitical structures that work to preserve the status quo (Blase, 1998). During periods of change; however, micropolitical interactions tend to intensify and become more visible in both formal and informal arenas of school life (Blase, 1998). Educational change tends to provoke and exacerbate these interactions, as groups organize and compete with other groups, within the politics of education, to express their values and to secure their interests in the public school (Blase, 1998; Tyack \& Cuban, 1995). This happens as educational change puts vital school components at stake. According to Fullan (2007), educational change involves a change in practice. As a result, at least three components are at stake-materials, approaches and beliefs (Fullan, 2007). For educational change to take place, the possible use of new materials or activities, new approaches or strategies and the alteration of beliefs need to occur in practice (Fullan, 2007). Consequently, real educational change may involve loss, anxiety and struggle, since change is often implemented too quickly for people to cope with (Hargreaves, 1998). Change also cannot be done alone. Resources of time and money, practical designs for change and support are needed (Darling-Hammond, 1993; Tyack \& Cuban, 1995). Principals must also employ participation from teachers to commit to educational change or potentially risk resentment or resistance (Hargeaves, 1998). Subsequently, principals play a key political role in facilitating new 
governance processes and structures with parents, superiors, colleagues and teachers in their school settings.

The challenge principals face in creating educational change is identifying and negotiating the needs of school staff members in relationship to the individuals in a larger social organization, or the school community (Miskel, Meisner, \& St. Clair, 1971). The interactions of both groups will influence and help determine school policy and facilitate educational change. Novice principals also need to negotiate the dominant values, interests and aspirations for the school expressed by community leaders, with the values, interests and aspirations expressed micropolitically by students, teachers, non-teaching staff members and administrators.

Fullan (2007) also noted that principals face the task of running a smooth and efficient school environment, while being responsive to school community members' needs. Simultaneously, principals are required, at the end of the day, to show improved test results and exhibit an ideal learning organization (Fullan, 2007). Principals face the compounded challenge of negotiating order in their landscapes, while balancing macropolitical expectations and pressures (Bacharach \& Mundell, 1993). In recent years, however, strong macropolitical influences have increased political conflict at school levels, as principals face the implications of contracting local and state budgets and retrenchment (Blase \& Bjork, 2009; Boyd, 1982, 1983). Subsequently, micropolitical structures that exist in schools are often shaped by their macropolitical realities, especially during periods of personnel and academic program cutbacks (Boyd, 1982). Formal federal and state legislation, district-level policy mandates and school district ideologies significantly impact and influence principals' behaviors, existing school-based structures, and relationships between teachers and administrators (Blase, 1991). However, external change agents, such as state governments, are mistakenly often viewed by principals as 
often forgotten, peripheral players (Marshall, Mitchell \& Wirt, 1989). Consequently, these macropolitical pressures have the potential to derail holistic educational change.

Organizational politics is a power game. Consequently, principals who have considered quitting pointed to policy and administration, relations with subordinates, lack of support from superiors and politics as reasons for dissatisfaction (Fullan, 2007). They expressed the challenge of performing all the tasks principals were expected to do, including the politics of dealing with various constituencies (Fullan, 2007). Undoubtedly, assessing the capacity of schools to support and sustain change is a prerequisite for accomplishing educational change (Bjork \& Blase, 2009). However, principals who were able to enact educational change were also able to maintain an inclusive and facilitative orientation, maintain efficient management, provide an institutional focus on student learning and combine pressure with support when implementing school improvement plans (Fullan, 2007).

\section{Rationale, Conceptual Framework and Research Questions}

This study examines how novice middle school principals navigated micropolitical landscapes in their public school environments. Previous studies (Martin \&Willower, 1981; Parkay, Currie \& Rhodes, 1992; Wolcott, 1984) described the daily managerial experiences and behaviors of principals. Other studies (Anderson, 1991; Blase, 1990, 1991, 1993; Blase \& Blase, 1994, 1999; Hoy \& Sweetland, 2001; Scribner, Hager, \& Warne, 2002) have described principals' behaviors, from the perspective of teachers, within various micropolitical landscapes; however, few studies have described how novice middle public school principals, in their own words, politically navigate and negotiate school community voices and relationships involved in influencing school decisions that determine the allocation of valuable, scarce and dwindling school resources. More importantly, prior studies have not described how this task differs 
between novice principals, entering a new school from an outside district, in comparison to a novice principal, who was promoted within the district into the principalship.

This study also attempted to describe the progression novice principals experienced in negotiating the politics of educational change in their school communities, while balancing macropolitical pressures. Despite previous researchers (Bacharach \& Mundell, 1993; Bjork \& Blase, 2009; Blase, 1991; Blase \& Bjork, 2009; Boyd, 1982, 1983; Darling-Hammond, 1992; Hickcox \& Doris, 1979; Mawhinney, 1999) detailing the relationships between macropolitical pressures and the micropolitical realities of schools, the process in which novice middle school principals navigate the micropolitics of education, within their macropolitical environment, to create holistic educational change is not explicit.

This process entails the orientation of the principal to the micropolitical landscape and the attempts to lead within the landscape. It also describes how principals negotiate internal micropolitical pressures in relationship to external macropolitical pressures to achieve holistic educational change. The conceptualization of the politics of education, or the interactions, activities, and sentiments of the members contributing to the micropolitical and macropolitical climate, is illustrated through the following figure: 


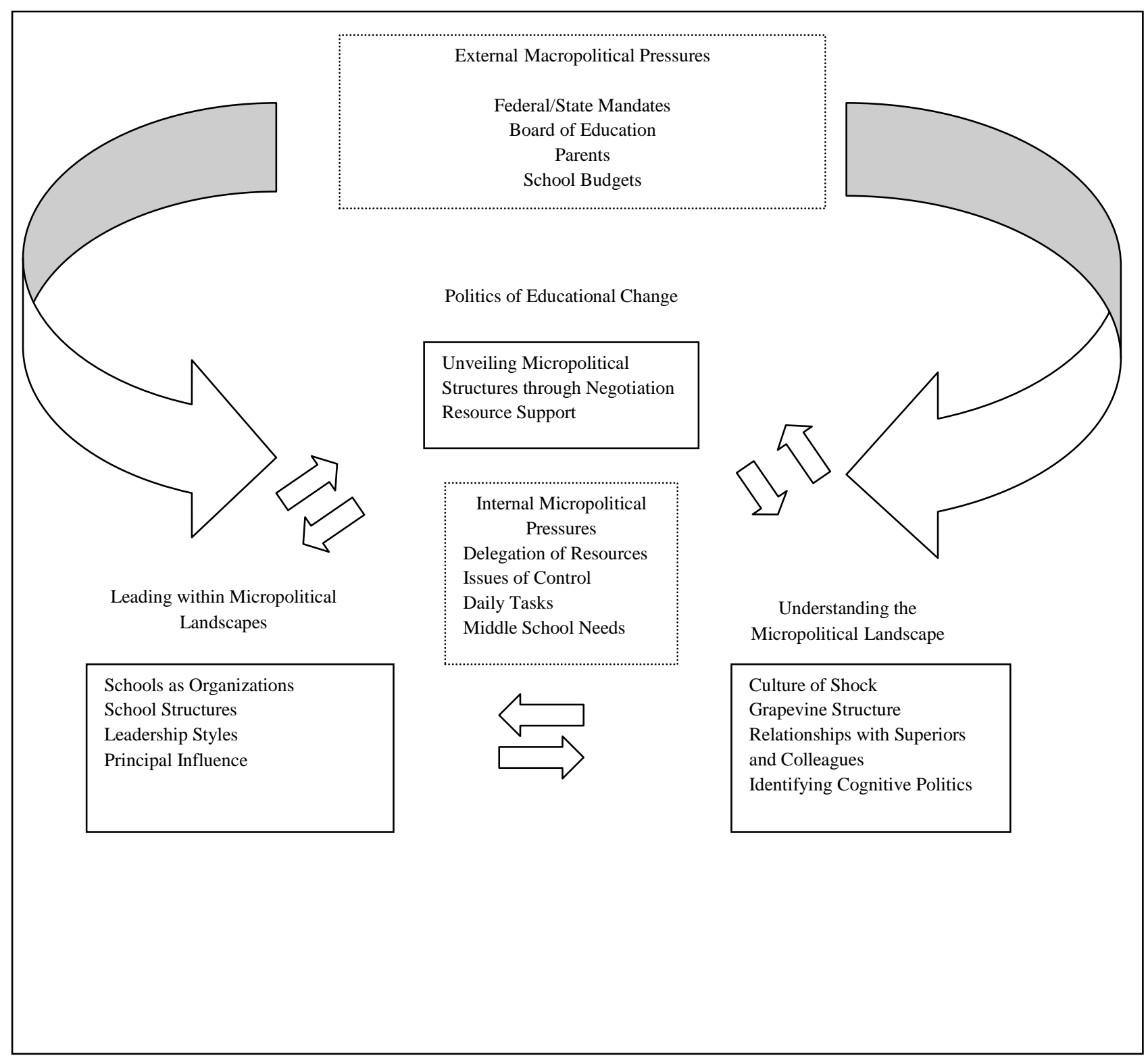

Figure 1.

The guiding questions for this study were:

How do novice middle school principals navigate micropolitical landscapes in their public schools to create educational change?

a. How do new middle school principals identify key micropolitical power structures and individual power brokers in their school communities? 
b. How do new middle school principals situate themselves within the micropolitical structures of their schools?

c. How do new middle school principals navigate micropolitical structures and conflicts in schools to create educational change?

Summary

Novice middle school principals enter a culture of shock facing the political challenge of identifying new tasks and roles, such as supporting school community members, negotiating with policymakers, addressing the needs of the middle school landscape and upholding community and district relations, and negotiating the allocation of values and resources by applying notions about who gets what, when and how (Marshall \& Scribner, 1991; Marshall, 1984). They also have the daunting task of navigating internal micropolitical structures and interactions in relationship to external macropolitical structures while negotiating educational change (Bacharach \& Mundell, 1993; Hargreaves \& Goodson, 2006; Willower, 1991). It is also imperative for novice principals to understand how organizations work within daily interactions and tasks to identify micropolitical structures (Achinstein, 2002). The process of how administrators navigate and understand daily managerial tasks is well documented (Bridges, 1965; Parkay, Currie \& Rhodes, 1992; Wolcott, 1984). This proposed research will attempt to describe how novice middle school principals navigate and negotiate micropolitics, while balancing macropolitical pressures, to create holistic educational change.

A principal's potential to lead within the micropolitics of education is dependent on his or her ability to identify cognitive politics, which are formed through cultural values of a social organization and are shared between all members of the school community (Marshall \& Scribner, 1991). These values of subsystems exist within the political ideologies of social 
systems comprised of teachers, administrators and students (Marshall \& Scribner, 1991). A principal's ability to navigate through cognitive politics will help develop and maintain integrated communities with his or her school (Kardos et al, 2001).

Finally, the proposed research studying two novice first-year middle school principals will look to build a complex and holistic picture of how they perceive the micropolitical landscapes in their schools, while balancing macropolitical pressures. The one-year study will help aspiring and established principals better understand the relationship between the micropolitical interactions within their schools, communities and macropolitical environments. 


\section{CHAPTER III}

\section{METHODOLOGY}

In this study, I explored how novice public middle school principals navigated their micropolitical landscapes in their schools. The study specifically described how novice principals navigated and negotiated internal micropolitical pressures in relationship to external macropolitcal pressures to create holistic educational change. Each principal's navigation entailed the understanding of the micropolitical landscape, leading within the landscape and negotiating the politics of educational change. Through this research, I constructed a complex and holistic picture, reported the detailed views of informants and conducted the study in a natural setting (Creswell, 1998). I also captured the circumstances and conditions surrounding the micropolitics of education. Subsequently, data was collected through two specific case studies in order to capture the individual lived experiences of novice middle school principals. The multiple cases allowed the topic of interest to be studied in depth and provided robust and comparative evidence (Yin, 2009). The cases also described how the micropolitics of education changed over two academic school years, as the data collection began in January 2010 and concluded in December 2010. The collected data and written report offered a one year examination of the perceptions and lived experiences of two novice middle school principals during their first or second year in the principalship.

Qualitative research was used to identify and build a complex and holistic picture of perceptions of novice principals entering their first or second year within the principalship. At this stage in the research, micropolitics of education is described as the "interaction and political ideologies of social systems of teachers, administrators, parents and pupils within school buildings" (Iannaccone, 1975, p. 43). A case study tradition was used to reach understanding 
through inquiry. The study of two novice principals allowed me to explore comparative cases. One principal was considered an outsider, since she was hired from another district to assume the principalship. The other principal was considered an insider, since he was hired from within the district. Both principals had previous administrative experiences.

Although the main unit of analysis was collectively principals, attention was given to other participants. School community voices, such as influential teachers, staff members and parents, were included. These members included established and respected teachers and faculty members, school-based union representatives, school and district-based committee members and parent-teacher association representatives and executive members. These participants were also active in the existing micropolitical and macropolitical structures and provided an extra layer of data which either refuted or substantiated events and interactions that occurred within the micropolitical environment. The study of these active members allowed an independent source and perspective of the existing micropolitical landscape in the school. These members also had specific knowledge, insight and experiences within the cases being studied. Their perspectives also created a complex picture of the existing micropolitics of education in a given case (Patton, 1987). The layered perspectives from the principals and school community voices added significant opportunities for extensive analysis and enhanced the insights into each case (Yin, 2009). Data collection in both schools utilized multiple sources of rich information from informants and participants to develop a holistic description of each case (Creswell, 1998). The purpose of this case study was to describe how novice principals navigated the micropolitical landscapes that existed within their schools.

Sample Selection 
Purposeful sampling was used to capture the varying perspectives of first or second year public middle school principals. This form of sampling helped me identify specific middle schools that were under the leadership of novice principals. In order to find potential principals for the study, I identified public school districts that were looking for a new middle school principal. During the spring of 2009, I logged all New Jersey public middle school principal vacancies through local newspaper postings and Internet forums. I also contacted administrative acquaintances to seek participants in a snowball or chain effect. Here, I identified public middle schools that were looking for a new principal for the 2009-2010 school year. Subsequently, I also utilized the help of the New Jersey Principals and Supervisors Association to identify newly appointed middle school principals and potential candidates.

Through this method, I identified twenty-one New Jersey public school districts that were looking for a new middle school principal for the 2009-2010 school year. Letters were sent to each superintendent and described the purpose of the study and the qualifications for each subject. I made follow up phone calls to each superintendent to ensure his or her letter was received and reviewed. The study looked to comprise of two middle school principals, who were to be employed in their first or second year of the principalship during the 2009-2010 academic year. I also focused on candidates who achieved at least a Masters of Education in Educational Administration through a state approved preparation program. One participant was considered an 'insider' because he or she assumed his or her principalship through promotion within the district. The other candidate was an 'outsider' to his or her new school, since he or she was hired from another district. All participants were required to work in suburban middle schools that contain between 300 and 700 students. The use of small suburban schools ensured that more school community members would have access to decision making. Hess and Leal (2001) 
concluded that districts with higher incomes and lower student-teacher ratios offered more access to decision making.

Out of twenty-one school districts, five superintendents expressed an interested in having their first or second year middle school principals participate in the study. All of the principals were then contacted and interviewed after I received board of education approval to enter each site. During each interview, I had an opportunity to understand the demographic make-up of each school and the micropolitical issues that each principal faced. I also learned about each principal's past experiences and goals for his or her middle school. After each interview, I confirmed with all the principals that if they were not chosen, they could still participate in the study if a participant dropped out of the study. The following table represents the schools and novice middle school principals that were eligible for this study:

Table 1: Overview of eligible participants

\begin{tabular}{|c|c|c|c|c|c|}
\hline & $M . S . \# 1$ & M.S. \#2 & M.S. \#3 & M.S. \#4 & M.S. \#5 \\
\hline Location & Suburban & Suburban & Rural & Suburban & Suburban \\
& K-12 District & K-8 District & K-8 District & K-12 District & K-12 District \\
\hline DFG & GH & I & GH & GH & I \\
\hline Grades & $5-8$ & $6-8$ & $6-8$ & $6-8$ & 6 \\
\hline Population & $69 \%$ White & $84 \%$ White & $96 \%$ White & $34 \%$ White & $71 \%$ White \\
& $23 \%$ Asian & $7 \% \%$ Asian & & $31 \%$ African & $24 \%$ Asian \\
& $6 \%$ Spanish & $5 \%$ Spanish & & American & \\
& & & & $25 \%$ Asian & \\
\hline Students & $600-650$ & $600-650$ & $300-350$ & $450-500$ & $450-500$ \\
\hline Principal & Year Two & Year One & Year One & Year One & Year One \\
& White/Male & White/Male & Person of & White/Female & White/Female \\
& Inside Promotion & External Hire & Color/Male & External Hire & External Hire \\
& & & Internal Hire & & \\
\hline
\end{tabular}

To conduct a cross-case analysis for this study, I focused on picking two comparable cases. Subsequently, each middle school had to be a member of the same District Factor Group, which represented a community's socioeconomic status and was a useful tool in comparing similarly situated school districts. Each school also was required to contain a true middle school model, which encompassed at least sixth to eighth grade students. Finally, one principal, who 
was an inside hire, and one principal, who was an external hire, had to be considered. After interviewing each principal, the following districts, schools and principals were chosen for this

study:

Table 2: Overview of selected districts

\begin{tabular}{|c|c|c|c|c|c|c|}
\hline $\begin{array}{l}\text { Central } \\
\text { School } \\
\text { District }\end{array}$ & E.S.\#1 & E.S. \#2 & E.S. \#3 & E.S. \#4 & I.S. \#1 & I.S. \#2 \\
\hline Grades & $\mathrm{K}-3$ & $\mathrm{~K}-3$ & $\mathrm{~K}-3$ & K-3 & $4-5$ & $4-5$ \\
\hline Population & $\begin{array}{l}33 \% \text { Asian } \\
25 \% \text { African } \\
\text { American } \\
22 \% \text { Spanish } \\
20 \% \text { White }\end{array}$ & $\begin{array}{l}\text { 33\% African } \\
\text { American } \\
\text { 31\% Asian } \\
19 \% \text { White } \\
16 \% \text { Spanish }\end{array}$ & $\begin{array}{c}33 \% \text { Asian } \\
28 \% \text { White } \\
27 \% \text { African } \\
\text { American } \\
11 \% \text { Spanish }\end{array}$ & $\begin{array}{l}\text { 48\% Asian } \\
22 \% \text { African } \\
\text { American } \\
\text { 18\% White } \\
12 \% \text { Spanish }\end{array}$ & $\begin{array}{l}35 \% \text { African } \\
\text { American } \\
23 \% \text { Asian } \\
20 \% \text { White } \\
21 \% \text { Spanish }\end{array}$ & $\begin{array}{l}\text { 35\% Asian } \\
32 \% \text { African } \\
\text { American } \\
23 \% \text { White } \\
10 \% \text { Spanish }\end{array}$ \\
\hline Students & $550-600$ & $650-700$ & $500-550$ & $450-500$ & $500-550$ & $500-550$ \\
\hline Principal & $\begin{array}{l}\text { White/Male } \\
\text { External Hire }\end{array}$ & $\begin{array}{c}\text { Person of } \\
\text { Color/Male } \\
\text { Internal Hire }\end{array}$ & $\begin{array}{c}\text { Person of } \\
\text { Color/Female } \\
\text { External Hire }\end{array}$ & $\begin{array}{l}\text { White/Male } \\
\text { Internal Hire }\end{array}$ & $\begin{array}{l}\text { White/Female } \\
\text { Internal Hire }\end{array}$ & $\begin{array}{l}\text { White/Female } \\
\text { Inside Hire }\end{array}$ \\
\hline $\begin{array}{c}\text { Years in } \\
\text { District as } \\
\text { Principal }\end{array}$ & $2-3$ & $3-5$ & $2-3$ & $3-5$ & $10+$ & $10+$ \\
\hline
\end{tabular}

\begin{tabular}{|c|c|c|c|c|}
\hline $\begin{array}{l}\text { Central } \\
\text { School } \\
\text { District }\end{array}$ & M.S. \#1* & M.S. \#2 & M.S.\#3 & H.S. \\
\hline Grades & 6-8 & 6-8 & $6-8$ & $9-12$ \\
\hline Population & $\begin{array}{l}34 \% \text { White } \\
31 \% \text { African } \\
\text { American } \\
25 \% \text { Asian }\end{array}$ & $\begin{array}{l}40 \% \text { African } \\
\text { American } \\
24 \% \text { Asian } \\
19 \% \text { White } \\
17 \% \text { Spanish }\end{array}$ & $\begin{array}{l}40 \% \text { African } \\
\text { American } \\
22 \% \text { Asian } \\
20 \% \text { White } \\
18 \% \text { Spanish }\end{array}$ & $\begin{array}{l}36 \% \text { African } \\
\text { American } \\
30 \% \text { White } \\
22 \% \text { Asian } \\
12.5 \% \text { Spanish }\end{array}$ \\
\hline Students & $400-450$ & $500-550$ & $550-600$ & $2000-2500$ \\
\hline Principal & $\begin{array}{l}\text { White/Female } \\
\text { External Hire }\end{array}$ & $\begin{array}{c}\text { Person of } \\
\text { Color/Female } \\
\text { External Hire }\end{array}$ & $\begin{array}{c}\text { White/Male } \\
\text { External Hire }\end{array}$ & $\begin{array}{c}\text { White/Male } \\
\text { External Hire }\end{array}$ \\
\hline $\begin{array}{c}\text { Years in } \\
\text { District as } \\
\text { Principal }\end{array}$ & $1-2$ & $5-8$ & $5-8$ & $3-5$ \\
\hline
\end{tabular}

*Central Middle School 


\begin{tabular}{|c|c|c|c|c|c|c|}
\hline $\begin{array}{c}\text { Northern } \\
\text { School } \\
\text { District }\end{array}$ & E.S. \#1 & E.S. \#2 & E.S. \#3 & E.S. \#4 & E.S. \#5 & M.S. \#1* \\
\hline Grades & K-4 & $\mathrm{K}-4$ & $\mathrm{~K}-4$ & $\mathrm{~K}-4$ & $\mathrm{~K}-4$ & $6-8$ \\
\hline Population & $\begin{array}{c}58 \% \text { White } \\
31 \% \text { Asian } \\
9 \% \text { Spanish } \\
2 \% \text { African } \\
\text { American }\end{array}$ & $\begin{array}{c}53 \% \text { White } \\
32 \% \text { Asian } \\
\text { 12\% Spanish } \\
3 \% \text { African } \\
\text { American }\end{array}$ & $\begin{array}{l}69 \% \text { White } \\
24 \% \text { Asian } \\
6 \% \text { Spanish } \\
1 \% \text { African } \\
\text { American }\end{array}$ & $\begin{array}{l}63 \% \text { White } \\
30 \% \text { Asian } \\
6 \% \text { Spanish }\end{array}$ & $\begin{array}{l}\text { 78\% White } \\
\text { 17\% Asian } \\
\text { 3\% Spanish }\end{array}$ & $\begin{array}{l}69 \% \text { White } \\
23 \% \text { Asian } \\
6 \% \text { Spanish } \\
1 \% \text { African } \\
\text { American }\end{array}$ \\
\hline Students & $200-250$ & $350-400$ & $300-350$ & $250-300$ & $300-350$ & $600-650$ \\
\hline Principal & $\begin{array}{l}\text { White/Male } \\
\text { External Hire }\end{array}$ & $\begin{array}{l}\text { White/Female } \\
\text { Internal Hire }\end{array}$ & $\begin{array}{l}\text { White/Female } \\
\text { External Hire }\end{array}$ & $\begin{array}{l}\text { White/Female } \\
\text { Internal Hire }\end{array}$ & $\begin{array}{l}\text { White/Female } \\
\text { Internal Hire }\end{array}$ & $\begin{array}{l}\text { White/Male } \\
\text { Inside Hire }\end{array}$ \\
\hline $\begin{array}{c}\text { Years in } \\
\text { District as } \\
\text { Principal }\end{array}$ & $10+$ & $3-5$ & $3-5$ & $3-5$ & $2-3$ & $2-3$ \\
\hline
\end{tabular}

\begin{tabular}{|c|c|c|}
\hline $\begin{array}{c}\text { Northern } \\
\text { School } \\
\text { District }\end{array}$ & M.S. \#2 & H.S. \\
\hline Grades & $6-8$ & $9-12$ \\
\hline Population & $58 \%$ White & $66 \%$ White \\
& $34 \%$ Asian & $27 \%$ Asian \\
& 6\% Spanish & $7 \%$ Spanish \\
& 2\% African & $1 \%$ African \\
& American & American \\
& & \\
\hline Students & $650-700$ & $1300-1350$ \\
\hline Principal & White/Male & White/Male \\
& Internal Hire & External Hire \\
\hline Years in & $10+$ & $2-4$ \\
District as & & \\
Principal & & \\
\hline
\end{tabular}

*Northern Middle School

Table 3: Overview of schools

\begin{tabular}{|c|c|c|}
\hline Name & Central Middle School & Northern Middle School \\
\hline Location & Suburban & Suburban \\
& K-12 District & K-12 District \\
\hline DFG & GH & GH \\
\hline Grades & $6-8$ & $5-8$ \\
\hline Population & $34 \%$ White & $69 \%$ White \\
& 31\% African American & $23 \%$ Asian \\
& $25 \%$ Asian & $6 \%$ Spanish \\
\hline Students & $400-450$ & $600-650$ \\
\hline
\end{tabular}


Table 4: Overview of principals

\begin{tabular}{|c|c|c|}
\hline & Central Middle School & Northern Middle School \\
\hline Name & Lisa Miller & Robert Wilson \\
\hline Age & $40-45$ & $40-45$ \\
\hline Race & White & White \\
\hline Gender & Female & Male \\
\hline Hire & External & 8.5 \\
\hline $\begin{array}{c}\text { Years Experience in } \\
\text { Administration }\end{array}$ & 9.5 & $\begin{array}{c}\text { Supervisor of Social Studies } \\
\text { Athletic Director } \\
\text { Middle School Assistant Principal } \\
\text { Experiences }\end{array}$ \\
$\begin{array}{c}\text { Previous Adminstrative } \\
\text { K-12 English Supervisor } \\
\text { 6-12 English Supervisor } \\
\text { English and World Languages } \\
\text { Department Chair }\end{array}$ & 2.5 \\
\hline $\begin{array}{c}\text { Years Experience in } \\
\text { School }\end{array}$ & 1.5 & 5.5 \\
\hline $\begin{array}{c}\text { Years Experience in } \\
\text { District }\end{array}$ & 1.5 & 18.5 \\
\hline $\begin{array}{c}\text { Years Experience in } \\
\text { Education }\end{array}$ & 17.5 & \\
\hline
\end{tabular}

I also identified active school community members during the first site observation of each school. During this visit, I introduced myself to faculty members and discussed the goals of the study. From there, faculty members who were interested in participating in the study approached me. Influential parents were referred to me through the principals. Each principal introduced me to parent-teacher association current and past presidents. I was also referred to parents who currently held a position on the Association. These school community members included various teachers and faculty members, influential parents, such as the president of the parent-teacher association, school based union representatives and district and school-based committee members. This process allowed me to identify teachers, faculty members and parents who were engaged within the micropolitical and macropolitcal structures of the school. These individuals provided a holistic picture and view of the micropolitcal and macropolitical structures that existed in the school community. The documented, lived experiences of active school community members also allowed me to check how accurately the novice principals' 
perceived their micropolitical realities (Creswell \& Miller, 2000). The following tables describe the school community voices in each middle school:

Table 5: Overview of school community voices

\begin{tabular}{|c|c|c|c|c|c|c|c|}
\hline $\begin{array}{l}\text { Central } \\
\text { Middle } \\
\text { School }\end{array}$ & Age & Gender & Race & Role in School Community & $\begin{array}{c}\text { Years } \\
\text { Experience in } \\
\text { the School }\end{array}$ & $\begin{array}{c}\text { Years } \\
\text { Experience in } \\
\text { District }\end{array}$ & $\begin{array}{c}\text { Years } \\
\text { Experience } \\
\text { in Education }\end{array}$ \\
\hline Anne & $50-55$ & Female & White & $\begin{array}{l}\text { PTA Co-President } \\
\text { Parent in Community }\end{array}$ & 3 & 11.5 & N/A \\
\hline John & $45-50$ & Male & $\begin{array}{l}\text { Person of } \\
\text { Color }\end{array}$ & $\begin{array}{c}7^{\text {th }} \text { and } 8^{\text {th }} \text { Grade Teacher } \\
\text { Discipline Committee Chair } \\
\text { Leadership Committee Member } \\
\text { Adequate Yearly Progress } \\
\text { Committee Chair }\end{array}$ & 4.5 & 4.5 & 13.5 \\
\hline Curtis & $45-50$ & Male & $\begin{array}{l}\text { Person of } \\
\text { Color }\end{array}$ & $\begin{array}{c}\text { School Counselor } \\
\text { Parent in Community }\end{array}$ & 5.5 & 5.5 & 12.5 \\
\hline Barbara & $45-50$ & Female & White & $\begin{array}{c}\text { PTA Co-President } \\
\text { Board of Education Community } \\
\text { Relations Committee Member } \\
\text { Parent in Community }\end{array}$ & 3 & 9.5 & N/A \\
\hline Grace & $50-55$ & Female & White & $\begin{array}{c}\text { Music Teacher } \\
\text { Parent-Teacher Liaison } \\
\text { Committee Member }\end{array}$ & 4.5 & 11.5 & 20.5 \\
\hline Kim & $30-35$ & Female & $\begin{array}{l}\text { Person of } \\
\text { Color }\end{array}$ & $\begin{array}{c}7^{\text {th }} \text { Grade Language Arts } \\
\text { Teacher } \\
\text { Advisory Committee Member } \\
\text { Social Committee Chair } \\
\text { Teacher Association Executive } \\
\text { Member } \\
\end{array}$ & 6.5 & 6.5 & 8.5 \\
\hline Carolyn & $45-50$ & Female & White & $\begin{array}{c}6^{\text {th }} \text { Grade Science Teacher } \\
\text { Mission Statement Committee } \\
\text { Member } \\
\text { Student Recognition Committee } \\
\text { Member } \\
\end{array}$ & 10.5 & 10.5 & 17.5 \\
\hline
\end{tabular}




\begin{tabular}{|c|c|c|c|c|c|c|c|}
\hline $\begin{array}{l}\text { Northern } \\
\text { Middle } \\
\text { School }\end{array}$ & Age & Gender & Race & Role in School Community & $\begin{array}{c}\text { Years } \\
\text { Experience in } \\
\text { the School }\end{array}$ & $\begin{array}{c}\text { Years } \\
\text { Experience in } \\
\text { District }\end{array}$ & $\begin{array}{c}\text { Years } \\
\text { Experience } \\
\text { in Education }\end{array}$ \\
\hline Christine & $25-30$ & Female & White & $\begin{array}{c}5^{\text {th }} \text { Grade Special Education } \\
\text { Teacher }\end{array}$ & 4.5 & 4.5 & 6.7 \\
\hline Mary & $45-50$ & Female & White & $\begin{array}{c}\text { Part-time Administrative } \\
\text { Assistant } \\
\text { Parent in Community } \\
\text { Former PTA president }\end{array}$ & $\begin{array}{l}1 \text { (secretary) } \\
7.5 \text { (parent) }\end{array}$ & $\begin{array}{l}1 \text { (secretary) } \\
12.5 \text { (parent) }\end{array}$ & N/A \\
\hline Tracy & $35-40$ & Female & White & $\begin{array}{c}6^{\text {th }} \text { Grade Social Studies } \\
\text { Language Arts Teacher } \\
\text { Liaison Committee Member } \\
\text { Professional Development } \\
\text { Committee Member } \\
6^{\text {th }} \text { Grade Team Leader }\end{array}$ & 12.5 & 12.5 & 16.5 \\
\hline Jackie & $40-45$ & Female & White & $\begin{array}{l}\text { Parent in Community } \\
\text { PTA President }\end{array}$ & 4 & 9.5 & N/A \\
\hline Jennie & $45-50$ & Female & White & $\begin{array}{l}\text { Parent in Community } \\
\text { PTA Member }\end{array}$ & 4 & 10.5 & N/A \\
\hline Jane & $55-60$ & Female & White & $\begin{array}{c}\text { Administrative Assistant } \\
\text { Member of Safety Committee }\end{array}$ & 4.5 & 14.5 & 16.6 \\
\hline Samantha & $30-35$ & Female & White & $\begin{array}{l}7^{\text {th }} \text { Grade Language Arts } \\
\text { Teacher } \\
\text { Language Arts Committee } \\
\text { Member }\end{array}$ & 9.5 & 9.5 & 9.5 \\
\hline
\end{tabular}

\section{Method of Collecting Data}

The data collection, involving two novice middle school principals, yielded extensive and multiple sources of information, collected over time, through direct observations, in-depth interviews, and documentation. During the year-long study, I conducted seven direct observations, which included formal and informal field visits, observations of faculty and administrative meetings, daily activities and informal encounters with parents and staff members. I recorded the events and activities during each field visit through digital notes. Seven in-depth interviews allowed the principals to share their experiences of navigating through their micropolitical landscapes. 
The interviews also provided a time for the principals to share insights into specific occurrences and events. It also allowed me to probe further into certain situations (Yin, 2009). The interviews took place over an extended period of time, not just in one sitting. The first interview, in January 2010, required each principal to reflect on how he or she oriented to a new school environment. The questions focused on the processes that allowed the principal to identify key school community members, influential teachers, school expectations and goals. During the first interview and observation, the principals were also able to refer me to other school community members to interview. This allowed me to begin to identify school community members that held positions on school or district-based committees or held membership to associations. These influential members eventually became participants in the study as school community voices. Each subsequent interview related to the school year in general. Principals were able to reflect on formal and informal encounters and experiences with colleagues, staff members, superiors and parents. These interviews also contained a standardized open-ended approach, where principals discussed their experiences with politics, board of education members, time management, stress, mandates and school culture. The intent behind these questions was to establish the principals' perceptions of the experiences that helped them understand and lead within their micropolitical landscapes to create holistic educational change.

Each principal also supplied me with other sources of evidence, such as faculty and administrative meeting agendas. These documents helped me further understand the existing topics of interests, initiatives, goals and concerns in the school. Finally, documentation allowed researcher to corroborate evidence from each case. I also accessed monthly board agendas and minutes to identify external macropolitical concerns, such as state budget cuts, in the school or district. Through this data collection, a detailed description of the cases emerged, leading to an 
analysis of themes or issues that appeared within both cases. Subsequently, a thematic analysis, across two cases, was used through a cross-case analysis (Creswell, 1998).

Finally, each principal wrote bi-monthly e-mail logs, which acted as a reflective journal. Each journal entry enabled both principals to recount recent formal and informal encounters with school members within a two week period. The principals also reflected on their decisionmaking processes and noted success and challenges within those processes. The logs allowed me to preview upcoming events and activities in each school.

Role of the Researcher

During the data collection period, ethical treatment of all participants in the study was crucial. School routines were not altered or interrupted in any way during the study to ensure ethical treatment of the site. I remained a complete observer and did not engage at all in social interactions during observations. During the fall of 2009, I discussed, with each principal, the issues surrounding the purpose of the study and the inclusion of active school community members in the study. It was made clear that the purpose of including school community voices was to ensure I understood the micropolitical landscape in each school. I also clearly communicated that school community voice perceptions would not be shared with each principal. Each principal consented to participate in the study and understood that his or her identity and work site would also remain confidential throughout the study. In January, I met with school community voice participants and explained the purpose of the study. All participants consented to their participation in the study and understood that their identities would also remain confidential. I also ensured that their comments would not be shared with their principals. Finally, prepared research questions and instruments ensured I made good use of each principal's time. 
As an assistant principal, I have experienced working closely with principals who have faced the micropolitics of their school environments. Subsequently, I am interested in learning more about how principals navigate through various micropolitical landscapes in order to contribute to the body of knowledge that already exists. However, my experiences have led me to hold numerous assumptions. In this study, I assumed that each school setting will contain specific active school community members. These members included influential teachers, the president of the parent-teacher association and school-based union representatives. Each school in this study, however, contained different active school community members that were included in the study in order to obtain a realistic perspective of the micropolitical environment of each school. These members included administrative assistants, school counselors and influential parents. This study also relied on the assumption that each school setting contained an active school community that was engaged in school decision-making processes.

It was also challenging to escape the macropolitical realities and implications of the New Jersey state budget cuts, as an active public school administrator. All New Jersey public school districts lost various portions of their state aid funding, as the state was attempting to close a 10.7 billion dollar deficit (NJDOE, 2010). As I observed both principals grapple with the consequences of losing faculty members, academic and extra-curricular programs due to the significant loss of state financial aid, I returned to my working environment to deal with the same stresses and implications. As an administrator, who was involved in staffing and program decisions in my own working environment, it was difficult to reserve my judgments on the macropolitical conditions. However, as an observer and researcher, the macropolitical climate tested the skills and abilities of each principal to create trust with parents and staff members to ensure that negotiations could take place to create educational change within a climate of distrust 
between local communities and their schools. The principals' perspectives within these processes served as models within a trying political climate.

Professionally, I am also an active member of the principals' association on a county level. I ensured that I did not know the principals of the selected schools. I also ensured there was not any conflict over familiarity with each site or subject. Finally, it is hoped that the completion of this study represented the principals' perspectives and experiences of how they navigated through micropolitics of education to create holistic educational change.

Interviews and Observations

To triangulate the data, I focused on three data collection methods - in-depth interviews, direct observations and documentation. The participants participated in seven direct observations and seven in-depth interviews, which paralleled Wolcott's (1984) annual cycle of the principalship. Wolcott (1984) noted that principals' tasks and responsibilities peaked and waned based on an annual cycle. Subsequently, the observations and in-depth interviews were conducted during tense and peak activity times. These times were January, March, May, August, September, October and December. The observations were conducted to gain an in-depth understanding of the formal and informal encounters with various school community stakeholders. They captured the principals' interactions before the school day began and after students were dismissed. These events and activities were recorded through digital field notes. These notes allowed me to match principals' responses to his or her interactions throughout the day. During the observations, I remained an observer and did not interfere or engage with the school environment. After the observation, a sixty minute in-depth interview was conducted to discuss the encounters and routines the principals participated in during the day. The in-depth interviews followed a combination of a general interview guide approach and standardized open- 
ended approach. The general interview approach outlined a set of issues that were explored with each principal. These included issues, such as teachers, parents, school culture, time management, board of education members, superiors, politics, hidden politics and local and state mandates. This approach allowed respondents' flexibility in answering topics of concern. The standardized open-ended approach portions of the interview consisted of carefully worded and set questions that took each respondent through the same sequence and questions (Patton, 1990). This approach provided uniformity and consistency within all the interviews.

The first interview took place in January. By this time, the principals had a sense of the major players and stakeholders within their school communities (Wolcott, 1984). There was an emphasis on public relations and the how principal related his or her objectives and expectations for the year to the school community (Wolcott, 1984). A second interview was conducted in March during a time when the principals were responsible for central office budget preparation, teacher evaluations, school management and pupil discipline. This was also a time when school officials received notification from the commissioner of education concerning their loss of state aid. During this time, principals met frequently with their superiors to negotiate the movement and implications for staff members and programs. A third interview, in May, came during a time when state and national pressures were high, as principals were administering high-stakes tests to their pupils. This was also a time when staff members received notification on the status of their current assignments in the midst of budget cuts. Administrators, parents and faculty members also had a clearer picture of what the educational model would look like next year in their communities. August was a time when the principals were preoccupied with becoming oriented with their roles for the following year. The principals also identified expectations within their positions and the school communities. The principals prepared for the formal opening of school 
in September. An interview in September came during a time when the principals implemented procedures and activities to facilitate a smooth opening. They also hosted public relations events to transition students and parents into the school. A sixth interview in October came at a time when the principals oriented new staff and pupils, dealt with public relation activities concerning Back to School Night and addressed parent concerns and worries. A final in-depth interview was conducted in December to serve as a reflection for the principals on how they identified and navigated the micropolitical landscapes over the past two years. The questions were devoted to the principals' perceptions of who were the major players within their school communities, how they prioritized and managed these players and how they led within the micropolitical landscapes to create educational change. It was interesting to note how the principals' career stages and previous experiences (Parkay, Currie \& Rhodes, 1992) influenced their ability to identify and navigate micropolitical landscapes. All interviews were held in privacy in the participants' offices and digitally audio-recorded. The audio-recording allowed the interviewer to capture the actual words of the person being interviewed (Patton, 1990). I also took field notes during the interviews to ensure data was not missed. The audio recordings were stored electronically and transcribed immediately after the interview. After transcribing each interview, I sent the transcription to each participant, where he or she made additions or revisions to his or her comments. I also noted where gaps existed and later followed up with participants during future contacts.

\section{Review of Documents}

Finally, the principals participated in bi-monthly e-mail logging, where they recorded journal and self-reflection entries through an e-mail format. The principals sent me, every two weeks, a brief textual narrative of formal and informal encounters they faced with school 
community members and stakeholders. This form of documentation allowed principals to gather events, analyze and interpret the events, situations and dilemmas they encountered. When compiled together, the e-mail logs told individual stories about each principal. This created a sense of self for each participant and helped engender trust between me and the principals. The documents included e-mail correspondences, which acted as a journal for each principal. In the event a subject did not supply an e-mail log, I followed up with a brief phone check. I also accessed the bi-monthly board agendas and minutes to identify external macropolitical concerns in the school or district. Finally, after completing an observation, I reviewed all field notes and compared them to the in-depth interviews each participant completed. Through this data collection, a detailed description of the cases emerged, leading to an analysis of themes or issues that appeared within both cases.

\section{Inclusion of School Community Voices}

Influential school community members, who possess an active voice in the school community, were interviewed three times during the study. These members included teachers, school counselors, administrative assistants and parents that were influential and active in the micropolitical landscape of the school. Some of these members were members of committees or organizations, such as the union and parent-teacher association. Three in-depth interviews were conducted throughout the study, which helped me identify aspects of the existing micropolitical environment in comparison to the principals' perspectives of the landscape. Each interview followed a standardized open-ended approach, where each respondent answered carefully worded and set questions. Each member was interviewed in January, June and November. The first interview took place in January. This is a time where I identified established and influential power structures that existed in the micropolitical landscape. The participants shared with me 
aspects of the existing culture and climate in the school community. They shared the key needs of the micro and macropolitical environments. The second interview took place in June. This was time where members identified which needs were addressed within the first year of the princpalship and the processes the principals took when addressing needs. I also identified how the principals oriented and led within the micropolitcal environment. Finally, school community members were interviewed in November. This was a time when these participants reflected on the needs that were addressed and the processes the principals took to address issues concerning educational change over two academic years. These interviews gave me background information. In turn, I compared the principals' perspectives with those active in the micro and macropolitical arenas.

\section{Review of Documents Timeline}

The prolonged engagement in the field, through repeated observations, interviews and logging, allowed me to build trust with all the participants in the study. It also established a rapport to allow participants to feel comfortable disclosing information. Including multiple perspectives, through novice principals and active school community members, helped gain a credible account by building a tight and holistic case. Being in the field over time solidified evidence, as I had the time to validate data and compare interview data with observational data (Creswell \& Miller, 2000). Finally, the following table provides a calendar and an overview of who was interviewed and observed and when these procedures occurred: 


\section{Table 6: Data collection calendar and matrix}

January

March

Interview \#2 with novice principal from each school.
Interview \#1 with novice principal from each school.
February

\section{Interviews}

Observations

Observation \#1 of formal and informal encounters and routines as principal orients to the micropolitical landscape

Interview \#1 with identified lead teachers, school-based union representatives and parentteacher association president.

April

May

Interview \#3 with novice principal from each school.
Observation \#2 of formal and informal encounters and routines as principal orients to the micropolitical landscape.
Bi-monthly email logs: Orienting within the micropolitical landscape

Review of Board of Education agendas and minutes to identify school community issues.

Review of Board of Education agendas and minutes to identify school community issues.

Bi-monthly email logs: Orienting within the micropolitical landscape.

Review of field notes

Review of Board of Education agendas and minutes to identify school community issues.

Bi-monthly email logs: Orienting and leading with the micropolitical landscape.

Review of Board of Education agendas and minutes to identify school community issues.

Bi-monthly email logs: Leading within the micropolitical landscape.

Review of field notes 
June

Interview \#2 with identified lead

teachers, school-based union

representatives and parent-

teacher association president.

August Interview \#4 with novice

principal from each school.

September

Interview \#5 with novice principal from each school.

Interview \#6 with novice principal from each school.

Interview \#3 with identified lead teachers, school-based union representatives and parentteacher association president.

December

Interview \#7 with novice principal from each school.
Observation \#4 of formal and informal encounters and routines as principal leads within the micropolitical landscape.

Observation \#5 of formal and informal encounters and routines as principal attempts to create educational change within the micropolitical landscape.

Observation \#6 of formal and informal encounters and routines as principal attempts to create educational change within the micropolitical landscape.
Review of Board of Education agendas and minutes to identify school community issues.

Bi-monthly email logs: Leading with the micropolitical landscape.

Bi-monthly email logs: Leading within the micropolitical landscape

Review of Board of Education agendas and minutes to identify school community issues.

Review of Board of Education agendas and minutes to identify school community issues.

Bi-monthly email logs: Leading within the micropolitical landscape.

Review of field notes

Review of Board of Education agendas and minutes to identify school community issues.

Bi-monthly email logs: Politics of educational change

Review of field notes

Review of Board of Education agendas and minutes to identify school community issues.

Bi-monthly email logs: Politics of educational change.

Review of Board of Education agendas and minutes to identify school community issues.

Bi-monthly email logs: Politics of educational change

Review of field notes 


\section{Data Analysis}

The data collected during the study were evaluated using cross-case synthesis and analysis. This helped develop common constructs, themes, and patterns between both cases. The analysis led to robust findings across two cases within the themes of understanding the micropolitical landscape, leading within the landscape and negotiating with school community members to achieve holistic educational change (Yin, 2009). The data also captured a comprehensive overview of what takes place in the observed activities (Creswell \& Miller, 2000). I immediately transcribed all audio recordings after each interview with the principals or school community voices. Field notes were also documented electronically as I was visiting each school. All documents were stored electronically and were converted to a portable document format. I created an annotated bibliography of these documents to facilitate storage and retrieval (Yin, 2009).

After each interview or field visit, I reviewed all responses and highlighted common themes and patterns that emerged within both cases. I grouped the data by site. A case study database was used to show that all the data had been documented and organized. This database recorded the number of times a specific theme was discussed between both cases and highlighted the major themes of the study. All interview transcriptions were emailed to participants, as they had a chance provide additions or revisions to their responses. This allowed participants to review the evidence directly using a member checking process. Within this process, data and interpretations were taken back to the participants in the study. The participants then confirmed the credibility of the information and the narrative account (Creswell \& Miller, 2000). This ensured accuracy. I identified significant statements that were common across all participants. I also clustered these statements into themes. Each principal had various experiences as they 
worked within different micropolitical landscapes. The data collection yielded, however, many commonalities, which further described the experiences of novice principals, as they navigated various micropolitical landscapes. The commonalities and consistencies between the cases also reinforced the validity, dependability and the transferability of the data.

The most important aspect of data analysis was ensuring data verification, trustworthiness and credibility (Cresswell, 1998). To ensure this, member checks were employed to validate that all data, analyses, interpretations and conclusions were accurate and credible with each participant (Cresswell, 1998). Member checks also allowed me to check how accurately the participants' realities were represented in the final account (Creswell \& Miller, 2000). Finally, I maintained a chain of evidence to increase the reliability of the information in both cases. The chain of evidence allows an external observer to follow the derivation of any evidence from the initial research questions to the case study conclusions (Yin, 2009). The chain will outline the following evidence: 
Case Study Questions

$$
\int
$$

Case Study Protocol (linking questions to protocol topics)

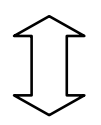

Citations to Specific Evidentiary Sources in the Case Study Database

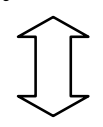

Case Study Database

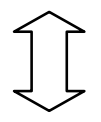

Case Study Report

Figure 2: Maintaining a Chain of Evidence (Yin, 2009, p. 123)

The report will make sufficient citation to the relevant portions of the case study database, for example, by citing specific documents, interviews and observations. The report will also reveal actual evidence and indicate the circumstances under which the evidence was collected. Finally, the circumstances will be consistent with the specific procedures and questions contained in the study protocol, to show that the data collection followed the procedures stipulated by the protocol (Yin, 2009).

\section{Summary}

Novice public middle school principals face the challenge of identifying key micropolitical structures and landscapes within their public schools. They also have the daunting task of navigating internal micropolitical structures and interactions in relationship to external macropolitical structures while negotiating educational change (Bacharach \& Mundell, 1993; Hargreaves \& Goodson, 2006; Willower, 1991). However, the first or second public middle school principals in this study were responsible for daily tasks and responsibilities, while trying 
to navigate a micropolitical climate that was driven by the macropolitical climate. In addition to learning about key members in their school communities, frequently visiting classrooms and team meetings to understand how the school works, gaining efficacy with superiors, colleagues and staff members and creating partnerships with parents, these principals were required to negotiate decisions with school members within a school climate that was penetrated by the school aid budget cuts that occurred across New Jersey. The process of how administrators navigate and understand daily managerial tasks is well documented (Bridges, 1965; Parkay, Currie \& Rhodes, 1992; Wolcott, 1984). This study will describe the navigation and negotiation of the micropolitics of education for first or second year public middle school principals in relation to promoting educational change.

A principal's potential to lead within the micropolitics of education is dependent on his or her ability to identify cognitive politics, which are formed through cultural values of a social organization and are shared among all members of the school community (Marshall \& Scribner, 1991). These values of subsystems exist within the political ideologies of social systems comprised of teachers, administrators and students (Marshall \& Scribner, 1991). A principal's ability to navigate through cognitive politics will help develop and maintain integrated communities with his or her school (Kardos et al, 2001).

The questions posed to the participants during this study captured their experiences working in distinct micropolitical environments and school cultures. The study documented their journeys while learning a new school environment, as each principal attempted to create his or her own school culture. The study also investigated the micropolitical obstacles and realizations each principal faced along the way. Those findings are presented in detail in the upcoming 
chapter as the product of this qualitative study of the lived experiences of two novice public middle school administrators entering their first principalships in a new school. 


\section{CHAPTER IV}

\section{UNDERSTANDING THE MICROPOLITICAL LANDSCAPE}

"My major focus was to learn the players, communicate and build trust"-

\section{Robert Wilson}

Many themes and findings emerged during the full-year study of how Lisa Miller and Robert Wilson navigated their micropolitical landscapes to create holistic educational change. In the first six months of the study, each principal was required to participate in a micropolitical process by learning existing school values, content behind policy making and the decisionmaking process by understanding their landscapes. This often resulted in each principal orienting with colleagues and staff members through formal and informal "getting to know each other" encounters, such as administrative, team and faculty meetings or informal discussions in the hallway. Miller's and Wilson's ability to understand their climates was heavily dependent on their ability to identify existing beliefs and ideologies, and their leadership styles and approaches with staff members as a whole and individually (Anderson, 1991; Marshall \& Scribner, 1991).

Lisa Miller began her first year as a middle school principal after years of serving as a department chair and curriculum supervisor for other districts. The districts she previously worked for were predominantly white and affluent, and her move to Central Middle School was a change for her since she was leading within a more racially and economically diverse micropolitical landscape. Entering the new role, she knew it was going to be difficult to ensure that all students met academic requirements because the district implemented a strategic action plan emphasizing to parents, teachers and administrators that failure was not an option.

Early on, Lisa Miller mentioned the challenges of understanding the existing school culture. However, she felt her previous experiences prepared her to learn the specifics of a new building and understand existing cultures and subcultures. She leaned on her knowledge of 
recent research-based curricular trends, since she was focused on improving student proficiency. She acknowledged the difficulty of being seen as an outsider and "staying true to herself," while compromising with teachers and support staff. Her main goal was to improve student achievement by increasing student proficiency on state assessments, which was in accordance with district goals and initiatives. Miller looked to support curricular changes within the existing language arts curriculum that were initiated the previous year. To successfully understand her new landscape, while implementing curricular changes as an outsider, it was important for Lisa to attend every team meeting and work closely with teachers to ensure she understood and learned existing values and ideologies, while building trust. Miller, through these established relationships, lobbied, debated and negotiated for educational change.

While Lisa Miller was an outsider trying to grasp the inner workings of her micropolitical environment, Robert Wilson was an insider who relied on established relationships within his district. Robert Wilson was previously an assistant principal in the district's other middle school. At the beginning of this study, he was a second year principal at Northern Middle School and had established relationships with his superiors and colleagues. Although he did not personally know faculty members at his new middle school, staff members knew of him. Some teachers worked with Robert on district level committees. In many ways, Robert Wilson was a known commodity.

Entering his second year as principal, Wilson wanted to continue open communication to improve instruction in his middle school. One of his goals was to "ramp up" instruction and student achievement. Specifically, Wilson looked to implement a new master schedule that allowed longer instructional periods and new math and literacy curricula. His goal was to provide more instructional time and enhance curricular standards to provide more student- 
centered learning strategies. This was an effort to reduce teacher-centered approaches, such as lecturing. He acknowledged the challenge of balancing his school and district goals with his everyday obligations of being visible in the school and classrooms. However, Wilson realized that his challenging and anxiety-ridden curricular and scheduling changes were implemented with success partly because he was an insider and a known quantity.

Both Lisa Miller and Robert Wilson implemented challenging goals that created holistic educational changes through instructional and curricular initiatives to improve student learning. These goals and changes were tough to implement in any micropolitical environment, especially for a first or second year principal. The micropolitical process of identifying influential school community members, forming positive relationships with colleagues and superiors, creating a network of communication with all school community members, while supporting students socially, academically, physically and emotionally overwhelmed each principal. In this case, micropolitical interactions were usually intense. However, typically peripheral macropolitical concerns became the singular focus three months into this study. All New Jersey local public school budgets were slashed thanks to state budget cuts (New Jersey Department of Education, 2010). Lisa Miller and Robert Wilson both were making educational changes while their school resources and faculty members were being devastated by losses in state aid funding.

\section{Macropolitical Budget Crisis and Culture of Shock}

"The budget has been an impromptu and huge challenge and looking people in the eyes and telling them that they might not have a job has been extremely

$$
\text { challenging”-Lisa Miller }
$$

Lisa Miller and Robert Wilson were subjected to routine micropolitical pressures when they first entered their new middle schools. They both entered a culture of shock where events were unpredictable, emotions over acquiring valuable resources were raw and individuals and 
coalitions were challenging existing norms and boundaries (Achinstein, 2002; Marshall, 1985). Both principals worked through dilemmas, tensions and challenges, while appearing calm, competent and in control. Still, the change to a new role, as a building principal, was traumatic and stressful. The demands of the job from implementing school and district goals to supporting teachers in the classroom to addressing parents' concerns to accommodating central office requests were difficult to fulfill for any novice principal (Marshall, 1985). However, Miller and Wilson were not adequately prepared to deal with the management or implications of an unpredictable macropolitical budgetary crisis, which included retrenchment through personnel and program cutbacks (Boyd, 1982). During routine site visits, both principals rarely had time to check e-mail, as they were constantly working through building issues. The novice principals were also faced with trying to identify their own micropolitical landscapes while trying to implement goals, work with teachers and resolve parent concerns.

Robert Wilson initially did not see politics shaping his job. He spoke about smaller political issues, such as setting specific schedules for students who were related to prominent community figures, such as board members, to working with teachers who were resistant to change. However, Robert generally described politics as "part of playing the game" and being able to compromise within hidden and overt political agendas to do what was best for students. Overall though, Robert did not think politics controlled his environment or his interactions with school community members. Lisa Miller similarly initially downplayed politics in her landscape; although she did acknowledge that politics played a role, at times, in her position, especially when resolving teacher conflicts and issues. During the spring of 2010, however, both principals realized the gravity of macropolitics within their micropolitical landscapes, which heightened 
interactions and reinforced a culture of shock in their middle schools once their districts lost state funding.

As Lisa Miller and Robert Wilson worked through their micropolitical dilemmas, New Jersey lawmakers hammered out a state budget that looked to close a projected 11 billion dollar deficit (NJDOE, 2010). To do this, the newly elected governor decided to slash state funding to all New Jersey public schools. As a result, Central School District lost $28 \%$ of their state aid, or 4.8 million dollars, while Northern School District lost nearly $100 \%$ of their state aid, or 3.5 million dollars (NJDOE, 2010). Both districts planned personnel and program cutbacks that had the least impact to curricular initiatives. Consequently, Central School District terminated 21 classroom teachers across all schools, 17 specialists including media and technology specialists, six administrators, three elementary guidance counselors and five clerical employees. Middle school and freshman year sports were also eliminated. Central Middle School specifically lost four classroom teachers. Northern School District eliminated 18 staff positions; however, cutbacks targeted positions that had minimal impact on student services. The district cut specialists in addition to two elementary classroom teachers, a high school French teacher and four special education teachers. Northern Middle School lost reading specialists, enrichment teachers, a media specialist and a physical education teacher. During the fast-paced macropolitical crisis, the principals' toughest task was selecting staff members who fit in their buildings and those who did not fit at all. Consequently, the macropolitical environment created an opening for upper administrators and principals to release non-tenured or tenured teachers or staff members who did not meet their expectations to help enact educational change.

Lisa Miller described the state cuts as an unexpected and huge challenge, since she had to look people in the eye and tell them they did not have a job for the subsequent year. The painful 
realization that she had to ensure a quality education for all children with fewer teachers was summarized, as she was forced to "become accustomed to the devastation of the budget cuts." She "kept telling" herself "it was going to be okay," but she was "not really sure that was the case."

Robert Wilson had similar concerns about implementing new curricular and scheduling changes. He was initially satisfied that he had enough teachers to successfully implement the new changes immediately. However, he struggled with the notion of being asked by his superiors where he could cut in terms of staff. As a principal, it violated his values, as he stressed 'It's hard in the ways that you don't want to put people out of jobs. You don't want to hurt kids by not being able to implement every program you want in terms of their basis skills or enrichment programs. As a principal, we fight for our building; we fight for our kids in our building; we fight for what's best, but ultimately across the street they have to make tough financial decisions. Those we have to live with."

The potential loss of faculty members, as well as extra-curricular and academic programs, were harsh realities for both principals. Their jobs became extremely political because they were put in a position to negotiate for staff members and programs with their colleagues and superiors. However, even through crisis, each principal was still expected to successfully implement new curricular programs and goals in their schools. They were also still expected to understand their micropolitical environments by getting to know teachers, support staff and parents. However, the macropolitical environment made this process difficult because Lisa and Robert were working within an escalating climate of distrust.

\section{Getting to Know Each Other}

"During the first year, I think he [Wilson] was trying to feel us all out and be on our side"-Christine, Northern Middle School 
Micropolitics refers to the immediate, ongoing and dynamic interaction between and among groups and individuals. These interactions help groups or individuals to use formal and informal power to achieve their goals (Blase \& Blase, 2002). Goals are often reflective of the interests, preferences, purposes and differences related to existing needs, values and ideologies (Anderson, 1991; Marshall \& Scribner, 1991). Novice middle school principals have the primary responsibility to identify their micropolitcal landscapes by getting to know the organizational stakeholders, individuals and groups at any given time. They also have a responsibility to solve problems associated with teaching and learning. Miller and Wilson accomplished this through their work with grade-level interdisciplinary team structures (Hoy \& Hannum, 1997). Whether through a hierarchical or lateral approach, novice middle school principals must find ways to develop teacher loyalty, trust, commitment and motivation to influence and negotiate educational change. This is usually done through intense, short and informal experiences (Parkay, Currie \& Rhodes, 1992).

Novice middle school principals participate in a "grapevine structure" or informal channels of communication among individuals or groups to identify and learn the web of values and ideologies that exist within their building climates (Licata \& Hack, 1980). Similarly to Wolcott's (1984) depiction of the principalship as a verbal culture, principals learn the ways of their micropolitical landscapes through informal or chance encounters. In Central Middle School, Miller often found herself listening to teacher concerns, needs and ideas in weekly grade-level team meetings. Lisa's participation during all team meetings allowed her to identify the culture of her school and district, which was very different from her previous experiences. During meetings, Miller presented formal school issues and topics and gave staff members a chance to provide feedback. In many cases, these formal team meetings contained informal conversations 
about topics ranging from philosophy of instruction, to curriculum integration, to building management and communication. During these times, Miller acted as a fact finder and a problem solver. These encounters also gave Miller a preview of hurdles or issues that arose in general faculty meetings.

In addition to resolving school issues, Miller worked closely with teachers to refine their teaching techniques and strategies to enhance student learning in the classroom. These encounters created an atmosphere where Lisa identified and compared teachers' expectations of student learning with her own. Subsequently, teachers collaborated with Lisa to create interventions for students who needed assistance in fundamental skills. As the year progressed, Miller felt confident that her collaboration during weekly grade-level team meetings allowed her to make some in-roads in terms of developing an identity and relationships with staff members. She felt it allowed her to focus each team on the goal of improving student proficiency, and helped solidify a positive culture. In addition to these meetings, Miller also made it a point to be visible in the building, where she would informally speak with staff members. Miller walked the building every morning to check-in or follow up with teachers or just to say 'hello.'

Subsequently, establishing formal and informal relationships with staff members created a comfortable environment where Miller frequently visited classrooms and offered meaningful feedback to all teachers.

Similarly, Lisa Miller created formal and informal opportunities to build positive relationships with parents. Through formal Coffee with the Principal and PTA dinner events, Miller articulated recent school activities and events to parents and provided a forum for parents to share their perspectives. It also gave Miller an opportunity to create new relationships or rebuild damaged relationships. In February, Miller faced her first significant crisis after several 
students were involved in a fight. Since the fight occurred between students of different races, parents perceived the incident as a racial issue and were rattled by the incident. Lisa invited parents to have coffee with the principal to communicate, control her message, remain calm in the face of a crisis and stress her values of student safety; it also allowed her to dispel rumors that circulated amongst parents. She also formed many new relationships and identified central community members during these encounters.

Initially, five out of eight school community voice members acknowledged that Lisa Miller was going through a "getting to know each other" orientation stage with the staff and community as she started her first year at Central Middle School. John, a Discipline and Leadership Committee member and seventh grade teacher, noticed how Miller used grade-level team meetings to identify school culture and discuss new initiatives. The message that failure was not an option was conveyed during formal team meetings and it gave teachers a chance to provide feedback to Miller. John thought people would be more willing to communicate in a small group format rather than a large group setting, such as a general staff meeting. Although failure is not an option was communicated through team meetings, John admitted that teachers still did not know what that actually meant in relationship to their teaching practices.

A number of voices also communicated the same theme of Miller "feeling her way" through the climate and "trying to get through her first year." Barbara, the Parent-Teacher Association co-president and active community member, perceived Miller as going through a learning process, since Lisa was trying to understand what was going on. Overall, teachers and parents viewed Lisa Miller as being available to get to know the people, who made up Central Middle School, to listen to their values, needs and ideas. 
As Lisa Miller worked hard to develop new relationships with her teachers, support staff and parents, news of the state funding cuts to New Jersey public schools hit Central Middle School and disrupted communication. Teachers felt stressed, wondering which programs or staff positions were going to be cut. During this time, Miller and her teachers were thrown into survival mode (Marshall, 1985). Teachers heard rumors concerning staff members being laid off. Miller was trying her best to communicate what she could regarding possible staff and budget cuts. Her informal and formal meetings were efficient avenues to discuss professional development or curricular changes, but Miller could not cast a web of communication to openly discuss the budget crisis. Overall, teachers felt communication was lacking, which impeded the "getting to know each other process". These sentiments were represented well by John, as he admitted that the 'getting to know each other' process was stressful, especially in the midst of lost funds. As teachers heard rumors of staff cuts, anxious feelings and sentiments flowed freely at Central Middle School. Teachers felt nervous about curricular changes and school initiatives. They voiced their fears and frustrations at the prospects of teacher layoffs, larger classes and reduced resources (Hickcox \& Ryan, 1979). Some teachers did not trust the administration to be honest about the budget crisis. Kim, a seventh grade language arts teacher and influential teachers' union member, did not know what the budget cuts meant for teachers who had to implement changes to the language arts curriculum the following year. She didn't fault the district for having to make cuts, but she wondered what it meant professionally for staff members next year. Kim was also concerned that the staff changes and cuts would adversely affect curriculum development and test scores. She, as all the teachers, remembered failure was not an option. 
Grace, an experienced music teacher, echoed this confusion and lack of communication. She acknowledged that all the teachers "were a little bit nervous and did not quite understand what was happening. Maybe it's because of the stuff in Trenton and all the talk about cutting back staff and they're trying to either make people angry or retire; I'm not really sure what their game plan is. But I think everybody is very aware that people are being cut that shouldn't be." As Lisa Miller was trying to survive her first macropolitical crisis, which dramatically reshaped her micropolitical landscape, Robert Wilson was going through a similar process at Northern Middle School.

Wilson's ability to build a foundation of communication and trust during his first year as principal of Northern Middle School gave him the opportunity to implement curricular and scheduling changes during his second year. Wilson acknowledged that his first year was spent getting to know teachers and support staff members through formal and informal communication. His goal was to develop trust through communication with his staff and identify members whom he could reach out to during the year. Like Miller, Wilson participated in weekly grade-level team meetings and Liaison Committee meetings, which gave Wilson a chance to form relationships with formal union members. These members often voiced concerns over building and contractual issues. The relationships Wilson built during his first year opened a forum of honest communication during his second year.

His relationships proved useful because Wilson often met with his Liaison Committee representatives informally to work out disagreements before formal committee meetings. Wilson described these meetings as arenas where constant informal conversations took place and ideas were freely shared. However, Liaison Committee meetings were not conflict-free. At times, representatives voiced their concerns over teacher schedules and new curricular and scheduling 
changes. Teachers were anxious that they were missing valuable class time due to curriculum training. Wilson encouraged his staff members to voice their concerns, stressing "opportunities for open dialogue where people weren't banging heads or yelling and screaming or sending emails with tones to them." He valued gaining input from his staff members and giving them the ability to voice their concerns.

Grade-level team meetings at Northern Middle School were arenas where Wilson could talk about the new math curriculum and schedule initiatives. Here, teachers often discussed curricular issues and planned interdisciplinary units together. Wilson's participation on the teams allowed him to keep his finger on the school's pulse. These informal and formal encounters also created a climate in which he readily visited classrooms to observe how instruction and curriculum was being implemented. During team meetings, Wilson recognized that teachers felt stressed by the middle school restructuring goals. Wilson acknowledged that teachers' anxieties should not be ignored, but at the same time he was aware that the school initiatives had to be developed and implemented in time for the next school year. Wilson noted that he often pushed for change through grade-level team and liaison meetings, but it was important for him to identify situations where he had to manage these changes and listen to staff input and concerns. However, as the state budget cuts were announced, the battles mounted with the teachers' association pushing back, as anxiety over curricular and scheduling changes escalated.

Teachers and parents viewed Robert Wilson's first year experience at Northern Middle School as a time where he had an opportunity to learn his landscape. Christine, a special education teacher, noticed how Wilson was "trying to feel us all out and be on our side" during his first year. She continued by describing his first year experience as "winning staff members over" to later implement school initiatives. Samantha, a language arts teacher and committee 
member, also noticed Wilson "learning" during his first year. Through this process he was open to all voices and opinions. He familiarized himself with the schedule and the school.

Wilson's use of team and committee meetings allowed him to develop positive relationships with his teachers. Tracy, a Liaison Committee member, noted that her experiences working with Robert on the committee created a comfortable environment where she was more likely to speak with him privately in his office if she had a concern, need or a question. She admitted without those experiences "I don't think I would have done that because I wasn't quite sure what his response would be or I just kind of wanted to let him do what he needed to do." Christine saw Wilson initiate more decisions and develop confidence during his second year as he became acquainted with the teachers and identified their concerns.

As with Central Middle School, the clear and consistent communication that took place in team meetings stopped. Robert Wilson shifted the majority of his time to impromptu administrative meetings to discuss solutions and outcomes to the recent news that the state was cutting school funding. Face-to-face meetings were replaced by memos and emails to staff members. As Wilson's leadership became top-heavy and controlling, the school climate became segmented (Kanter, 1983). Tracy described it as a confusing time where communication was lacking. Teachers were looking for direction from Wilson, and "everybody kind of assumed that the teachers knew what was going on." Team meetings, which were attended by Wilson once a week, were cancelled. Important messages from Wilson to his staff were often lost in translation through emails and memos. Jane, a member of the School Safety Committee, perceived that Wilson was "distracted" by state budget cuts. Priorities shifted from communicating with staff members to working with central office administrators. Gaps emerged as Wilson missed team meetings and had difficulty touching base and following up with teachers. 
Like Central Middle School, staff members at Northern Middle School grew increasingly anxious about new curricular and scheduling changes amid talk of staff and program cuts. Christine, who taught both reading and writing, was concerned over the amount of time she was taken out of her classroom to be trained in new curriculum. She felt anxious. Even though she received training, she was unsure of the right ways to implement the new instruction. Samantha, also a language arts teacher, shared Christine's concerns. She was "scared being held accountable for 100 children in language arts.” The change of language arts instructional periods to sixty minutes worried her because sixth and seventh grade language arts classes were ninety minutes the previous year. Eighth grade language arts classes were only forty-five minutes. Samantha was also anxious that new curriculum changes would not be finished in time. "I try to keep my fingers crossed that it's going to get done, but it's a lot of work and we have somebody from the outside coming in and helping us. But it's a lot of change in difficult times." There were many changes happening in both Northern and Central Middle Schools—macro and micropolitically. Through this, both principals worked very closely with their superiors and colleagues to handle the changing climate.

\section{Building Relationships with Superiors and Colleagues}

"School administrators derive satisfaction from a shared perception that no one can really understand what it is like to be a principal until he [or she] has been one him [or her] self"-Wolcott, 1984, p. 221

Wolcott (1973) portrayed novice principals' autonomy, in relationship to their superiors, as anything beyond the absence of a feeling that the central office was breathing down a principal's neck. Both Miller and Wilson stressed the importance of staying calm and cool while working in a culture of shock; however, they also relied on the support of their colleagues and central office administrators to be successful while understanding their schools' micropolitical 
landscapes. Novice principals are commonly torn over their sense of what is right and good for education and staying loyal to goals and initiatives set forth by their direct superiors (Marshall, 1985). As new principals learn their micropolitical landscapes, they must keep in the back of their minds the need to stay in control, present a united front with their colleagues and superiors and implement district initiatives, while balancing school needs, or else be seen as incompetent, insubordinate or uncooperative (Marshall, 1985). They are also expected to work within an established system of rules and values that governs official decisions and actions (Bridges, 1965). To manage this enormous pressure, novice principals create guild or clan-like relationships with their colleagues (Licata \& Hack, 1980). Principals who create guild-like formal and informal associations feel that other principals in their district would be able to understand the problems specifically relevant to their position or situation. These types of principals tend to interact predominantly with those in their informal group. Principals who participate in clan-like associations create socialization ties and linkages with certain principals. Often, these relationships tend to share common factors, such as sharing a mentor or common professional aspirations (Licata \& Hack, 1980). Miller's and Wilson's experiences were affected by central office personnel, as these members represented the formal authority of the hierarchy, peer group influence and support. These relationships would help them identify key players, while surviving their micropolitical processes.

Lisa Miller and Robert Wilson created positive and collegial relationships with their superiors and peers and constantly communicated with them. Miller and Wilson often tested new ideas with these members. Miller had daily interactions with her assistant superintendent. She often reached out to her assistant superintendent to gauge school community reaction concerning activities, such as disciplinary actions or school events. By contrast, Miller reached out to her 
superintendent only in emergency or tenuous situations. Miller spoke about the importance of keeping her superiors in the loop to ensure all members were on the same page. She wanted to make sure she had the support of upper administrators, especially during times when parents reached out to them during disagreements over school policy and procedures.

Miller also had a very close relationship with a mentor who was a former principal at Central Middle School. Although her mentor was principal before the previous administrator, Miller leaned on him to identify the culture of the school community and influential school community members. Whether reaching out to her assistant superintendent or mentor, Miller never hesitated to ask for assistance at any point during her first year as principal. At times, Miller's superiors and mentor offered her key strategies to identify and create partnerships within her school. These relationships were best described as guild-like, since Miller was often given assistance and support out of respect for her position as a principal (Licata \& Hack, 1980). When interacting with her colleagues, they collaborated to help her perform, survive and succeed within her professional setting (Licata \& Hack, 1980). Although Miller mostly viewed her superiors as helpful and supportive, she was reminded that the result of her interactions with parents, teachers and students had to create a school culture that holistically stressed failure was not an option.

Robert Wilson exhibited clan-like relationships with his colleagues and superiors (Licata \& Hack, 1980). His previously established relationships with colleagues and central office administrators were evident since he was an insider at Northern Middle School. Wilson pointed out that he quickly gained trust from his superiors, since he had an established identity as an administrator in the district. He also co-chaired the district level math committee and was a member of the Middle School Restructuring Committee, which helped him gain efficacy and 
respect amongst his superiors. Like Miller, Wilson had numerous and open interactions with his superiors. He often communicated how new scheduling and curricular changes were being implemented in his middle school. He also gave upper administrators insight into how certain changes would work within his school's existing climate. Wilson was seen as an expert of his school. Also, similar to Miller, Wilson spoke about the importance of keeping superiors in the loop, especially during the implementation of new district initiatives. Informing superiors of these events would later help Wilson secure valuable resources during the macropolitical budget crisis.

Wilson enjoyed a close clan-like relationship with a specific colleague in the district- the other middle school's principal. At administrative meetings, it was common to see Wilson and his colleague embrace, share ideas and jokes. During site visits, Wilson phoned his colleague daily and they worked very closely together during the budget crisis to negotiate staff member positions between schools. The intangible connection between these two members was unclear at first; however, it became evident why their relationship was naturally close and supportive. Wilson's colleague was an assistant principal at Northern Middle School before Wilson assumed the principalship. Furthermore, Wilson was an assistant principal at his colleague's middle school, which allowed both of them to rely on each other to identify key staff members, past school community issues and overall climate.

It was crucial for Wilson to sustain his relationship with this colleague during the first years of his principalship, since his colleague held key information to help him identify significant micropolitical structures. These relationships, with colleagues and superiors, proved invaluable during New Jersey's school budget crisis, as Miller and Wilson negotiated with 
principals and central office administrators over staff and programs. These relationships would also help them identify previous administrative cultures that existed in their middle schools.

\section{Understanding Previous Administrative Culture}

"One of the key challenges that confronts the rookie principal is dealing with issues related to his or her predecessor"-Parkay, Currie \& Rhodes, 1992, p. 47

Lisa Miller and Robert Wilson both had the challenge of identifying and understanding

the previous administrative cultures in their schools, as they both entered new micropolitical landscapes. Behaviors, norms, dominant values, knowledge, ideologies and rules were revealed, as each principal learned about their predecessors and the culture they created by getting to know the school community and forming relationships with colleagues and superiors (Erickson, 1987; Schein, 1985). In both schools, the previous administrative culture that was present during the first few months of each principalship could have been problematic for Miller and Wilson (Parkay, Currie \& Rhodes, 1992). Each principal began his or her principalship succeeding a principal who exhibited closed or conflictive approaches (Blase, 1990, 1991).

Various school community voices, including parents and staff members, agreed that the previous principal was not accessible to the school community or to the needs of Central Middle School. Teachers were often met with resistance or a closed door. One faculty member felt her relationship with the previous principal was contentious. She did not feel heard when concerns and issues arose and teacher morale in the building waned. Another staff member added that teachers were not given opportunities to find solutions collaboratively with the principal. "Egos came into play. There were never any conversations or any type of resolution. We pretty much just walked around feeling unappreciated." Teachers found it difficult to communicate with the principal, since information was not readily shared pertaining to school initiatives or goals. 
By working with faculty members on grade-level teams and gaining insights into the previous culture with colleagues and superiors, Lisa Miller knew that her faculty desperately wanted to be heard. She also recognized that teachers did not readily receive needed materials for their classrooms or instruction. Quickly, Miller "heard" the teachers' needs for materials, such as bulletin boards. "People wanted bulletin boards and because they felt they weren't listened to before." Miller made it a priority to listen to their needs and concerns. She had an intact budget by the time she started her principalship and was able to give items that meant so much to teachers.

Miller built a culture of collaboration and openness, through grade-level teams and staff meetings, where teachers could freely discuss ideas, participate in shared decision making and voice their concerns and perspectives. She understood that Central Middle School staff members valued being active in their school. While Miller became visible in the school, one staff member noted the change in culture between the two administrations. "My role now is much more active; I'm more involved in meetings. When there are times that the administration needs some assistance they will call me in, and I find myself more visible and more active. I'm also allowed to make some suggestions to the administration rather than having the administration make suggestions to me.”

As Miller transitioned to establish her own culture, she understood the values, norms and ideologies that pervaded her micropolitical landscape. Her staff consisted of members who were eager to share their perspectives regarding the needs of Central Middle School. This insight into the existing culture of Central Middle School caused Miller to identify key and influential staff and school community members who wanted to contribute to the school 
Robert Wilson, at Northern Middle School, was identifying his micropolitical landscape while succeeding a similar administrative culture. The previous veteran principal was wellrespected at Northern Middle School. However, faculty members and parents felt that communication was lacking and their concerns were not taken seriously. Some parents like Mary, a former Parent-Teacher Association president, thought the previous principal was "very seasoned" and had his "own way of doing things." Teachers did not feel comfortable speaking privately with the previous administrator and parents expected him to communicate more about school programs and activities.

Wilson realized quickly that this was an issue for him, especially when dealing with a teacher situation. Early in his principalship, Wilson was caught "off-guard" during a Liaison Committee meeting, when a teacher noted on the agenda a concern regarding a student disciplinary action taken by Wilson. He was upset that the concern was not brought to his attention privately, as he felt the teacher was looking to discuss the situation in front of central office administrators. The situation revealed the staff's difficulty with speaking to Wilson privately. Some teachers commented that the previous principal "had a more closed door policy and that a few staff members were still uncertain about coming to see him." This experience reinforced the notion that Wilson had to remain visible in the classrooms to build a positive rapport with his staff members.

In both cases, distinct leadership styles evolved throughout the study as each principal learned about the culture created by their previous principal. Miller and Wilson also had to find ways to re-energize their staffs and empower faculty members to become active school community members. The process of understanding their micropolitical landscapes by getting to know staff members, identifying existing beliefs and ideologies, building relationships with 
superiors and colleagues and identifying previous administrative cultures, aided Wilson and Miller in leading within their micropolitical landscapes and forging their own administrative cultures. 


\section{CHAPTER V}

\section{LEADING WITHIN MICROPOLITICAL LANDSCAPES}

"The many things principals do are done not because principals want to do them, but because other people expect it"-Wolcott, 1984, p. 318

Miller and Wilson began working and leading within their bureaucratic structures, as they continued to understand their micropolitical landscapes and the organizational behaviors or values that existed within their schools. Formalization gave each principal good insight into the written rules, regulations, procedures and policies that he or she were expected to uphold and follow; however, Miller and Wilson strove to enable, implement and create an interactive and inviting dialogue among their staff members, parents and themselves regarding school issues and concerns (Hoy \& Sweetland, 2001). Both principals succeeded administrators who did not work collaboratively with their staff members and parents, which created the perception of a conflictive or closed leadership style (Blase, 1990). Although Miller and Wilson believed in working openly and collaboratively with their staff members, colleagues, superiors and parents, there were times they had to implement coercive procedures and use their formal authority to gain staff compliance and push school and district initiatives forward. During the macropolitical budget crisis, both principals relied on bureaucratic or hierarchical structural approaches, where decisions were made with little or no involvement or consultation from school community members. Miller and Wilson had to gain confidence in their decision making skills to decide when to uphold organizational and hierarchical norms, procedures and rules and when to negotiate norms, procedures and rules with staff members and other school community members to create an open and consensual dialogue. They also had to prioritize which school community members were given access to participate in deciding who got what, how and when. During the crisis, however, Miller and Wilson attempted to manage retrenchment, through teacher cutbacks, 
forcing both principals to centralize their decisions (Boyd, 1983). Consequently, closed leadership approaches became routine to Miller's and Wilson's repertoires throughout the study.

Within the middle school environment, Miller and Wilson formed grade-level teams, consisting of teachers, to communicate openly, make decisions, solve problems and resolve conflicts. These discussions addressed core issues surrounding new curricular changes. The principals' open behaviors with parents, superiors and faculty members, regarding the discussion of effective curriculum implementation and instruction, created a sense of competency and efficacy between each principal and their school community members. The principals immersed themselves in social interactions and discussions surrounding the new curricular and academic program changes in an effort to shape and control messages, ideologies and values surrounding these changes within their micropolitical landscapes.

As an outsider, Lisa Miller quickly exhibited her competency and efficacy within the area of instruction, relying on her years of experience as a district language arts supervisor. Since Central Middle School was in the midst of changing the language arts curriculum, Lisa felt more than qualified to support those changes. Her previous experiences also meant she was comfortable giving feedback to veteran staff members. Miller's knowledge of current researchbased educational trends gave her the ability to contribute to formal and informal conversations regarding curricular changes.

Robert Wilson strove to be regarded as a curriculum specialist, especially since Northern Middle School was undergoing significant curricular changes in math and language arts. Wilson knew that he had an uphill battle to gain efficacy with his staff members, since he was viewed as a "social studies person." Wilson was confident that he was a strong building manager, since he had been an assistant principal; however, he learned as much as he could about math pedagogy 
to gain efficacy with superiors, colleagues and teachers. He also utilized the grade-level team structures in his school to collaborate with staff members.

\section{Forging an Administrative Culture}

"Changing working conditions, in common with all successful organizational change, involves two components-structure and culture”-Fullan, 2007, p. 292

Entering Central Middle School, Lisa Miller established a culture that stressed values, such as friendliness, respect, accessibility and support. She seriously regarded teacher and parent feedback and strove to respond to concerns in a timely manner. Her participation during gradelevel team meetings exemplified her open and consensual leadership style (Blase \& Anderson, 1995). Miller started each team meeting with teacher and staff concerns. These were opportunities for staff members to discuss real issues that they faced in the school or classrooms. The atmosphere was often relaxed. During these moments, Miller took notes and tried to supply a rationale for certain issues. At times, she assured teachers that she would look into situations and get back to them. Follow through was important to her. She also routinely included support staff members, such as counselors, during the team meetings to provide varying perspectives.

Grade-level team meetings were also a time where teachers looked to compete for valuable school resources. During one meeting, a teacher asked if Miller had looked into the possibility for funding for a specific student to participate in a program. Another teacher requested that the administration monitor a specific hallway before lunchtime because students were slow getting to lunch; while another staff member asked if she could be released from a scheduled committee meeting to plan an upcoming school event. Lisa Miller's visibility on grade-level teams significantly impacted her time spent on other building issues, such as returning parent phone calls or paperwork; however, it gave her the opportunity to employ a 
collaborative leadership style, where teachers had access to a formal authority figure who could grant permission and distribute resources to staff members with specific needs.

The grade-level meetings also allowed Miller to control the ideological message or cognitive politics behind school initiatives and curricular changes (Anderson, 1991). When the study first began, Miller visited grade-level teams to reinforce teachers’ professional development. She presented staff members with current research regarding curriculum and instructional development. These videos discussed student-centered teaching strategies, which required teachers to utilize group learning in the classroom. Teachers had a choice of three strategies to learn. Miller also required the teachers to select a classroom assessment they had used earlier in the year. Teachers then were required to refine their assessments based on the strategy they chose to learn. They were expected to complete this task during an upcoming inservice meeting. Miller stressed to her teachers that she realized that these modifications might have already taken place and that teachers' completion of these assessments would help support the district initiative and ensure that failure was not an option.

Lisa Miller's experiences as a district supervisor exposed her to current research-based ideologies surrounding curricular change. Her background also showcased her strengthscurriculum development, lesson planning and evaluating teachers. As an outsider, Miller also felt comfortable sharing new ideas with her staff members. Her visibility on the grade-level teams ensured a close collaborative relationship between her teachers. Miller worked closely with teams to refine strategies, such as differentiation and multiple learning styles, to develop interventions for students who needed assistance in fundamental skills. Miller felt that she "made some in-roads and tried to change the administrative culture a bit" with her contributions to the teams. Although Miller was pleased with the teams' progression and growth, she aimed to have 
the teams develop individual identities. The minute someone walked in the door, Miller wanted them to know hallways were a specific team's hallway. However by April, Miller realized that her plans would have to be placed on hold because rumors were filtering out from central office about staff cuts in the face of lost state funding.

Although Miller's leadership style was inclusive, she did employ coercive tactics when she encountered resistance. Miller enjoyed providing a democratic environment before the macropolitical budget crisis; however, Miller acknowledged she needed to get tasks done during the crisis (Eagly, Karau, \& Johnson, 1992). When teachers resisted implementing school or district initiatives, Miller shifted from listening to concerns and negotiating with staff members to handing down mandates to gain staff compliance. In one case, teachers requested Miller to shift their time to talk about classroom and grade-level issues to an afterschool staff meeting. This type of meeting usually took place during grade-level team meetings or when teachers shared a free period. Miller was concerned that she would lose time to address curricular issues. She mandated that the teachers would have to find time to meet during their regularly-scheduled grade-level team meetings. Miller felt that it was her obligation to try to move school initiatives, such as curricular changes, forward, which she "didn't see either at a level that was appropriate or even moving in the right direction.” Miller also acknowledged the pressure from her superintendent to "move teachers in a direction that was beyond fixing the student." For that reason, she was "reluctant to give up what she perceived as a very limited window to discuss instructional philosophy." During Miller's principalship, she was faced with numerous situations where she had to lead with tact and decide when to compromise and negotiate school procedures, and when to use her formal authority and power of the principalship to influence teachers and push forward. 
Within the first six months, staff members and parents felt the change in administrative cultures. Parents noticed that having a new principal "opened a lot of communication up." PTA Co-President Barbara felt comfortable asking Miller to post the policy and procedures about how students can achieve advanced placement as they progress through middle school. This information, once considered difficult to get, became easily accessible to the public when Miller made it available on the school website. Miller sent mass emails to parents regarding school issues and upcoming events. Barbara saw these examples of open communication as "a good thing parents needs to see happening and to keep parents involved." Barbara also felt that as copresident she could voice any concerns to Miller, as she had "been very receptive and felt really comfortable coming in and saying anything that didn't seem right."

Staff members also recognized the openness of Miller's leadership. Teachers routinely commented on the Miller's visibility during grade-level team meetings and hallway conversations. Curtis, a school counselor, believed that Miller's work on teams helped facilitate an open climate, which created a sense that she was "proactive" in helping teachers address problems. He also viewed Miller as being able to "push" goals and objectives to the staff. Overall, "she had a very open-door policy" and she tended to be "person-centered." Her opendoor policy "met a lot of needs" in Central Middle School that "weren't met in the previous administration." Miller was very open to addressing teachers' needs. If there was a problem, she "put everything aside and addressed it" while "letting you know that she was on board with you."

Robert Wilson initially created a similar open leadership approach to contrast the closed approach of the previous administration. Similarly to Miller, Wilson situated himself in his micropolitical landscape and gained efficacy through instructional leadership, especially since he 
was implementing vigorous curricular and scheduling changes for the following year. Compared to Miller, however, Wilson's supervisory experiences were limited. During Wilson's first year in the principalship, he worked to establish open communication to build trust with his staff. He did this through an open-door policy, where staff members were encouraged to see him privately with any concerns. Wilson was also visible in the hallways and maintained communication with grade-level teams. As Wilson began to learn the players, communication opened up to allow "sometimes difficult, oftentimes pleasant conversations with teachers about how to improve their instruction" during his second year. To facilitate this progression of honest communication, Wilson made it a priority to be seen as a content specialist in the face of implementing a new master schedule along with new math and language arts curriculuma. To be regarded as a content specialist, Wilson aimed to be visible in classrooms, which presented a "challenge to still be known as a principal who was in the hallways and in the cafeteria." However, Wilson believed that his presence in the classroom would allow open discussions about curricular and instructional change to take place.

As Wilson vied to "be seen as a math person," he participated on several district-based committees, including the Middle School Restructuring and Math Curriculum Committees. These committees gave him immediate access to holistic educational decisions, such as the purchasing of specific math curriculum and the formation of a master schedule to promote effective student-centered instruction. Wilson's participation on the committees also allowed him to hear teachers' concerns. Teachers felt anxious, since the curriculum and scheduling changes were happening simultaneously, and Wilson conceded that there were numerous and rigorous school initiatives being implemented. Wilson strove to reach a "balance of moving forward, but not moving too fast where people felt anxious." However, he conceded that "anxiety was okay" 
and his main goal was to recognize the "breaking point." Wilson risked resistance and resentment if teachers did not remain committed to the implementation of new school initiatives (Hargreaves, 1998).

As Wilson formally and informally visited classrooms, spoke to staff members in the hallway, listened to team concerns, and met with teachers in his office, he realized that teachers were becoming anxious over all the changes. Wilson attempted to ease teacher anxieties and provide training concerning language arts and math instructional strategies to give teachers the tools to transition from a forty-five minute teaching period to a sixty minute period. However, "one of the biggest anxieties for the teachers was that they were out of their classrooms a lot, as they were being trained." Through this, Wilson focused on communicating with his teachers to alleviate certain concerns and gave them opportunities to have their voices heard. He wanted to make sure he maintained communication through the new school initiatives. He wanted to let his teachers know why they were happening; Wilson realized "they still might not agree with me, but I need to have open dialogue and communication" throughout the process.

Like Miller, Robert Wilson met resistance from staff members, as Northern Middle School was undergoing massive and holistic educational changes. During his second year, Wilson recognized "the fine line in terms of dealing" and compromising certain procedures, rules and norms. There were certain issues that Wilson did not mind negotiating. He based his decisions on priority. In one case, teachers requested a longer lunch during a professional development day. At first Wilson was hesitant to extend the hour-long lunch; however, he took a step back and asked himself, "was it really a big deal?" Wilson resolved that the staff would skip their scheduled break in the morning and take an extended lunch. Wilson insisted that "if that's what made them a little bit happier, that's not a battle I'm going to fight, especially if it means 
are we going to implement our new curriculum." Wilson exemplified consideration for teachers' requests when they did not impact school initiatives (Eagly, Karau, \& Johnson, 1992). However, procedures and expectations regarding the implementation of new curricular and master scheduling changes were not debatable. Wilson clearly communicated the reasons why these changes were being made and teachers did not have the choice to block or resist these changes. In some cases, teachers brought forward labor "contractual disputes" surrounding the coordination of committee or training meetings. Wilson, knowing the teachers' labor contract, countered contractual disputes by threatening to hold teachers to their contractual working requirements. These tactics quickly gained teacher compliance.

Like Central Middle School's school community, parents at Northern Middle School appreciated Wilson's willingness to listen to parent concerns and their opinions regarding school issues. Jackie, the PTA president, was satisfied how Wilson "counted on" them to be involved in decision making. Jennie, another PTA representative, liked the open-door policy that Wilson implemented. The policy solidified for her that "they really were listening and they took everything into consideration." She also stressed that Wilson had a positive approach with parents and staff members when he first began building his administrative culture. He "continued the programs and activities that were already" present at Northern Middle School. He did not make any drastic changes; when he did make small changes, he was open "to whatever parents were asking." Wilson communicated the scheduling and curricular concerns to parents through memos and emails. Parents, along with teachers, were eager to see how those changes would be implemented in Northern Middle School.

Although Wilson strove to create an open climate and culture, by his second year as principal, teachers were increasingly nervous over the "big changes". Wilson took charge to 
make sure the master schedule and curriculum changes were implemented and successful for the 2010-2011 school year. One teacher perceived these changes as "a district wide initiative to change the schedule and it was not the principal's decision." She emphasized that Wilson "wanted what was best for everyone; it was just a lot of change." The administrative cultures that Miller and Wilson created, through their leadership styles during the first few months of their principalships, would be vital to the challenging initiatives they implemented for the 2010-2011 year.

\section{Implementing District and School Initiatives}

"We have a vision of what is needed in terms of personnel and staff to make our program run the right way, and then we're being asked, 'okay, but where can

$$
\text { you cut? ",-Robert Wilson }
$$

Miller and Wilson created a community within their middle schools through seemingly open leadership styles, but they also controlled beliefs and ideologies surrounding instructional and curricular implementation (Anderson, 1991). During the last six months of the 2009-2010 school year, Miller and Wilson were consumed with balancing central office demands and implementing challenging district initiatives, while addressing daily tasks, such as student discipline, returning parent phone calls, handling various 'voices' in their school community, evaluating teachers, and remaining visible in their schools. Miller and Wilson were not leading within insulated organizations during this time, but within an arena of political activity (Bacharach \& Mundell, 1993). Superiors, parents and staff members expected an organized, formal, predictive, and efficient input-output system during these changes. Miller and Wilson were also expected to provide middle school programs that addressed their students socially, physically, emotionally and academically, while resources were eliminated (Hoy \& Hannum, 1997). Any novice middle school principal would be expected to negotiate politically with 
school community members in their micropolitical landscapes, as these changes were being made; however, Miller and Wilson were at odds with their macropolitical realities, which caused a certain level of disorder in both schools. Turf battles erupted between teachers and their principals, especially since the focus of implementing school initiatives was redirected to surviving budget cuts. Consequently, the macropolitical school budget crises made Miller's and Wilson's ability to lead within their micropolitical landscapes difficult. Both principals relied on their formal authority to influence their hierarchical systems.

At the onset of the study, Lisa Miller made it clear that her main priority for her school was to work with staff members to refine and implement the district's mission and strategic action plan. According to 2009 state reports, Central Middle School did not make adequate yearly progress (AYP) in language arts and mathematics (NJDOE, 2009). AYP is a measure of year-to-year student achievement on state assessments in reading, writing and mathematics and is a requirement of the government-sponsored No Child Left Behind Act (NJDOE, 2009). Each school and district must meet yearly AYP goals as a whole and by student population groups. These groups are delineated by $N C L B$ as race, ethnicity, students with disabilities, limited English proficient students, and students who are economically disadvantaged (NJDOE, 2009).

Miller was faced with the challenge of creating a school mission and goals to support the district initiative that failure was no longer option. Her superintendent also made it clear to her that one component of success during her principalship was to focus on increasing student proficiency on state assessments. Miller created a mission statement committee, consisting of teachers, which created a mission that stressed that it was their responsibility "to target the needs of our students and provide them a setting that addresses their growing need for freedom and opportunity, which will help them envision the exponential opportunities and possibilities that 
lay before them, yet maintains security and structure" (Central Middle School Strategic Plan, 2010, p. 1). The committee also created goals guiding staff members to "identify students' skills proficiencies and address any skill deficiencies in all content areas" and decrease the achievement gap by "creating instructional interventions and programs to address gaps" (Central Middle School Strategic Plan, 2010, p. 1). During grade-level team and general staff meetings, Miller communicated that academics were the primary focus and that failure was not an option. Additionally, Miller scheduled meetings with specific teachers to discuss students who had failed two consecutive marking periods.

In late January, Miller began to experience teacher resistance to school initiatives she was implementing. "Some teachers understood it and some truly did not." Miller recognized that the initiative differed from existing philosophies and ideologies. Miller knew that some teachers "chose not to understand" that failure was not an option, and these same teachers interpreted that statement to mean "give" passing grades to students. Miller attempted to refocus her message and communicated that the initiative meant continued hard work with children and trying strategies that might work with students. However, some teachers were still unsure what they were being asked to do.

The staff, however, was unclear and had mixed reactions to the initiatives. Early in the year, teachers heard about the new achievement initiative and understood that it was an edict from central office. However, they were interested in understanding what the initiative really meant and how it would influence their instruction in the classroom. Some teachers were adamantly opposed to the initiative, describing it as "unrealistic." Some thought that the administration was putting children in a "precarious position" by stating that every child will go to college. That's not realistic, since not every child might want to go to college." 
Although a few teachers disagreed with the initiative, parents saw it as a step in the right direction. Anne and Barbara, the PTA co-presidents, worried that students were not prepared to enter high school. Anne wanted to ensure that students were equipped with the skills needed to succeed in the larger high school environment. Barbara shared the same feelings, as she was concerned that students were ready for the "rigor" of high school. Overall both parents and PTA co-presidents were satisfied and happy about the quality of education at Central Middle School, but they wanted to see a continued progression and commitment to academic rigor in preparation for high school.

By May, implementing these initiatives was placed on the "back burner," as Miller and her staff focused on the New Jersey public school budget cuts. As Miller negotiated with colleagues and central office administrators over personnel and programs, staff members panicked. Though the focus shifted, Miller redirected teachers' attention to one of her top priorities - academic achievement. Teachers became anxious over curriculum adaptations and changes. Kim, a language arts teacher, noted that there was a lot of transition working with a new principal and a refined curriculum. Kim was nervous because the development of the curriculum was "bumpy." "There were a lot of add-ins and changes that had to be done, which was presented to us as an 'as is' program." Kim searched for ways to be creative within her instruction and admitted "it makes me second-guess myself as an educated person as far as creativity goes." She was also concerned about how to implement the new curricular changes and meet the needs of all her students. Specifically, Kim was worried about addressing students who were on an accelerated track. "I don't know that I could do the multi-levels of this program to the best of my ability." Although Kim was concerned about the new curriculum, she could not keep her mind off the pending budget cuts and rumors. She was most concerned about 
maintaining "a cohesive teaching team together since there were so many people moving around." She wondered "what that was going to look like next year." It was a significant concern.

Miller knew the superintendent believed in the revamped language arts curriculum at Central Middle School. She refocused her staff and worked with teachers to develop effective student-centered instructional strategies and continued to refine changes in the language arts curriculum. However, Miller believed that her staff was distracted by the recent budget woes, as uncertainty challenged her school's purpose (Boyd, 1983). By late May, morale was low and Miller was getting the sense that "everything that was forward thinking" in terms of implementing initiatives was "getting a not now response from the faculty." Consequently, Miller questioned her own use of consensual-based and democratic approaches. She believed her "kindness was interpreted as 'weakness"” and weighed using a more "micro-managing" or autocratic approach.

There were times when Miller exercised "control” and led through edicts. In June, Miller issued a firm memorandum that "no student in question of failing an academic class should begin graduation rehearsal until he or she was clear of all assignments that ultimately determined their final grade." This was in response to a situation, under the previous principal, where a student was pulled out of promotion rehearsal to be told that he or she was being retained. This year, on the third day of rehearsal, Miller learned that a student was going to be retained because of a failing grade in a specific subject. She asked the teacher to work with the student during rehearsal and the student was able to walk during the promotion exercises. Although Miller did not want teachers to give students passing grades, she advanced that message while facilitating 
passing grades for all students eligible for promotion exercises. Consequently, Miller's edict that failure was not an option was interpreted by her teachers as figure out a way to pass students.

As a second year principal, Robert Wilson confidently implemented school and district initiatives. His district's push to revise the outdated math curriculum and change the existing master schedule aligned both middle schools in the district and provided consistent experiences to all middle school students. The new changes also attempted to improve student proficiency in mathematics, since Northern Middle School did not make AYP in that content area (NJDOE, 2009). The initiatives also focused curriculum on student-centered instruction and discouraged lecturing. The changes were spearheaded by central office administrators, and Wilson was in charge of "managing it" and "promoting it." Wilson, however, was not worried about the numerous changes. In January, he compared implementing new initiatives to his first year in the principalship. "My top concern last year was change, being a new principal. This year, it's very similar, just a different kind of change.”

By late January, however, Wilson started to hit political resistance, since the teachers' union was negotiating a new labor contract for the upcoming year with the board of education. Turf battles over "minutes of teaching and student contact time, what the changes would look like and how they were going to be worded in the new contract" consumed Wilson's time. While planning and implementing new initiatives, Wilson tried to stay within contractual parameters. Teachers, like Christine, worried about the curriculum, scheduling changes and teaching assignments. As a special education teacher, she taught five different subjects, while most teachers in her school taught two or three subjects. Christine watched staff members battle over "who had more teaching time and who had less teaching time; who was getting books and who was getting training." Christine was anxious about receiving training to incorporate new 
curricular materials within longer blocks of teaching time. "We were going to have sixty minute period long classes and that's been a really big concern," since some teachers were used to teaching forty-five minutes, while sixth and seventh grade Language Arts teachers were used to ninety minute teaching periods. The curricular changes also brought new universal grading policy changes, which met resistance. Teachers were expected to weigh grading categories, such as homework, class work and tests consistently. "We're going to a universal grading system where everybody is grading homework, for example, twenty percent. Universal grading really doesn't work for me.” Teachers, like Christine, faced the challenge of applying standardized grading policies to students with skills, abilities and needs.

Within the new curricular changes, Wilson moved teachers across grade-level teams and classrooms. Teachers felt anxious about receiving new books, curricular materials, time to move their materials to new classrooms and training to implement new teaching strategies. Although Wilson attempted to create a consensual-based leadership approach, teachers felt anxious about voicing their concerns and feelings about the changes. Subsequently, most teachers' concerns were circulated amongst each other and kept from Wilson. By keeping concerns from Wilson, teachers escaped hierarchical control and protected their autonomy of classroom activities (Brooks, 2005; Lortie, 1975). Consequently, teachers primarily sought Wilson for permission and access to material resources, which was indicative of a closed relationship between Wilson and his teachers (Blase, 1991). Wilson perceived the few dilemmas that were voiced as "territorial;" however, Wilson acknowledged that "asking teachers to pack up their items to move was stressful." However, Wilson was charged with the responsibility to "balance pushing Northern Middle School forward at a pace where change occurs, while staff stays on board" by 
his superiors. Wilson's ability to successfully complete his goal was important since parents were anticipating a new curriculum and schedule.

All three parents who participated in the study were eager to see how scheduling and curricular changes would be implemented and affect instruction in their school. Mary, a former PTA president, was curious to see what the new math curriculum would look like and how teachers would adjust to it. "Everything was clear and in place on paper. It was just a matter of time before the changes came to fruition to see how it actually worked out on a day to day schedule.” Jennie, who was also a PTA member, was aware that Wilson and his teachers were involved in the process of implementing a new curriculum and schedule. She wanted to see "all the new programs that were mentioned and worked hard for." However, once the state aid funding cuts were announced in late March, parents grew concerned over the new changes. Mary and Jennie heard anxious speculation and rumors about how the potential budget cuts could impact the new changes in Northern Middle School. Jennie felt "caught in the middle", since she had "three kids in the school system, as the school might run into a problem." She "was not sure what [administrators] were actually going to do.”

Staff members were unsure how the potential budget cuts would affect colleagues and new curricular changes. Samantha, a language arts teacher, worried about the new teams for the following year. She was concerned how "content specific" each team was going to be. The plan called for each team to consist of four teachers, who specialized in math, language arts, science and social studies. Samantha was confident in her skills as a language arts expert; however, she was worried about the incomplete curriculum. "We're basically considered the expert and I think I'm equipped, but there's not an organized curriculum." Tracy, a language arts and social studies teacher, noted that "originally we were worried we were going to lose a lot of staff. Originally, 
we were told back in March, we were going to lose maybe nine or ten teachers here. What we saw was a very dark, bleak future for the following year." However, the following year was not as bleak as Tracy first thought.

Robert Wilson worried about how the macropolitical crisis would reshape his vision for new school initiatives. During the budget issues and cuts, Wilson wanted to see his new programs implemented. He had a vision of what was needed in terms of personnel and staff to make it run the right way. Then he was asked, “okay, but where can you cut?" by superiors. Although Wilson was concerned, the budget cuts were out of his control. By June, Wilson learned that he had retained most of his teachers and programs, which did not affect his school initiatives. He also learned that the teachers' union settled on a new labor contract for the upcoming year. Overall, Wilson was happy with the manner in which teachers were responding to all the changes. "I felt confident that I had a terrific staff, who really cared about kids and wanted to do well. That was seen with these initiatives and it was really big for me to see teachers talking about curriculum or work that they were doing in their committees." However, he was not in-tune with teachers' nervousness about receiving training about how to teach during a sixty minute period or implementing new teaching strategies in their classrooms. Wilson was also still battling teacher resistance.

Like Miller, Wilson tackled these battles through mandates. In one case, Wilson called a meeting outside the teachers' contractual time to discuss the implementation of the language arts curriculum. The teachers voiced their concern during a Liaison Committee meeting and Wilson rebuked their concern by mentioning that he would hold the teachers to their contractual time during an upcoming event — the birthday breakfast. Normally, some teachers would attend this breakfast past the contractual time when teachers were obligated to attend to their duties. Wilson 
let the teachers know that he expected the breakfast to end at the contractual time. The teachers understood and backed down from their objection over the impromptu curriculum meeting.

Each principal's tact and ability to recognize which formal procedures, norms and expectations to concede and which to uphold was pivotal in the face a macropolitical crisis and helped implement school and district initiatives. Utilizing autocratic and consensual approaches helped Miller and Wilson lead within their micropolitical landscapes, as they handled and addressed routine parent and teacher concerns. Miller and Wilson both moved from consensualbased or democratic approaches to autocratic approaches to implement their initiatives during macropolitical shock (Eagly, Karau, \& Johnson, 1992; Blase \& Anderson, 1995).

During the full-year study, macropolitics penetrated the environment and decisionmaking processes in both middle schools. The "politics of decline" that plagued public school systems in the 1970s returned as teacher and support staff cutbacks devastated morale and created conflict (Boyd, 1983). Significant budget cuts from the governor greatly reshaped existing interactions and structures that influenced social action and decision making in each school (Blase, 1991; Bacharach \& Mundell, 1993; Mawhinney, 1999). Similarly to the 1970s, teachers in both middle schools absorbed the brunt of the funding cuts, which adversely affected their job satisfaction. Meanwhile, they were still expected to provide quality instruction with fewer resources (Boyd, 1982). Miller and Wilson were immersed with similar pressures, as parents expected their schools to deliver quality academic programs to students with fewer teachers (Boyd, 1982). Although each principal primarily negotiated within his or her micropolitical landscape, they were not working in a vacuum or immune from political pressures. Instead, each principal's micropolitical landscape was influenced and depended on the macropolitical environment (Bacharach \& Mundell, 1993). Consequently, the macropolitical 
climate heightened school community members' concerns and anxiety, as members jockeyed for scarce and potentially disappearing resources and for access to decide who got what, when and how during an uncertain and stressful time.

\author{
Addressing Parent and Teacher Concerns \\ "The way in which principals achieve autonomy appears to be universally \\ recognized and practiced: keep to a minimum the dissatisfaction that might \\ threaten it"-Wolcott, 1984, p. 209
}

Throughout the study, Miller and Wilson constantly engaged in open dialogue with their superiors to keep them informed about how school and district initiatives were implemented. Miller and Wilson were often expected to report details of programs, activities and events that supported their efforts to provide holistic educational change. At times, the principals relied on their ability to keep their "fingers on the school's pulse" and to "pitch" their cases to superiors concerning issues, such as non-tenured staff renewals and non-renewals. And many times, Miller and Wilson leaned on their superiors for help during escalating parent and teacher concerns. Miller and Wilson, however, wanted to prove to their superintendents that they were calm and in control, while implementing school and district initiatives in the wake of a constraining macropolitical budget crisis. They also wanted to showcase how they were achieving holistic educational change through the work of committees and grade-level teams. However, the principals did not want a dissatisfied school community member or faction in the community to gain their superiors' attention (Wolcott, 1984).

Miller and Wilson aimed to run efficient middle schools and satisfy concerned parents and teachers who were jockeying for scarce and disappearing school resources. Subsequently, both principals watched for signs of any mounting level of discontent and attempted to prevent volatile situations that would catch their superiors' attention. Miller and Wilson both engaged in 
open and positive relationships with their superiors; however, they did not want to receive a phone call from their superintendents asking or telling them what was wrong at their schools. They understood that complaints to their superiors left them with little potential for remaining in their positions. Instead, Miller and Wilson quickly "put out fires" and intervened when vocal parents or teachers arose. Their ability to handle complaints "in-house" within their micropolitical landscapes preserved their autonomy, since superiors were not involved. However, Miller and Wilson were making "big changes" within their initiatives. Subsequently, Miller and Wilson were careful not to get caught in the "crossfire" when complaints emerged. Miller constantly communicated with her superiors to ensure that they were aware of escalating parent concerns revolving around disciplinary actions taken by her assistant principal. She spoke with superiors to ensure they understood all pertinent information before parents appealed to them. However, Miller was told early on by her superiors that she would be "judged" by how she handled crises and that her "staff expected her to project a calm and professional demeanor during these times." Early in the study, Miller handled volatile parent complaints firmly. In one situation, a parent was angry that her child did not have an opportunity to participate in a prestigious art program because of lack of funding. Since funds were limited, priority for entry into the program was given to high school students. The parent was unhappy with this decision, and ultimately had a conversation with the superintendent. However, Miller immediately contacted her superiors. "They knew she was calling them and they were able to research the situation, and be well prepared for the conversation when it came."

In another case, Miller suspended students who were involved in a fight after school. However, the parents of one student believed their child was "unfairly punished" because of his race. Miller felt nervous about these accusations and immediately implemented decisions to 
control her "message" and maintain the positive school culture, as she called an emergency faculty meeting and had teachers speak to all students through homeroom classes. She did not want her school culture or structures perceived as racist or unsafe. Miller quickly contacted the superintendent to ensure that he was aware of the situation, since the parent would appeal the disciplinary action to him.

However, Miller became wary of always leaning on her superiors for assistance during serious situations. She was close with her assistant superintendent, who was in charge of the district's public relations, and consulted with her on items, like student suspensions and curricular issues. The assistant superintendent often gave Miller an idea as to how her decisions were perceived. Through this volatile situation involving race, Miller's superior reminded her "I want you to be real careful about what you're doing, why you're doing it and how it's going to be perceived."

Perception was important to Miller. While handling parental complaints, she tried to rebuild relationships with parents by creating partnerships. Miller invited parents who had shown dissatisfaction with what she was doing in Central Middle School to school events. "I've actually reached out to them and said, 'I really want you to come to this PTA meeting. I care about what you think." Throughout the year, she invited these parents to have coffee with the principal and breakfast with the superintendent to give them a voice and let them know she valued their perspectives.

When handling teacher complaints, Miller maintained an appearance of calm and control. Miller respected the teachers' labor contract as she implemented new initiatives. She wanted to ensure that the district's message, failure was not an option, would not be impeded by a mandate that failed to take the teachers' contract into consideration. When asking teachers to view 
curricular materials or meet to discuss initiatives during grade-level team meetings, Miller always concluded by asking if there were any teacher association concerns with her requests. She also attempted to anticipate teacher complaints by maintaining relationships with veteran teachers, who often voiced perspectives for non-tenured staff members. "Within the school, I feel that there are people who seem to represent other people, especially those who feel they can't speak out, and I try to touch base with them every day." Miller thought her consideration of teachers' perspectives and contractual obligations would create a perception that she was not trying to dupe them. However, Miller's proactive measures did not prevent teacher complaints during the macropolitical upheaval.

In May, teachers felt the pressure of administering the annual high-stakes state assessments to their students. Numerous teachers were concerned about how their students would perform on the assessment, especially since Miller was focused on increasing student proficiency. The compounding issues of students' performance on high-stakes testing, while teachers' jobs were at risk, eroded morale. During state assessments, emotions were raw and teachers were vocal. In a grade-level meeting, special education teachers openly challenged Miller on how much additional time special education students were to receive on the state assessments. In previous years, the teachers gave their students an unlimited amount of time to finish test sections; however, Lisa was directed by her Director of Special Services to allow only a specific amount of time - time and a half. Teachers were upset because they wanted their students to have an opportunity to be given as much time as they needed to perform well. Miller stood her ground and pushed through the complaints, but checked with her superior to ensure that she led with the right response. The director assured her that giving a specific allotted time 
was consistent with district expectations. Miller was satisfied that she had upheld the expected procedures. However, complaints continued throughout May.

During that same time, three teachers approached Miller in the hallway to discuss some concerns they had over the state assessment schedule. One teacher was upset that Miller included homeroom announcements during state assessment days. Miller turned to the teacher and said, “Announcements? All I did was salute the flag." The teacher walked away from Miller upset. Miller wanted to "clear the air" with the teacher and later met with her privately. The teacher voiced that she felt unheard and "no longer was going to speak on behalf of other people." Miller was hurt and responded, 'I haven't made up my mind about you; please don't make up your mind about me.” The teacher replied, “I still don't think you're hearing me.” Miller asked the teacher to next time discuss concerns with her privately in her office instead of the hallway. That "painful" conversation bothered Miller because she wanted to let teachers know she was listening.

However, complaints regarding staff cuts, lack of communication and student discipline from teachers were mounting. Teachers, like Kim, admitted that "people were uncomfortable watching other people leave; it was a sad thing." Amidst the cuts, the staff did not "trust that they were being told everything." Grace saw the building climate change. "I've definitely seen some changes in school climate and attitudes of kids and teachers and unfortunately they're not necessarily good observances." Grace was also concerned about the staff cuts because the challenge of increasing student achievement with fewer teachers seemed daunting. She felt that Miller was not listening. "We tried telling our administrators how we felt and we've made suggestions that we thought might help and it fell on deaf ears. I think most of our conversations dealt with shock, fear and concern because we were saying, what's going on?" Curtis, a school 
counselor, agreed that there were numerous voices confronting Miller. "I wanted to see teachers allow the administration to do their job because too many voices disrupted the harmony. I think our new principal was filtering out [all the voices]."

By June, Miller realized that things were not going as planned. Communication was an issue and Miller did not want staff complaints to travel to her superiors. Earlier in the month, Miller was frustrated that a music teacher, who had lost her job during the crisis, voiced her frustration during her closing remarks at a school music concert. Miller aimed stay out of the watchful eyes of her superiors. Subsequently, Miller held an after school general staff meeting where teachers anonymously communicated using notes detailing the positive aspects and needed areas of improvement in the school. The open forum revealed that teachers were upset with communication in Central Middle School. After reading the staff concerns, Miller presented the anonymous feedback to the staff and asked her Leadership and Association-Liaison Committees to review the information with her. Miller attempted to regain control and improve the climate of her building, as she led her teachers through state mandated assessments, a budget crisis and new school initiatives. Her efforts to rebuild the building climate would prove pivotal if she wanted to subdue teacher complaints and negotiate within her micropoltical landscape for holistic educational changes. Robert Wilson was dealing with a similar reality at his school.

Wilson valued making parents a part of the educational process at Northern Middle School and often reached out to parents during difficult times, such as the transition between fourth and fifth grade, to limit complaints. "The elementary-level parents are really involved in the school on a daily basis and then they transition here. We want to try and build some more independence for kids in middle school. The parents realize they're not going to have as big a role in the classroom and that's an issue." However, Wilson felt passionate about creating a 
climate where parents were encouraged to participate in his middle school. "They're in the school all the time at the elementary level. And they come here and no one tells them they can't come in, except for their own kids, but it seems to happen; it's a shock for them. They're invited here. We would love to see them come in, talk to them and show them what we're doing, but they choose not to." As Wilson implemented a new master schedule, he looked to ease parents' anxieties by hosting numerous "open house" events. He invited parents to a math and literacy night to showcase the new curricular changes that were made in Northern Middle School.

Like Miller, Wilson leaned on influential parents, like the PTA president, to help communicate school initiatives and listen to parent concerns. Wilson held Coffee with the Principal events to increase parent participation in his school. Wilson also utilized the teachers to deepen these partnerships. "I'm still working with the teachers to start inviting parents in for classroom celebrations." However, some teachers were hesitant and felt too vulnerable to invite parents into their classrooms because of previous disagreements with parents. Wilson handled parents who were frustrated or angry with his teachers using a protection strategy (Blase, 1987). These incidents forced Wilson to protect his teachers, since Wilson did not tolerate angry parents. "I have no problem telling a parent 'that's just not the way it works around here' when a parent may act inappropriate with a teacher during conversations. They are more than welcome to come and talk about things and I can understand that they can get upset or angry, but that's still not going to be accepted here." When dealing with parental complaints, Wilson always supported his teachers in front of parents and then met with teachers privately about parents' concerns. In one case, a parent complained openly about a teacher "demeaning" her child. Wilson discussed the matter privately with the parents. Behind closed doors, Wilson 
communicated the parent's concerns to the teacher and created a plan to help alleviate the situation.

Generally, Wilson addressed parent complaints quickly and efficiently. As a second year principal, he worked closely with PTA representatives to identify parent concerns and created solutions before public meetings and encounters. Wilson did not have significant "issues that popped up, since concerns were handled immediately or ahead of public meetings." Wilson's goal was to "get that stuff done and out of the way," and he spent time creating avenues to involve parents and the community. Similarly to Miller, Wilson dealt with parental concerns firmly and implemented existing procedures, policies and rules. He believed he was making decisions based on "what was best for the child" and if parents or teachers disagreed with it, then "so be it." Wilson routinely gave his superiors a "heads up" during major student infractions; however, parents generally did not appeal to Wilson's superintendent. Unlike Miller, however, Wilson did not lean, as much, on his superiors for assistance during student incidents and disciplinary actions.

Wilson applied his philosophy of "open and honest communication" to avoid teacher complaints. He met with teachers privately to discuss teaching assignments or grade-level team changes during the planning of the middle school restructuring initiative. In January, he also gave staff members a questionnaire to survey their preferences for teaching and grade-level team assignments. Wilson felt satisfied that he took the time to meet with teachers and feel the pulse of his staff surrounding the new changes before he officially presented his middle school restructuring changes to the staff.

Wilson also felt confident as a second year principal to document teachers who did not meet expectations. In February, Wilson privately met with two teachers, who were openly and 
constantly arguing with each other, which interfered with their professional obligations. The teachers worked on the same grade-level team. After the discussion, Wilson gave them the opportunity to "act professionally" for the rest of the year, since he already planned to move one of the teachers to another team for the following year. However, he told the teachers that "one would be transferred to the other middle school next year if issues continued." During a gradelevel team meeting in February, Wilson was informed that a teacher was arriving late to his class every day. Wilson had also heard this concern from students. He made it a priority to be in the teacher's room on several occasions to document the situation. Wilson openly communicated his concerns about the teacher with his supervisors and superiors. It was clear that Wilson was in control of his micropolitical landscape.

Throughout the year, Wilson maintained his control by sending memos to teachers who did not hand in lesson plan books on time or update their homework assignments on the school website. However, there was one situation that Wilson regretted. In one incident, three teachers, who were "coaches" and helped develop new curriculum changes, missed a "mandatory faculty meeting." Angrily, Wilson "wrote up" the teachers without talking to them privately first. Wilson admitted he made a mistake. He "would have still written up the teachers and sent the memo, but he would have worded it differently." Wilson's proactive tactics to intervene when procedures were being ignored by teachers allowed him also to avoid situations that would dissatisfy superiors. Even though Wilson tried to at times "reward teachers who did a great job and who were loyal," his coercive tactics and use of sanctions were unpopular with his teachers.

Consequently, Wilson could not prevent all teacher complaints, especially since he was planning drastic changes to the school's master schedule during a time when the teachers were working without a contract. Wilson tried his best to respect the teachers' contract; however, by 
March teachers were upset that the new scheduling changes would "change their working conditions." Wilson pushed through these complaints by communicating privately with his Liaison Committee leaders and worked out solutions before official meetings. He stayed in close contact with his superintendent to keep him informed of any contractual disputes. Wilson also advised his superintendent if any new scheduling changes would break the existing labor contract and could not be implemented in his school. Often, Wilson led through mandates when he heard teachers' complaints about new curricular and scheduling initiatives. He viewed the implementation of these initiatives as "not up for debate." However, Wilson always "made sure that he communicated that message the right way. He tried to let teachers know why the initiatives were happening. "They still might not agree with it," but Wilson felt comfortable that "he had communicated openly."

Overall, Wilson believed that teachers were generally happy since he was not dealing with a lot of conflicts or complaints; however, that was not the case. A clear disconnect emerged, as Wilson saw himself as a principal who employed a consensual-based leadership approach. However, staff members did not feel their voices were heard as clearly as Wilson believed. Teachers saw Wilson as controlling the process and content of discussions. Teachers who sat on initiative committees felt their contributions were ignored and decisions were already predetermined by administrators. They viewed committee work as a pseudo opportunity for Wilson to provide teacher participation in decision making, or give the impression that their collaborative relationships were present in his school, while maintaining an autocratic leadership style (Eagly, Karau, \& Johnson, 1992; Blase \& Anderson, 1995). Some teachers felt they "were asked to be on committees and put in their feedback. Sometimes their perspectives were really considered, but sometimes they had the notion that decisions had been made already." Tracy, 
who worked in Northern Middle School for over twelve years, believed that this type of collaboration had been part of the culture in the district. There was a committee that was started to help research and implement a new middle school schedule. Teachers met every other month, visited other schools, and talked to other administrators and teachers. They came back, discussed what they could do and "then were basically handed a schedule." Tracy felt her input on the committee was asked for, but did not feel teachers had as much input in the decision-making process.

Some staff members thought Wilson was working hard to create a positive and collaborative environment in their school, while others thought "minds were already made up" when it came to committee work. Although Wilson was "trying to say, we're listening" and thought committees "brought parties together so that they can have a say and were wonderful for brainstorming ideas," he also believed committees "were not always great at getting things done." Wilson deemed there had to be "one person that says 'this is the way we are going to do it." He "didn't want to have committees [in his building] if it was not worthwhile." Wilson emphasized that unless a committee focused on an ultimate goal and agenda "it was a waste of time."

By May, frustration among some teachers escalated, as Wilson handled the budget crisis with his staff. Committee meetings were cancelled and teachers met without Wilson present. Some teachers felt decisions could not be made without the consent of an administrator, which slowed down the progress of initiatives. As morale began to wane, some teachers felt parents' voices were preferred to their voices, since parental issues were resolved quickly by Wilson. As one teacher observed, "Parents are regarded more highly than the teachers' input and our 
principal has been trying to change that over the past years. But I think many parents are used to their voices being heard."

As staff members became stressed, teachers did not feel comfortable voicing their opinions to Wilson. Meanwhile, Wilson prioritized how to address certain individuals and groups, as he tackled concerns over proposed losses of teachers, support staff and programs. Like Miller, Wilson led within a micropolitical landscape that was decimated by the governor's school aid cuts. "Everyone was worried about who was going to get cut and for a while" in the Spring of 2010, "it was a big deal that no one knew what was going to happen."

Miller and Wilson confronted many uncertainties as they were leading within their micropolitical landscapes which were heavily influenced by macropolitical decisions completely outside their control. However, the principals had to rely on their own confidence to make decisions in a landscape where vocal teachers, staff members, and other school community members were vying for position to gain access to valuable and scarce resources. Moreover, the macropolitical environment congested existing communication networks between teachers and their administrators. Both principals found themselves constantly working vertically with superiors and laterally with colleagues to negotiate personnel and program decisions. Consequently, staff members in each school were alienated from existing shared decisionmaking processes (Anderson, 1999). As Miller and Wilson legitimized the organizational hierarchy through their formal power, they understood that superiors, parents and staff members would hold them accountable for their decisions. Subsequently, their ability to make decisions within an uncertain climate proved vital during their first three years of the principalship.

\section{Leading through Decisions}

"I'm going to be more confident and more authoritative; I will also try to do a little bit better in terms of establishing parameters"-Lisa Miller 
As Miller and Wilson understood their micropolitical landscapes during their first year in the principalship, they participated in a grapevine structure to identify existing school values, procedures and norms and got to know people in their school communities. Through their presence on grade-level teams, Miller and Wilson developed relationships with their teachers to understand dilemmas they were facing in the classroom and listen to existing ideologies of instructional and curricular delivery. These interactions helped create a comfortable atmosphere and shape instructional and content ideology where the principals could later observe classes and provide critical feedback to the teachers. Communication and visibility were important to both principals, as they "felt out" their landscape and portrayed an image that they were willing to "listen to others' opinions" concerning school issues. As Miller and Wilson learned their micropolitical landscapes, they did not make any drastic changes and worked within existing social and decision making structures.

During her first year, Lisa Miller facilitated the Scholarship Committee, where teachers chose a high school senior to receive a scholarship. During the process, Miller understood, through the eighth grade team, that a student was traditionally chosen by eighth grade teachers. However, Miller wanted to include other grade-level teachers in the process to showcase perspectives that reflected the growth of the candidates throughout their middle school experience. As the eighth grade teachers chose a recipient, Miller was not satisfied with the process. However, Miller knew that she could not change the process during her first year in the principalship because she did not want to "rock the boat." Instead, Miller spoke to the lead eighth grade teacher on the committee and they agreed to include a PTA parent and two additional teachers from other grade levels the following year. Miller was also still trying to grasp how particular programs and staff members fit with existing school values and goals. 
By her second year, Miller was more confident, assertive and authoritative in her decision making. She was determined to do a better job establishing parameters with her staff members. Miller felt more confident and understood what needed to be done in terms of moving the building forward. She felt "burned" by her experiences during her first year, as she led within a culture of shock and an uncertain macropolitical environment. Miller also thought there were variables, such as communication, that were not in her sphere of control during her first year that should have been. During her second year, it was her "job" to make sure she had control and bore the responsibility of "captaining the ship."

By late September, Miller exerted her control over her micropolitical landscape primarily through mandates, rewards and sanctions (Blase, 1990). During interviews, Miller acknowledged the "right" way of leading was to introduce new research-based ideas, build consensus, implement change and ask teachers for feedback. "That's the right way to do it and I know that I haven't done that a lot." There were instances when Miller attempted to involve teachers in the decision-making process. Miller required all teachers to volunteer and participate on one of six school-based committees. The committees covered areas like school safety, climate, student discipline, teacher-parent relationships, student recognition and achieving AYP. After teachers ranked their preferences Miller and her assistant principal assigned teachers to specific committees. Although Miller valued teacher collaboration, teachers' participation on committees was coerced and required. Miller's top-down, rather than bottom-up, effort to move her building forward did not guarantee teachers would adopt any change in their practice or classrooms (Blase \& Anderson, 1995; Darling-Hammond, 1995; Fullan, 2007).

During her second year, Miller was overwhelmed by macropolitical pressures, such as exhibiting growth in student proficiency on state assessments, and micropolitical concerns, like 
combating teacher resistance to change. Even though Miller may have felt more confident as a second year principal, she was not comfortable within her micropolitical landscape. During her first faculty meeting in September, Miller requested that all teachers submit their lesson plans to her once a week. Instantly, a teacher questioned Miller, "What about tenured, we always did it once a month?" Without thinking, Miller surrendered to the teacher's request and communicated that tenured teachers could submit their plans once a month. However as Miller reflected on her decision with her assistant principal, she realized she made a mistake. Miller "really needed those lesson plans" and she "would not know which teachers were on the once a month plan or if they submitted plans in the beginning, middle or end of the month." Subsequently, Miller wrote her staff an email and required all teachers to submit their plans every week. Miller's discomfort in her micropolitical environment started to show through her indecision.

As the year progressed, Miller attempted to control her environment through autocratic, centralized and vertical structural approaches (Eagly, Karau, \& Johnson, 1992; Anderson, 1999; Bolman \& Deal, 2003). However, her decision to centralize school decisions at the top of the hierarchy fragmented her environment and stalled the adoption of holistic educational change (Kanter, 1983). Between March and the conclusion of the study, Miller relied on closed leadership styles and coercive tactics to push through teacher resistance, gain teacher compliance, and complete tasks to the satisfaction of her superiors and parents (Blase \& Anderson, 1995; Blase, 1990; Wolcott, 1984)

Wilson viewed his second year in the principalship as a time to work with teachers to solidify instruction in the classroom. As a second year principal, he was also more apt to have these conversations, since he got to know his staff members during his first year. In cases where he thought instruction could be improved, he openly discussed his perceptions with specific 
teachers. In one case, teachers who acted as coaches during curriculum development "were not fully living up to their responsibilities in the building." Wilson spoke to them privately and "made it very clear to them in an open, candid conversation that they need to make their coaching commitment first and foremost for them to continue" to move forward. The teachers were unhappy with the conversations, but Wilson believed that open and honest conversation defined his leadership within his micropolitical landscape.

Wilson's ability to control his micropolitical landscape through his leadership style was perceived by his staff as showing them "he was in charge and "this was how it was going to be." This orientation allowed his teachers "to start to see little bit more of what went through his thought process based on past decisions.” Some teachers, like Tracy, felt more comfortable seeing Wilson in his office, as she developed a rapport with him during his first year. She would not have usually seen him privately during his first year because "she wasn't quite sure what the response would be and she didn't want disrupt what Wilson needed to do." As Wilson grew confident and comfortable in his landscape, he began delegating roles and making more decisions. Wilson identified members he could trust and began delegating tasks surrounding new school initiatives to grade-level teams and existing committees. Wilson also relied on his assistant principal to attend grade-level meetings when he could not because of other obligations.

By his third year, Wilson was in control of his micropolitical environment as a Stage Two principal who achieved tenure status (Parkay, Currie, \& Rhodes, 1992). Wilson was on top of situations and tasks and exerted his positional power during educational change. However, he also frequently used coercive tactics out of fear of losing control and becoming ineffective, especially during an uncertain and demoralizing macropolitical environment (Parkay, Currie, \& 
Rhodes, 1992). Wilson was very cognizant that successful implementation of district mandated holistic educational changes would ultimately establish a "legacy" for him in the district.

Both principals made many stressful and significant decisions surrounding staffing and programs within the budget crisis; however, Wilson was more comfortable making those decisions as he had a good sense of which staff members and programs he needed to run his middle school. One of those key decisions was selecting new team leaders for the 2010-2011 school year. Wilson conceded that he could not appoint new team leaders as a first year principal. "It takes time to learn the personalities--who gets along well and who does not." Wilson also relied on the trust he developed, over three years, with parents, teachers, colleagues and superiors to implement school initiatives. Additionally, Wilson developed relationships with key inside players, such as board members, during the budget crisis. He conducted numerous presentations to the board concerning how curriculum and scheduling changes would impact learning at his school. This experience helped Wilson gain influence and efficacy within his micropolitical environment.

As the principals were leading within hierarchical structures and exerting their formal authority and influence, they began to make decisions, by their second and third years, that delegated resources, determined who got control of in-demand resources and supported middle school needs. Educational change in both middle schools came in the form of improving student learning and instruction, and restructuring their schools to support student learning. These changes typically involved anxiety, stress and struggle within micropolitical landscapes, as school community members decided to resist or accept change (Fullan, 2007). However, the uncertainty of educational change in both schools was coupled by macropolitical shock, which threatened existing resources that Miller and Wilson relied on to successfully create change. As 
the principals were looking to revise materials, introduce new teaching approaches and instill new beliefs, distrust began to pervade the micropolitical social interactions and decision-making processes. Staff members were unsure how new school initiatives would influence their practice and how changes would be implemented with the possible loss of teachers, curriculum training, finances, and support staff. The macropolitical crisis threatened the educational outcomes that Miller and Wilson were striving to achieve. The principals were expected to provide instructional and curricular changes that improved student achievement to their school communities, parents, superiors and staff members. Consequently, Miller and Wilson relied on conflictive leadership approaches, through sanctions, rewards and mandates, to control their micropolitical landscapes. Once Miller and Wilson were confronted with that reality, they entered their micropolitical arenas where they relied on their negotiating skills to preserve programs and staff members to deliver holistic educational change. 


\section{CHAPTER VI}

\section{THE POLITICS OF EDUCATIONAL CHANGE}

“All real change involves loss, anxiety and struggle”-Fullan, 2007, p. 21

Entering their micropolitical environments, Miller and Wilson initially did not see politics playing a significant role, as they met with superiors, colleagues and teachers to negotiate educational changes. However, once the principals learned of the potentially devastating budgetary losses they would endure through reduced state aid, their micropolitical interactions intensified and became more visible in both formal and informal arenas of school life, as uncertainty and ambiguity clouded their outlook. State government, which was typically an often forgotten and peripheral political player, suddenly became an influential and inside player (Marshall, Mitchell \& Wirt, 1989). Additionally, each principal was expected to provide holistic educational change within the first years of their principalships, but they were also expected to balance compromising dilemmas of "where they could cut?" to survive the budget crisis. Consequently, Miller and Wilson could not fulfill their roles as "gate-keepers" and protect their resources because their staff members and programs were at the mercy of the state budget cuts (Fullan, 2007).

Educational change typically provokes and exacerbates micropolitical tensions, as groups organize and compete with other groups to express their values and to secure their interests in the public school (Blase, 1998; Tyack \& Cuban, 1995). However, Miller and Wilson faced the proposition that the macropolitical environment could complicate their ability to negotiate for educational change in their schools because communication was significantly inhibited and distrust grew. Moreover, teachers had a personal stake in Miller's and Wilson's decisions and were dismayed that they were disregarded in the change process (Boyd, 1982). 
By the end of May, however, Miller and Wilson found ways to keep their school initiatives intact. Lisa Miller preserved teaching positions to create cohesive grade-level teams and support language arts curricular changes. Robert Wilson retained teachers to implement new math and language arts curricula and execute a restructured school schedule to support student learning. The principals' ability to rescue their resources from potential budget cuts depended on their ability to negotiate with upper administrators and colleagues. Whether hired as an insider or outsider, Miller and Wilson needed to know their place, cooperate with those in power, bet on winning political battles and carefully use their networks and grapevine structures to capture resources (Marshall \& Gerstl, 2005).

\section{Surviving Budget Cuts}

"I think most of our conversations with each other involved shock, fear and concern because we were like, 'what's going on?'”-Grace, Central Middle

\section{School}

In early March 2010, superintendents of both districts received notice from New Jersey's Commissioner of Education that their districts would lose a percentage of their state aid budgets. The memo directed superintendents to develop budget scenarios reflecting between five to fifteen percent reductions in state aid funding. As a worst case scenario, each superintendent prepared to lose up to fifteen percent in state aid. However, superintendents later learned that the governor eliminated up to five percent of each school's overall budget, which meant state aid funding was cut more than fifteen percent for each school. Lisa Miller had understood that her superintendent had planned for a loss of $\$ 2.5$ million; however, her district lost nearly $30 \%$ of their state aid funding, which meant an additional \$2.3 million was lost. Robert Wilson's superintendent had already cut $\$ 533,000$ from their budget; however, Northern School District lost $99 \%$ of their state aid funding. The district trimmed a total of $\$ 4.8$ million from their budget 
over several weeks to meet the state-mandated timeline (NJDOE, 2010). Central office administrators and their principals worked quickly to prepare district budgets that met the state mandate in time for their school budget vote, which was one month away. Miller and Wilson were still expected to run well-organized schools and be responsive to all school community members. However, both novice principals were not adequately prepared to manage an accelerated period of decline (Boyd, 1983). Consequently, anxiety influenced micropolitical interactions between Miller and Wilson and their staff members.

In late March, Miller navigated instructional and curricular changes, while handling parent concerns, student discipline, and proposed budget cuts. This period "had been very stressful due to the budget cuts and number of student incidents." Miller had "been feeling the stress," as "it had been absolutely escalating." However, Miller refocused her attention on preserving teacher positions on grade-level teams because she expected to lose at least four classroom teachers. To achieve this, Miller negotiated for staff members with two experienced middle school principals in her district.

Early one morning in late March, Miller attended a scheduled meeting with her middle school colleagues to negotiate personnel and teacher movement within the district. The district needed to close a budget deficit through academic program and staff cuts; these staff cuts loomed over Miller. She needed to secure quality teachers who could fit in her grade-level teams and building. Once the meeting began, rumors of administrative positions being consolidated circulated amongst the principals. There were concerns that supervisors would be lost and that the principals would take on additional supervisory responsibilities. The colleagues wondered among themselves how the budget crisis would change their own roles, let alone their staff members and their buildings. As the meeting continued, the principals discussed the instructional 
needs in their schools. Names of staff members, who each principal was willing to let go, were placed on a board, and the principals took turns discussing attributes and concerns for each staff member. They began to barter and provide rationales for specific teachers to be transferred into their schools. Miller, as a first year principal, was quiet and not as active in the meeting as her seasoned colleagues. However, she discussed her disappointment regarding her grade-level teams not working up to their potential. Miller wanted to see more articulation between the special education and regular education teachers on each team. When a colleague asked for one of Lisa's staff members, she did not resist. It was not until another principal joked with Miller that she was losing valued teachers that Lisa attempted to block these transfers. Her colleagues, however, did not take advantage of her inexperience. They fairly traded staff members and ensured that quality teachers and cohesive teams remained in all schools.

Personnel negotiations continued between March and June. The principals negotiated with central office administrators to keep media specialists. "The media specialists were on the table and we did not want the media specialists to be cut." Central office administrators "were able to trade and say as opposed to them, we could take this other group." In the end, Miller and her colleagues did not want to see anybody lose their jobs. Unfortunately, staff members did lose their jobs and Miller was expected to successfully implement school initiatives with fewer teachers. She went from having 24 teachers in the core content areas, such as math, language arts, social studies, and science, to 20 . In effect, she lost an entire grade-level team. However, Miller worked with her colleagues to redesign schedules to ensure that the grade-level teams would remain intact and cohesive. Consequently, teachers dealt with larger class sizes and taught across multiple grade levels. Robert Wilson dealt with similar implications at his school. 
In late February, Wilson began to worry that he would not be able to fully implement his new middle school model for the following year because of the potential budget issues. Robert continued to work with his teachers and decided to "sit back and wait to see what happened." As Wilson was tackling staff renewals, annual evaluations, student discipline and parent and teacher concerns, he attended an Administrative Council meeting in early March, where his superintendent, district administrators, principals and supervisors met to discuss district issues. Typically, Wilson regarded these meetings as "boring" and uneventful. However, he had little insight that administrative meetings were arenas to negotiate deals in the wake of the crisis.

Wilson was prepared for bad news from his superintendent regarding the budget crunch. Early in the morning, he reviewed contingency plans that were developed prior to the administrative meeting. As Wilson entered the Administrative Council meeting, he was greeted by principals and supervisors. It was a time for the administrators to "catch up" on what was happening in their schools. It was also a time for them to discuss resource needs in relationship to the budget worries. Before the meeting officially began, Wilson and his colleagues discussed shared resources between their schools and briefly negotiated potential deals. Wilson also informed supervisors about curricular and scheduling changes and possible needs for materials. The Administrative Council sessions proved to be a valuable time for Wilson and his colleagues to utilize grapevine structures and open communication to discuss needs and strike deals that supported the implementation of school and district initiatives (Licata \& Hack, 1980).

Once the meeting began, Wilson's superintendent discussed upcoming responsibilities, such as annual teacher evaluations. However, he quickly jumped to the topic that was on everyone's minds - the budget crisis. The room was still, as the superintendent outlined his worries over packaging a budget in time for board approval and a community vote in a matter of 
weeks. Wilson's superintendent warned that there would be high numbers of job losses and every area would be affected by the crisis. He then told his administrators that they had to work together to cut an additional 2.3 million dollars. This would include newly hired teachers and reading, media, and academic specialists. Wilson's superintendent welcomed any budget cut proposals from the principals and encouraged them to call him as they decided where to cut in their schools.

As Wilson made the slow walk back to his office after the meeting, he made a quick phone call to his colleague at the other middle school. Wilson was worried about losing new teachers whom he hired to help support the new curricular and instructional changes. He did not want to lose specialists, since he relied on them during the development of new math and language arts curricula. Wilson and his colleague negotiated a plan of attack to share a reading and math specialist between both schools and coordinated the schools' schedules to ensure that their proposed idea would work efficiently. Wilson immediately called his superintendent and ran the idea by him. His superintendent agreed with the proposal and asked Wilson to "write it up." Wilson was satisfied that he was able to utilize his close relationship with his colleague at the other middle school and quickly gain valuable resources. He was also relieved that his superintendent considered and accepted his plan. Wilson knew he was fortunate to have a strong and positive relationship with his superintendent--especially during the macropolitical budget crisis.

During the following months, Wilson had his work cut out for him, as he tackled the budget, while completing staff evaluations and implementing school initiatives. The budget consumed a lot of his time as Wilson worked on the school's new master schedule. Wilson's time was also consumed by meetings and phone calls, where he explained to his superiors how 
staff cuts affected his school initiatives. Finally, Wilson wanted to find time to do "justice" to his teachers' evaluations. These teachers "have done a tremendous job and I also wanted to be specific in terms of recommendations for teachers who needed improvement." Wilson had little time to attend grade-level meetings or informally visit teachers between the write ups and meetings with colleagues and superiors. Similarly to Miller, Wilson felt stressed and conflicted by the proposed staff cuts to be made by late March, since he was asked to rank his non-tenured teachers. "That was a very difficult thing to do because they all brought different strengths to the table and I wanted to bring them all back. They were all good for kids and I really cared about them. I hired them. So it was hard." Wilson also sympathized with his teachers during this time. "Right now, teachers are getting bashed in the news and it's terrible because most teachers love kids. Most teachers really care about what they do." Since the crisis was out of Wilson's control, he felt all he could do was "pat teachers on the back, encourage them to work as hard as they could and battle for staff members that were good for kids."

Wilson felt more stress as a second year principal navigating his micropolitical landscape because it was heavily influenced by the increasingly rancorous macropolitical climate. "I think it's even more stressful right now than it was even a year ago where it was my honeymoon period and now it's like, alright, let's go down and dirty and get things moving forward." He also saw the role of the principalship expanding amidst a distracting macropolitical crisis. "I think every year principals set out to do more like spend time in the classroom with teachers. Then we get side-tracked. But I think all of us, across the state, are going to be taking on more roles and duties with the budget cuts. It certainly consumes a lot of my time that I wish I could put towards being in the classrooms with kids and teachers. So that's the frustrating part." 
By April, Miller and Wilson awaited the budget votes for their districts. Both hoped that their communities passed their proposed budgets. A budget defeat would mean additional academic program and staff cuts, which would continue to threaten their efforts to implement school initiatives and create holistic educational change. Fortunately, both budgets passed, but at a cost.

The principals' constant bartering for resources with superiors and colleagues left staff members in both middle schools stranded. The macropolitical budget crisis forced Miller and Wilson to work vertically with their superiors and laterally with their colleagues to make personnel and program decisions. Retrenchment, through cutbacks, usually provokes centralized decision making (Boyd, 1983). Subsequently, lateral communication all but stopped between the principals and their teachers, leading to autocratic and authoritative leadership approaches (Eagly, Karau, \& Johnson, 1992; Anderson, 1999; Bolman \& Deal, 2003). Miller and Wilson had to find ways to engage teachers in frequent and continuous discussions about their practice; however, the macropolitical crisis blocked staff members from important communication networks because their principals were not accessible (Fullan, 2007). Consequently, in both schools communication between teachers and their principals was significantly inhibited. The macropolitical environment created vertical and top down social interactions because Miller and Wilson made decisions without consulting or including teachers and support staff (Anderson, 1999; Bolman \& Deal, 2003). The principals' vertical structural orientation through coercive tactics or mandates, while negotiating holistic educational changes, ensured the implementation of goals and objectives during the crisis (Anderson, 1991; Blase, 1990). Because of the fiscal turbulence, the principals tightly controlled resources, personnel and materials that were vital to their initiatives (Bolman \& Deal, 2003). However, formal constraints led to teacher resistance 
and low morale, as staff members were cut because of the budget crisis. The macropolitical climate rained down on both schools with disconnected and divergent demands. Parents still expected their schools to exhibit growth in test scores and student proficiency with fewer resources and larger class sizes (Boyd, 1982). The success of new initiatives and educational changes depended on the principals' ability to maintain open communication and relationships with their teachers and support staff. However during the crisis, ideas concerning holistic educational change were initiated and concentrated at the top of the hierarchy and left little room for negotiation, collaboration or innovation (Kanter, 1983).

Miller and Wilson were overwhelmed trying to handle the macropolitical environment that threatened their school initiatives. They were not prepared to manage the macropolitical budgetary crisis or understand the implications of the "politics of decline" (Boyd, 1983). Furthermore, the principals' inability to interact with state officials over their fiscal policies resulted in disillusionment and anger, as Miller and Wilson transitioned from negotiating for staff members and resources to support their educational changes to sitting down with staff members and telling them that they were not returning or that they were being transferred to another school for the following year (Marshall, Mitchell \& Wirt, 1989). These often difficult discussions led to intense micropolitical interactions, as watchful staff members were dissatisfied with seeing people moving around into different positions and losing their jobs.

\section{Staff Loss and Movement amid Budget Crisis}

"I've gotten to the point where I've become accustomed to this level of devastation, but you catch yourself saying 'it will be okay'. I'm really not certain that is the case"-Lisa Miller

Miller and Wilson confronted the difficult decisions of communicating to staff members that they were losing their jobs, being transferred to another school or not being renewed because 
of performance. The decisions surrounding these movements were influenced by staff members fitting a specific "profile" in their buildings. Members who did not fit this profile did not survive the budget crisis, as Miller and Wilson supported members who would support their curricular and instructional initiatives. During the fast-paced macropolitical crisis, the principals' toughest task was selecting between staff members who fit in their buildings and those who did not fit at all. Consequently, the macropolitical environment created an opening for upper administrators and principals to non-renew any teachers or staff members who did not meet their expectations to help enact educational change. It was also a tumultuous time when teachers in both middle schools did not understand why specific personnel transfers or cutbacks were required (Boyd, 1983).

Lisa Miller knew she had to navigate non-renewing teachers carefully, as she endured the painful conversations of 'yes, your position is going away, but you're leaving not because your position is going away, but because of performance issues and if a position does comes back, you do not have an opportunity here." Morale and trust deteriorated in Miller's building, and teachers were upset that well-liked teachers were being let go or transferred to other buildings. Some teachers, like John, felt some of the personnel decisions did not make any sense. "Decisions were probably made above the principal. But everybody looks at the principal and says 'why are you doing this and why are you taking our friends away and bringing in somebody we don't even know that we have to work with?'” Miller tried to heal the staff as best she could and moved them forward, while reinforcing the values that supported her initiatives. However, Miller conceded that she had to make decisions that reinforced to staff members "either needed to get on or off the bus." 
Before the budget crisis, Robert Wilson had planned to release several teachers due to their poor performance. Like Miller, Wilson did not renew teachers who did not reflect existing school values. These teachers had previous incidents with students or parents, which made it difficult for Wilson to see how they would fit within the new curricular and scheduling changes for the following year. In addition to these non-renewals, Wilson lost six teachers; however, he was still able to run the new middle school schedule. Wilson also received one new teacher from another building. He wondered how this teacher would fit with all of the changes taking place in his school. Wilson also needed to fill five vacant teaching positions in his school. He worried about finding the right teachers who bought into Northern Middle School's culture. During this time, Wilson was also battling to sustain teacher morale and a positive building climate. Teachers, like Samantha, described how difficult it was to see teachers lose their jobs, as "people who were very unhappy" about the cuts. She saw how it was affecting most New Jersey public schools, "but it was difficult to see a colleague of yours who has kids lose their job. You feel badly."

As Miller and Wilson finalized personnel decisions for the following year, their attention returned to implementing holistic educational changes. Miller and Wilson were accustomed to working vertically with their colleagues and superiors to make decisions about personnel and program. Subsequently, both principals returned to the negotiating table with colleagues and superiors, as they entered the 2010-2011 school year. In August, Miller negotiated a plan with her middle school colleagues to align the schools with common top priorities. These priorities included the full implementation of the district's overarching goal of failure is not an option with their staff members. The principals agreed to commit to the district initiative to refocus their staff members after their experiences with the budget crisis, and to promote the message that "nobody 
is going to do less for kids" because of budgetary consequences like larger class sizes. Similarly, Wilson also developed his priorities for the 2010-2011 academic year with his colleagues and superiors. He collaborated with the other middle school principal to focus their schools on district-wide goals.

In July, Miller and Wilson entered negotiations with their colleagues and superiors regarding new teachers who would be able to enhance their initiatives. Miller, in particular, looked forward to hiring new teachers to ease the current teachers' anxiety brought on by the budget crisis. Miller believed that hiring new teachers would set a positive tone for her school. She looked forward to her new teachers providing new perspectives to teachers on grade-level teams. Miller expected returning teachers to question the large class sizes. Both principals looked to re-establish teachers' commitment to their school initiatives, extinguish macropoliticallydriven anxiety and resentment and manage their educational changes (Hargreaves, 1998).

\section{Enhancing Initiatives through the Hiring Process}

"At this point, my number one priority has been selecting people who are student-friendly and who understand that kids learn differently"-Lisa Miller

Before the 2010-2011 year commenced, Miller and Wilson hired new teachers who, on paper, could enhance the implementation and success of their curricular and instructional changes. As the principals found respite from the macropolitical shock during the summer months, they gained valuable personnel resources. Lisa Miller learned that two previouslyeliminated math and language arts positions were restored. Lisa welcomed the news, as the preserved positions created class sizes of twenty students in math and language arts; however, Miller faced class sizes of 34 students in her social studies classes. Miller was also relieved to learn that her district had hired a new director of language arts and social studies, which absolved Lisa from taking on any additional supervisory roles. Assuming more supervisory 
responsibilities, across three middle schools, seemed daunting to Miller. Trying to implement her district's strategic action plan was challenging enough.

During the summer, Miller felt she had a good opportunity to move forward with her school initiatives through staff hires. She hired five new teachers, which was roughly ten percent of her staff. Miller went through an extensive hiring process for each candidate. She was required to recommend two candidates for each position to her superintendent. Miller looked for teachers who were student-friendly and who understood that various children learn in their own ways. Miller felt that reaching students “was something that you can’t teach. You either have it or you don't have it within your belief structure. I can teach you classroom management. I can teach you lesson design. I can teach you how to grade. It's been one of my foundational beliefs that every kid in this building will at least think that there is somebody in this building that loves him or her as though they were their own child." Miller felt she needed those types of teachers to succeed. She sought teachers who fit her belief structure in relationship to her ideals that all students had the potential to learn and succeed.

Miller recommended candidates who fit this profile to her superintendent; however, some candidates were not accepted and she was sent back to the drawing board. During the hiring process, Miller was quickly reminded of her status within her district's hierarchy. Her formal authority was not strong enough to push preferred candidates through the process. Even though she was a second year principal, she "was still was new and was feeling out what her organizational superiors were looking for." Miller knew what she was looking for, but she might not have known what her superiors expected. For example, there was one candidate who was extremely student-friendly and very good with struggling learners. However, the central office administrators thought she was not a good fit to push above average-learners. Miller was not 
offended that her selections were rejected, but had to refocus. She believed her teachers did an adequate job addressing kids who learned in a traditional manner and who were already proficient. Miller's priorities focused on supporting students who learned "differently". Once Miller's candidates were turned away, she started thinking about challenging above-average students in addition to struggling learners. She was able to negotiate for her candidates with central office administrators. In one case, Miller successfully negotiated with a colleague and a superior to hire a math teacher that she preferred. The Assistant Director of Mathematics was concerned about the candidate's content knowledge, but Lisa saw her as someone who had natural strengths that she needed in the building. Miller asked the Assistant Director to meet with the candidate to have a pointed conversation about math pedagogy. The candidate passed the rigorous inspection and was hired. During the hiring process, Miller believed that her new hires would help enable a paradigm shift in her school to affect educational change.

Wilson was relieved that his new master schedule and new curricula escaped unscathed through the budget crisis. He was also hiring new teachers to enhance his initiatives. In July, he looked for teachers who were passionate and who "loved working with children." However with every new hire, Wilson questioned how will they fit in? How will they work with their colleagues? How can he see their passion and care for children? Wilson expected every new teacher to be a team player, communicate openly, listen and share his or her knowledge on the grade-level teams. During the summer, Wilson learned that the middle schools received funds to appoint new grade-level team leaders. These positions would be filled by teachers and would enhance grade-level team meetings. Wilson appointed new grade-level team leaders to provide oversight on the teams. He wanted the lead teachers to facilitate and promote school initiatives during team meetings and help the teams build identity. Although teaming existed by name in 
Wilson's school, he wanted to see more discussions and provide teachers with opportunities to create more interdisciplinary connections. Wilson's team leader appointments were critical in allowing him to enhance teaming and develop math and language arts curricula.

Wilson expected his new team leaders to learn and promote teaching and learning strategies to enhance the new curricula. However, Wilson did not want to create a new formal hierarchical role in his school. Subsequently, he aimed for the team leader to be rotated every year to give every teacher the opportunity to display leadership. Wilson wanted to avoid having the same team leader in the position for ten years, since a formal role in the hierarchy would potentially allow teachers to gain access to decision making at the top (Wahlstrom \& Louis, 2008). Wilson had to have the "right people" in place for the 2010-2011 year, since the school went through substantial curricular changes. Candidates for the leadership positions were required to have two or more successful years teaching on a specific grade level. Candidates also had to work cooperatively with parents, colleagues, administrators and students. Team leaders were expected to organize their colleagues to achieve school and district goals. They were also responsible to review and modify grade-level curriculum, review student data and recommend changes to teaching practices.

In August, Wilson appointed new team leaders. He was looking for teachers who were easy to work with and had the ability to communicate with different personalities on the team. He avoided selecting math teachers for the position, since they already had been pulled out of their classrooms to be trained during the math initiative. These teachers would also "have an extensive amount of training and planning" during the new school year. Wilson anticipated that these teachers would be "overwhelmed" learning a new curriculum and implementing new teaching strategies during the 2010-2011 year. This led to some difficult conversations because 
Wilson discouraged teachers from pursuing the position. In one case, Wilson discouraged a teacher from seeking the team leader position. The teacher was not a math teacher; however, Wilson viewed the teacher as having a "conflictive personality". The teacher also already held some leadership roles in Northern Middle School. Subsequently, Wilson advised the teacher that the lead teacher position would be too overwhelming. Instead, he chose a teacher who could manage differing personalities on the team and who showed potential to be a leader.

In late August, Wilson met with his new team leaders to instill expectations and develop a positive message for the new school year. Wilson supplied each leader with a book describing active learning strategies for classroom instruction and they were expected to establish a commitment to the curricular initiatives. Politically, Wilson aimed to control the loosely-coupled structure of team leaders and control the ideological message by infusing instructional and leadership expectations with his leaders (Anderson, 1991). The book reinforced Wilson's beliefs, which team leaders were going to articulate to the staff. Wilson relied on their leadership to create autonomous teams, allowing teachers the freedom to create innovative lessons (Fullan, 2007; Wahlstrom \& Louis, 2008). He believed grade-level teams gave teachers "the opportunities to learn. It gave them the understanding that it's okay to take some risks, fail and learn from those mistakes, while working with colleagues." He valued reforming his grade-level teams to create small communities for learning, where decisions could be delegated to teachers, instruction could be correlated between different subjects and teachers could dedicate time to student achievement (Tyack \& Cuban, 1995). Wilson also aimed to create a common language with his team leaders to discuss literacy and math learning strategies. Wilson believed that team leaders would allow him to keep his finger on teachers' sentiments, while handling daily tasks. During the budget crisis in April, communication suffered since Wilson could not attend 
regularly-schedule grade-level team meetings. Consequently, meetings were cancelled and morale subsided. Wilson hoped teachers would access communication networks through their team leaders to spur instructional innovation (Fullan, 2007).

Lisa Miller and Robert Wilson both wanted a successful start to the new school year. During the summer months, they focused on hiring new staff members or appointing teachers to leadership roles who reflected their schools' values. The principals eagerly worked to put the pressures of the macropolitical tumult behind them and to re-establish their school climates. However, the principals expected teachers and parents to feel anxious with the loss of staff members. Subsequently, both principals strove to remain influential agents of change in their schools by controlling ideological messages and cultural values in their climates. Miller and Wilson were committed to rededicating their staff members to the goals of school and district initiatives; however, they still faced clashes and challenges with teachers who became apathetic and resistant to change.

\section{Creating Change through Initiatives}

"I'm feeling confident that we can a do a great job for kids and I will not take any excuses for doing less than a great job for kids"-_Lisa Miller

In September, Miller and Wilson were expected to enact change through district initiatives; however, the weight of the macropolitical crisis grinded communication to a halt and minimized opportunities for collaboration during the Spring of 2010 (Fullan, 2007).

Consequently, Miller's and Wilson's administrative cultures shifted to conflictive and closed approaches, as both principals frequently utilized mandates, rewards and sanctions to ensure that tasks were completed and their initiatives were implemented during the 2010-2011 school year (Blase \& Anderson, 1995). 
Whether the message was failure was not an option or nobody is going to do less for kids, Lisa Miller wanted to reinforce her bureaucratic control by leading authoritatively, while establishing parameters. She was disappointed that she lost control over some issues that "should have been" in her control during the 2009-2010 school year. Miller's centralized and authoritative leadership style was firmly established as her second year began. Miller rationalized that she made "large strides in some areas and with some people, small strides in some areas and with some people and no strides with others." She implemented initiatives and procedures without "giving staff input or veto power." Miller pushed district initiatives that supported closing the achievement gap. She required staff members to create professional development plans that included goals addressing students' proficiency and skills, while providing instructional interventions for students who needed remediation and support. Although Miller and her staff members endured a strained macropolitical climate during the previous year, she reinforced that "teachers had a job to do and there were no excuses for doing less for kids." Miller "didn't care if teachers had 34 kids in a class; they were going to do all they could for their students." These types of decisions allowed Miller to command her influence on the hierarchical system and reinforce her priority that failure was not an option.

As Miller faced pressure from her superiors to implement district initiatives to increase student proficiency on state assessments, she learned in late September that her students did not exhibit year-to-year growth on state assessments. Accordingly, Central Middle School did not make AYP for the second year in a row. Even with revisions to the language arts curriculum, special education students did not exhibit enough growth in the areas of reading, writing and mathematics. Economically disadvantaged students also did not reflect enough growth in the 
area of literacy. Consequently, Miller's school was in danger of being labeled by the state as "a school in need of improvement" and subject to state monitoring.

Miller impulsively worked with colleagues and teachers to remediate students who scored partially proficient on state assessments. She collaborated with the Assistant Director of Special Education and a social worker to provide a supplemental and remedial reading program to special education students. During a single meeting in late September, Miller and her colleagues identified special education students who scored partially proficient on the language arts portion of the state test. Without parent consent or teacher input, Miller and the Assistant Director of Special Education incorporated a new reading class that supplemented each student's current reading class. The new class took place during students' academic support or elective class. Academic support provided special education students additional assistance in their academic classes, such as science, social studies, language arts or mathematics. The students' elective class, called Investigations, was a project-based course that required students to investigate a problem. In order to implement the new course, Miller replaced students' existing academic support or Investigations class with the remedial reading course. Miller and her colleagues paired full time special education teachers with regular education teachers to support some students in the new reading program, while instructing other students in the Investigations course. On one grade level, Miller teamed certified special education teachers with non-certified teacher assistants to split the students and teach either reading or Investigations. In some cases, Miller did not have any special education teachers available to teach the remedial reading program. She debated the idea of using a media specialist to teach the course; however, the Assistant Director of Special Education vetoed the idea, since state monitoring would not allow it. 
Miller and her Assistant Director of Special Education negotiated the movement of staff members and implemented the new supplemental reading course in isolation. The administrators utilized insulation, concealment and secrecy to respond to superiors' concerns over making AYP (Blase \& Anderson, 1995). Miller alienated special education teachers from decision-making processes, which remained concentrated and centralized at the top of the organizational hierarchy (Blase \& Anderson, 1995; Kanter, 1983). She also tossed parents' educational decision-making rights aside, as Miller and the Assistant Director of Special Education directed their school social worker to change special education students' Individualized Education Plans, which were legally binding documents, to reflect a need for a reading support program. The Director and social worker also agreed to discourage parents from placing their children in the academic support class and instead place the students in the supplemental reading support class. Miller wielded power, control and formal authority, as she initiated new programs to change structures, processes and content of learning to encourage teachers to participate in school reform (Scribner, Hager, \& Warne, 2002). However, Miller clashed with teachers, as staff members staunchly resisted and challenged the legitimacy of her changes and decisions (Anderson, 1991; Scribner, Hager, \& Warne, 2002).

After meeting with the Assistant Director of Special Education, Miller rushed to discuss the new reading program with teachers who were affected by the change. She met with a teacher who worked with special needs students in a self-contained setting, since the teacher was responsible to support a constant group of children the entire day. Miller explained to the teacher that "we need to do everything we can to make kids proficient" and discussed the new supplemental reading class with her. The teacher hesitantly questioned Miller about which components of her current instructional program she could remove in order to fit in the new 
program because she taught all academic disciplines to her students. The teacher was concerned that "there wasn't enough time in the day" to implement the new program. She also stressed to Miller that she was currently teaching a sixth grader who was reading on a first grade reading level. Miller encouraged the teacher to "obey the spirit of the law and not the letter" by combining social studies concepts in reading class to free instructional time to teach the supplemental reading course. The teacher then asked Miller how her schedule would be changed to maintain a preparation period and a lunch. Miller was unsure and told her the Assistant Director of Special Education could help her with scheduling logistics. Clearly, Miller did not understand the implications of her decisions and how they would affect teachers' schedules and routines (Blase \& Anderson, 1995). Consequently, Miller rushed her decisions and struggled to understand her micropolitical landscape, which hindered her ability to negotiate within the politics of educational change (Achinstein, 2002).

During the same day, Miller approached another special education teacher to discuss the new reading program. Like the self-contained instructor, this teacher was wary of the new program, since she was concerned her students would "fall behind" without assistance in their other academic classes. Miller's impulsive decisions in the face of macropolitical pressures meant that she manipulated resources, altered the working conditions of teachers' classrooms and she ignored opportunities for teacher input (Blase \& Anderson, 1995). Miller continued to control her micropolitical environment, since she did not completely understand her landscape, through mandates, as she eliminated or reduced chances for teacher influence and access to key micropolitical structures (Blase \& Anderson, 1995).

When teachers heard that students did not meet the NCLB mandate of AYP, some of them questioned Miller on the effectiveness of the revised language arts curriculum. Miller 
responded, "It worked great with the general education population, which is where we used it. You didn't really use it with the special education population. So how can we say the curriculum doesn't work?” Angry special education teachers also challenged Miller because students received a limited amount of extra time on the state assessments. Teachers argued that students would have performed better with unlimited additional time on the tests.

As Miller faced opposition from teachers, she was pressured by superiors to immediately target and remediate students whose performance demonstrated a need for improvement (Bjork \& Blase, 2009). The district mandated change from the top. Miller participated in administrative meetings and in a hierarchy which held teachers responsible for supporting and tracking students who were not proficient in math or language arts (Kanter, 1983, Wolcott, 1985). In fact, Miller's professional survival depended on her ability to comply with superiors' expectations that teachers would promote student academic growth (Bjork \& Blase, 2009; Hoy \& Hannum, 1997; Wolcott, 1984).

By late September, all of the middle school principals in Central School District held extended faculty meetings to discuss the implications of not achieving AYP. As Miller battled resistance towards her grade-level team protocols and student intervention plans, she also confronted backlash towards the prospect of an extended meeting. Teachers pressured Miller to shorten or cancel the meeting. Miller "felt like she really needed to have a meeting, but she didn't know what to do." Miller "didn't have her thoughts together as to what the teachers needed to do" to understand how NCLB mandates would affect their practice. Although a second year principal, Miller was overwhelmed by macropolitical pressures and did not fully understand how these pressures shaped her micropolitical environment. Miller was also indecisive, and she found herself making decisions within a culture of shock (Marshall, 1985). 
Subsequently, Miller continued to use rewards, sanctions and mandates to control teacher behaviors when addressing curriculum, instructional delivery and student proficiency. Miller was displeased with what she saw during unproductive grade-level team meetings. She viewed the meetings as "an excuse for teachers to tell her everything that was wrong and everything that she needed to do." Miller also felt that the teams were unproductive when she was not in attendance. She consequently implemented a team meeting protocol where teachers followed administrative expectations and norms "to engage in effective, productive professional dialogue for the purpose of achieving student growth, maximum student understanding and professional development" (Common Planning Time Protocol, 2010, p. 1). Teachers were expected to create an agenda for each meeting, follow a structure, keep a record of the discussion and outcomes, report to other grade-level teams and incorporate reflection into each meeting (Common Planning Time Protocol, 2010, p. 1). During grade-level meetings, Miller also required teachers to create intervention plans for students who were not proficient in math and language arts. Subsequently, teachers were expected to gather information, such as prior grades, report cards, previous-year teachers' input and student portfolios, across disciplines to identify areas of concern for each student, and to create a plan to address those concerns. These plans were expected to include classroom interventions and strategies that targeted specific skills for each student in math and language arts. Miller negotiated with her teachers that if they completed the grade-level team meeting protocols and created cohesive student intervention plans, to her satisfaction, she would in turn excuse those teachers from the extended faculty meeting. However, she would hold the meeting for teachers who needed assistance in creating student intervention plans.

Teachers complained because Miller controlled their discussions during grade-level meetings and their ability to remediate students. Kim, a seventh grade team member, believed 
the protocols "kept her away from planning to teach." John, a math teacher, thought grade-level meetings "could be used more effectively." He wanted to use the time to work with special education teachers. Other teachers questioned, "How are we supposed to get all this done?" Teachers, like Carolyn, who was an influential member of the sixth grade team, visited Miller in her office to share teachers' sentiments that the required protocols were a lot of work. She pressed, "How do we make kids do better? How do we do this?" Miller admitted "the goal seemed daunting, but lets go down swinging on this." She also stressed to Carolyn that she "did not know if we did everything we could last year." Carolyn admitted that there were a lot of "hands in pockets" and teacher "resistance" the previous year. Privately, Miller emphasized “we're going to try everything. It very well may not be an attainable goal, but we're going to try every single thing we can do. So if we don't make adequate yearly progress, we're not sitting here saying, 'we should have done something else."' Miller's stance reflected her superiors' expectation to dig Central Middle School out of a "school that needs improvement" status. However, teachers were unclear how their school would increase student proficiency on state assessments with fewer teachers and larger class sizes. During observations of grade-level team meetings in October, eighth grade teachers reiterated that they were overwhelmed and frustrated over identifying and tracking many different types of struggling students who needed various forms of interventions to improve. Teachers were also unfamiliar with all the available classroom interventions to support partially-proficient learners. Subsequently, disputes about how teachers were going to support students in reaching AYP overtook Miller's landscape.

In turn, Miller attempted to manage the politics behind grade-level team meeting discussions. She engaged the teachers in seemingly open conversations about how students learn and how teachers can alter their classroom practices. During a seventh grade team meeting, 
teachers shared divergent beliefs on how to provide remediation for struggling students. Some teachers wanted to implement "cheat sheets" to provide strict modeling of tasks to students, while other teachers implored students to look for alternative and numerous ways to solve the same task. Miller attempted to utilize her efficacy as a former content area supervisor to influence conversations. She liked the teachers' idea of helping students learn various solutions to a common problem. Subsequently, Miller recommended this approach to teachers during sixth and eighth grade team meetings.

Although Miller advocated teachers' ideas in this case, one teacher during the sixth grade team meeting interpreted Miller's advocacy as a mandate. The teacher understood that Miller wanted her to implement a specific teaching approach; however, she stressed the difficulty of turning partially-proficient students into proficient students. Miller quickly stopped the conversation and accentuated she "was not mandating anything" and that seventh grade teachers recommended the strategy. She advised the teacher to try interventions she "was willing to do" to prove how she supported partially-proficient students in the classroom. During meetings, other teachers added that it was difficult to cover the entire curriculum, while slowing down to remediate students who needed additional support. Teachers were also upset about having special education students included with partially-proficient general-education students in the same classroom. Consequently, veteran teachers who taught mathematics or language arts asked Miller to move some partially-proficient students out of their classrooms. Miller viewed these teachers as "thinking about themselves as individuals." Ultimately, she had little control over the debate other than telling teachers to identify students according to their proficiency on state assessments and require that they provide appropriate interventions. 
Teachers were clearly accustomed to Miller's control systems directing their practices towards increasing student proficiency, which divided her school culture (Weber, 1946). Some staff members, like Carolyn, a science teacher, Curtis, a school counselor and Grace, a music teacher, rationalized Miller's decisions surrounding AYP initiatives as "coming from the very top" of the hierarchy. Carolyn thought that Miller "had no control over" district sponsored AYP mandates. She believed that Miller was being "told what to do" and stressed that teachers had to "understand" that Miller "was still learning." Curtis found Miller to be a very "genuine" person and thought teachers had to accept "responsibility" for supporting students in the classroom. Grace acknowledged that "behind closed doors" morale was "not great." There were "things that people were not happy about," but Grace thought "it could be worse." For the most part, Grace and Carolyn escaped implementing AYP initiatives since their content areas were not assessed during state testing.

Meanwhile, teachers like John, a math teacher, and Kim, a language arts teacher, "felt the pressure to perform." Both teachers agreed that communication was a concern, especially since Miller's directions and expectations regarding students achieving AYP on state assessments were "unclear." John, who chaired the AYP committee, believed that Miller heard teachers' concerns about communication, but "did not act" on them. He also "wanted some direction." He did not want Miller asking him, “What are you doing to remediate that child?" Instead, he wanted a concrete plan that listed interventions that would help students improve their skills. John also thought there was "a big strain on the building," especially since there was a "sense of urgency" surrounding students achieving AYP. Similarly, Kim also felt that her curriculum was "under fire." She thought Miller put "a lot of pressure on one teacher" and felt that teachers were "set up to fail with the numerous transitions and changes" that took place during retrenchment. Amidst 
poor communication and direction, Kim believed that teachers "made their own decisions" in their classrooms regarding implementation of AYP related initiatives.

Miller's leadership style through the use of conflictive and closed approaches significantly disrupted micropolitical social structures, clogged communication and marginalized teachers (Blase \& Anderson, 1995; Scribner, Hager, \& Warne, 2002). In turn, teachers viewed Miller's decisions regarding holistic educational change with cynicism and apathy, which devastated morale (Blase, 1990, 1991). Mandated educational change discouraged teachers from participating in setting goals and becoming engaged in their practice (Bailey, 2000). Several teachers felt unsupported throughout the change process since Miller did not focus on building capacity to help teachers undertake the task of increasing student proficiency (DarlingHammond, 1993). Rather, her use of sanctions, rewards and mandates placed a disproportionate amount of responsibility on the teachers to identify partially-proficient students in their classrooms, support students' academic growth through classroom interventions and track the progress of each student. Miller's leadership tactics also did not allow teachers time to organize themselves, create structures for collegial inquiry, openly communicate, make critical sense of district expectations and analyze their classroom practices in relationship to achieving AYP (Cuban, 2010; Darling-Hammond, 1993; Fullan, 2007). Even though Miller attempted to engage teachers in detailed talk about their practice, ambiguity about expectations contributed to misinterpretations and ambivalence, which spoiled success for curricular and instructional initiatives (Fullan, 2007).

Miller's structural top-down leadership approach also ignored the teachers' willingness to undertake the objective of improving student achievement and sabotaged any opportunities for Miller and her teachers to collectively process and engender the vitality to create educational 
change (Bolman \& Deal, 2003; Darling-Hammond, 2005). As Miller attempted to control the content and message of her new reading program, as well as grade-level team meetings, she viewed the veteran faculty members "to be a very resistant faction in this building. There's a very resistant faction in this building that says 'because I've done it for thirty years, it's good because I got results." By the conclusion of the study, she also became "impatient" with teachers' arguments that they "didn't have time" to implement AYP interventions in their classrooms. Miller understood that teachers were overwhelmed, but stressed they "needed to do" what was expected.

Consequently, Miller demanded, to her teachers, the need to increase student proficiency instead of actively encouraging discussions and consensus about pedagogical practices through a gradual process (Boyd, 1983). Miller's closed leadership approach coerced, controlled and directed these teachers to participate toward the district's mission (McGregor, 1957). Her bureaucratic control over teachers also disempowered teachers who wanted more influence and access to communication in the building. As a result, Miller's isolated decision-making had little effect on creating holistic educational change because teachers were alienated from the change process (Blase \& Anderson, 1995).

However, by the conclusion of the study, parents like Anne and Barbara, who were former Parent-Teacher Association co-presidents, thought Miller "kept everyone informed" as she implemented district initiatives. Anne in particular felt Miller was "very accessible" and "always available," while Barbara believed curriculum revisions prepared students for high school. She also believed that the initiatives helped keep Central Middle School competitive with neighboring private schools. Overall, both parents believed "good change" was brought about because of Miller's arrival. 
Similarly, Robert Wilson also alienated his teachers during the push to implement new curricula and overhaul the master schedule. Unlike Miller, Wilson's macropolitical pressures seemed to ease during the summer. State assessment reports showed that his school made AYP in mathematics (NJDOE, 2010). His revamped language arts and mathematics curricula were ready to be implemented and students were scheduled into the new format. Wilson's superintendent provided him with a budget for the school year and gave consent to spend money on books, desks, supplies and other necessities. Also contrary to Miller, district administrators did not pressure Wilson to raise student proficiency levels on state assessments even though $N C L B$ reports showed that his school did not achieve AYP in language arts (NJDOE, 2010). Before the new school year began, Wilson realized that he needed to address teachers' anxiety since they worried about working with new curricular materials and content. $\mathrm{He}$ acknowledged that teachers were anxious because they were pulled out of their classrooms to attend training during the previous year. Wilson wanted to establish a symbolic leadership by attending all training sessions once the new school year commenced. He "needed to feel the anxiety with them and be at every training instead of doing work" in his office, and show his teachers that he was "in it with them." Wilson also wanted to improve staff morale. It seemed like he intended to employ open approaches during the new school year.

However, Wilson continued to lead through closed and conflictive approaches during the 2010-2011 school year. Some teachers also anticipated that communication would improve since the budget crisis passed; however, teachers still found Wilson to be inaccessible and experienced "hit or miss" encounters with him. On occasion, teachers expressed concerns to him and "it was handled very nicely." For example, during a site visit, Wilson collaborated with an English as a Second Language (ESL) teacher and a guidance counselor to move an ESL class section to an 
earlier period in the school day. This ensured that fifth and eighth grade students would not be in the same ESL class. On other occasions, however, Wilson verbally reprimanded teachers for raising concerns, or became defensive, especially during group meetings. Consequently, teachers were reluctant to bring dilemmas and concerns to his attention.

Credulously, Wilson believed teachers were satisfied with curricular changes, since he rewarded them with tablet computers during planning and implementation stages of the initiatives. Wilson was sure that giving teachers resources would gain their support and compliance (Blase, 1990). Throughout the study, he believed teacher morale was high and communication was efficient, open and clear. Wilson was also confident that "the staff had embraced the new math and language arts curriculum programs." According to Wilson, teachers "seemed to be really excited about it as well. It was a breath of fresh air."

Wilson rationalized complaints, however, by stating that teachers needed "a little bit more coddling," as he "held their hands during the implementation of new curricula." Wilson reiterated that there will "always" be people who are "naturally unhappy" or "feel anxious and overwhelmed about change." Although Wilson felt he accommodated and addressed "legitimate" teacher concerns and scheduling errors, he believed that "teachers were overwhelmed every year." He was sure that he was a better communicator, as a third year principal, and listened to his teachers' concerns. Wilson believed he worked with "a wonderful group of professionals." He "knew the people that were going to whine and moan no matter what" and he knew which complaints were truly legitimate. However, according to Wilson, “there really weren't that many complaints." Through the collaboration of the Middle School Restructuring, Math and Language Arts Curriculum Committees, Wilson felt he successfully negotiated with teachers for educational change. 
Once the school year began, Wilson led his newly-appointed team leaders to develop, refine and implement curricula. The leaders met with Wilson and his assistant principal bimonthly during what Wilson called Leadership Council Meetings. During the first council meeting, team leaders received a handbook discussing roles and responsibilities of effective team leaders and characteristics of productive team meetings. Similarly to Miller, Wilson controlled the purpose of grade-level meetings, since team leaders used a specific agenda for each meeting. Agenda protocols required team leaders to discuss curricular updates, team and school-wide issues, upcoming events and student concerns.

Leadership Council meetings seemed like opportunities for Wilson to empower teachers to participate in key micropolitical decision-making processes and social structures (Blase, 1993; Blase \& Blase, 1994; Scribner, Hager, \& Warne, 2002). During these meetings, teachers were given chances to make small-scale decisions; however, they were not empowered to participate in substantial school-wide decisions. Council meetings were arenas, however, where teachers could voice their concerns. Several team leaders expressed that teachers had difficulty getting accustomed to a new schedule. Specifically, sixth and seventh grade team leaders expressed that the language arts teachers were overwhelmed trying to "fit" new curricular content into a sixtyminute period since they were accustomed to teaching a ninety-minute language arts period. In late October, however, one interaction between Wilson and a sixth grade team leader revealed the ramifications of his poor communication with teachers. During this council meeting, Wilson mentioned that a sixth grade student was returning to school after reporting perceived bullying and thoughts of suicide to school officials. The student was required to be medically evaluated before returning to school. But, teachers were never made aware of the circumstances surrounding the student's absence. After hearing that the student returned to school, Tracy, the 
sixth grade team leader, approached Wilson upset and communicated, "I think we should have been told." Wilson apologized and accepted responsibility for not reaching out to her.

Wilson recognized that he had to get into the habit of informing his team leaders of events. He believed he had open communication, but acknowledged "sometimes" he "missed people." However, Wilson relied on team leaders to "streamline" the communication process and listen to or "work through" teacher concerns. Team leaders were then expected to coordinate meetings with Wilson over issues. Wilson thought it was nice to have a team leader to ensure student and school-based information was communicated to all the teachers. This strategy, however, did not enhance communication as Wilson hoped. Instead, it assigned teachers, in the name of delegation and participation, the responsibility of listening to and figuring out how to solve classroom and teacher issues without reaching the top of the organizational hierarchy (Kanter, 1983).

Moreover, Wilson continued to openly communicate with parents. He created a new committee during the 2010-2011 school year called the Community Connections Committee. The committee was created to enhance community connections and communication especially in relationship to new curricular changes. Wilson included his assistant principal, parents and their children on the committee. However, Wilson did not include teachers (Blase \& Anderson, 1995). Although they were not members of the committee, parents like Mary, Jackie and Jennie, who were active in the Parent-Teacher Association, were pleased with the curricular changes. Mary thought the "changes were needed" and helped "move the school forward and be competitive with other schools." She was, however, a "little concerned about how much change" the school was going through "in one year." Mary did "wish the changes had been phased in a bit" because she knew it was difficult for the teachers, since she worked at Northern Middle School as a part- 
time secretary. The parents also believed that Wilson went out of his way to invite parents to evening events focused on math and literacy to explain new curricular and instructional changes. Jackie and Jennie noted that Wilson's open communication and ability to inform parents helped them with concerns or questions about new changes. Although the parents acknowledged some of the changes were difficult for teachers and students to adjust to, they noted that the transition to a new master schedule and curricula went smoothly.

Teachers also valued the importance of communication, especially since they were expected to integrate new lessons and classroom materials in the math and language arts curricula. Unfortunately, some teachers felt unprepared to teach parts of the new language arts curriculum, since they were handed the materials without explanation or proper training. Wilson acknowledged this misstep as an oversight, since a new supervisor of secondary education transitioned into the district. By late October, he conceded that his language arts teachers did not receive enough training to teach some content, which legitimized to their concerns. Wilson also found it difficult to affirm his language arts teachers' frustrations, while also supporting district administrators and colleagues who wanted the teachers to push forward and make adjustments to the curriculum in the following year. Wilson regretted not being more involved in the process of revising the language arts curriculum, since he dedicated most of his time to the math initiative. Consequently, Wilson ceded control to the Supervisor for Secondary Education, who Wilson described as the "point person" on the issue. By the end of the study, Wilson believed that district administrators were jeopardizing successful implementation of the new language arts curriculum. However, he continued to support his colleagues' and superiors' message of telling teachers "to just do it." Clearly, Wilson struggled with balancing and managing central office expectations for initiative implementation with his teachers' sentiments and realities. 
Ironically, language arts teachers did not receive new vocabulary textbooks for their students or themselves. Teachers complained, during a district-wide language arts meeting, that they did not have enough time to fit portions of the new curriculum, specifically vocabulary studies, into sixty-minute periods. As the teachers were required to use appropriate grade-level vocabulary words, special education teachers did not understand how this would work with their students since most of them did not read on grade level. The Supervisor of Secondary Education urged them to modify the words accordingly, but to be consistent with students' grade-levels. One special education teacher urged the supervisor that "we need to take a look at this, as the eighth grade vocabulary words were inappropriate" for her students. Teachers also pressed the Supervisor of Secondary Education to provide training. The supervisor informed teachers that they were not going to receive training because it was not worth the time for an expert to train them on the use of vocabulary since they were language arts teachers. Accordingly, teachers were overwhelmed by and resisted the new curricular revisions.

While district administrators built capacity within the math initiatives, they did not give teachers time or tools to understand the new language arts curriculum and how it would affect their practice in the classroom (Darling-Hammond, 1993; Fullan, 2007). Overall, teachers felt oppressed, powerless, devalued, scared and incompetent during these changes (Brooks, 2005; Friedman, Galligan, Albano \& O’Conner, 2009). Tracy, a social studies teacher and team leader, no longer felt comfortable voicing her concerns to Wilson since he "would see me as being a complainer and I would be nervous that something would happen because I was complaining." Christine believed communication with Wilson was "not as good as it used to be," causing "a big gap between" Wilson and the faculty. She also thought school decisions were "coming from the top." Samantha agreed that teachers had lost their influence on decision making (Brooks, 2005). 
Christine and Samantha also thought they took on too many complex initiatives simultaneously and found it difficult to be successful. They described the change process as "ineffective" and "a waste of time."

Teachers noted that while the language arts and mathematics curricula were updated, other subject-area curricula stagnated. Tracy felt her curriculum was "left out in the cold" because she did not receive any "training in her subject area" for over four years. The district supervisors who were responsible to maintain and develop social studies and science curricula retired or were eliminated during retrenchment (Boyd, 1982, 1983). Some teachers also did not like the new schedule since they lost the preparation time that they had in the old schedule. Wilson heard some of these concerns, but did not address them. While Wilson believed he promoted teacher buy-in, listened to teacher feedback and slowly worked over two years to implement successful holistic changes, teachers thought Wilson did not grasp what was going on in his building. Christine added, “The principal thinks everything is great. I don't think he's seeing or understanding [teachers'] frustrations." Teachers understood that Wilson was directed by superiors to implement district initiatives; however, they wanted him to acknowledge that curricular implementation was "hard work" and show "follow through." Consequently, some teachers focused on working with their students, and implemented language arts initiatives on their own terms. Christine admitted that she "created her own timelines" when applying new language arts curricular components, like vocabulary study, in her classroom. This made her feel uncomfortable. "That's not right; I should be [implementing new curriculum] when I'm being told." However, Christine did not understand how to fit the new vocabulary study in her instruction. 
Wilson's work to create educational change in Northern Middle School revealed that he ignored teachers' complaints and resistance because he viewed their anxiety as part of the change process. He also created pseudo-collaborative opportunities with teachers to superficially create a pretense of consensual-based approaches (Blase \& Anderson, 1995). Teachers like Tracy viewed committee agendas and outcomes as "already done." She believed administrators in her school already knew what they wanted to accomplish. "They're holding a committee just for the sake of saying, 'well, we held a committee,' but really they knew what they wanted to happen.” These coercive tactics helped push the implementation of school initiatives; however, they devalued teachers' contributions and clogged communication. In return, the teachers felt they had some access to decision making in their classrooms, but they generally still felt they did not have access to decision making within the school (Blase \& Anderson, 1995; Brooks, 2005; Lortie, 1975). For the most part, Wilson remained detached from his teachers because he believed the "teachers were really excited about the changes, since they've been part of the process." During the study, it became clear that in the face of dissent, Wilson was using a protective strategy to maintain a good image (Blase, 1990). Consequently, he was viewed by some staff members as protecting his own turf, mending his own fences and concentrating on pleasing his superiors and parents (Kanter, 1983).

Schools are influenced by the larger social and economic contexts in which they are embedded (Gordon \& Patterson, 2008). Miller and Wilson, bureaucratic in their orientation, strove to successfully implement holistic educational change through district initiatives. As macropolitical pressures, like vanishing state public school funding and federal student proficiency mandates, overpowered their micropolitical landscapes, Miller and Wilson attempted to maintain control over teachers' behaviors and content through mandates, rewards and 
sanctions (Blase \& Anderson, 199). Consequently, both principals controlled teacher access to key micropolitical social structures, processes and content during macropolitical uncertainty, which reinforced the formal hierarchy and provoked clashes between teachers and their principals (Scribner, Hager, \& Warne, 2002). As both principals lived through the politics of decline, they faced retrenchment, through personnel cutbacks, that demoralized staff members in each school (Boyd, 1983).

\section{The Politics of Change amid Decline}

"[During decline], administrators must worry about both the political costs of decisions and the costs in terms of maintaining the organization's ability to perform satisfactorily"--Boyd, 1983, p. 13

As economic conditions led to radical reductions in to public school districts, schools curtailed their own budgets through retrenchment, which included staff cutbacks and program contraction (Boyd, 1982). These reactions created adversarial relationships and conflicts within the politics of education as parents, teachers and administrators scavenged for shrinking resources. Parents rallied in an effort to preserve cohesive academic and extracurricular programs for their children and called for their board members to "cut the fat" and eliminate noninstructional support staff (Boyd, 1982). Consequently, tensions between administrators and staff members rose because teachers and non-instructional staff members did not want to be the "losers" in the fiscal fallout (Boyd, 1982). The perception of clear winners and losers during retrenchment made conflict management difficult during decline (Boyd, 1982). Consequently, Miller and Wilson reacted to the constant macropolitical pressure of decline by governing through the norm of impersonality and minimizing personal relationships since staff members were losing their jobs (Bridges, 1965). However once the macropolitical budgetary crisis passed in late May, the effects of decline prevailed, as morale continued to wane and teachers in both 
middle schools lost their purpose and motivation to implement change (Boyd, 1982). As a result, Miller and Wilson employed control systems to refocus staff members and maintain their jurisdiction and formal authority over the implementation of holistic educational changes (Weber, 1946).

Since both principals struggled to face the harsh realities of retrenchment, their conflictive leadership approaches had implications on the political process of holistic educational change. Subsequently, Miller and Wilson had to be much more attuned to big picture macropolitical policies and mandates, and much more sophisticated at conceptual thinking and transforming the organization through people and teams (Fullan, 2007). Their reliance on vertical coordination, while enforcing mandates, rewards and sanctions, ensured the completion of tasks; however, these approaches alienated staff members from vital communication networks and school-wide micropolitical social structures which impeded change (Bolman \& Deal, 2003; Hickcox \& Ryan, 1979; Scribner, Hager, \& Warne, 2002). Teachers viewed collaborative opportunities as token or trivial efforts. Consequently, teachers were excluded from decisionmaking structures that decided who got what, when and how during an overbearing macropolitical crisis (Lasswell, 1959).

Typically, experienced middle school principals who exhibit stability develop a sober outlook regarding the possibility of promoting meaningful educational change (Parkay, Currie, \& Rhodes, 1992). During the politics of decline, school initiatives and educational change often take a back seat to preserving staff morale (Boyd, 1982). However, Miller and Wilson were novice principals who were expected to negotiate with teachers, colleagues, superiors and parents to create holistic curricular and instructional changes. Their survival within a culture of shock depended on their ability to navigate the politics of educational change (Marshall, 1984; 
Wolcott, 1984). Consequently, Miller and Wilson had clear and consistent communication with their superiors and colleagues to negotiate personnel and program decisions, while public school state aid funding was slashed. In turn, both principals led through mandates with staff members to ensure that tasks were completed. They also used coercive tactics and employed rewards and sanctions to gain teacher compliance (Blase \& Anderson, 1995). Staff members who were in danger of losing their jobs already complied with administrative requests; however, Miller and Wilson wielded this tactic to engage experienced teachers who enjoyed seniority and who were resistant to educational change.

Early in 2010, Miller and Wilson utilized open-based leadership approaches to provide access to decision-making structures regarding ideologies and content, and empowered staff members to embrace and develop educational change (Fullan, 2007). However, once the politics of decline hijacked their micropolitical landscapes, Miller and Wilson did not dare risk losing control over expectations, or the policies and procedures surrounding their changes (Blase \& Anderson, 1995). Consequently, both principals relied on their formal authority to push through staff resistance and implement educational change. Once morale eroded in both schools, teachers questioned and ignored Miller's or Wilson's formal authority, as they lost motivation to implement their curricular changes, especially since they did not have clear access to social structures (Anderson, 1991; Scribner, Hager, \& Warne, 2002). To further describe this process, the conceptualization of the communication amidst decline is illustrated through the following figure: 


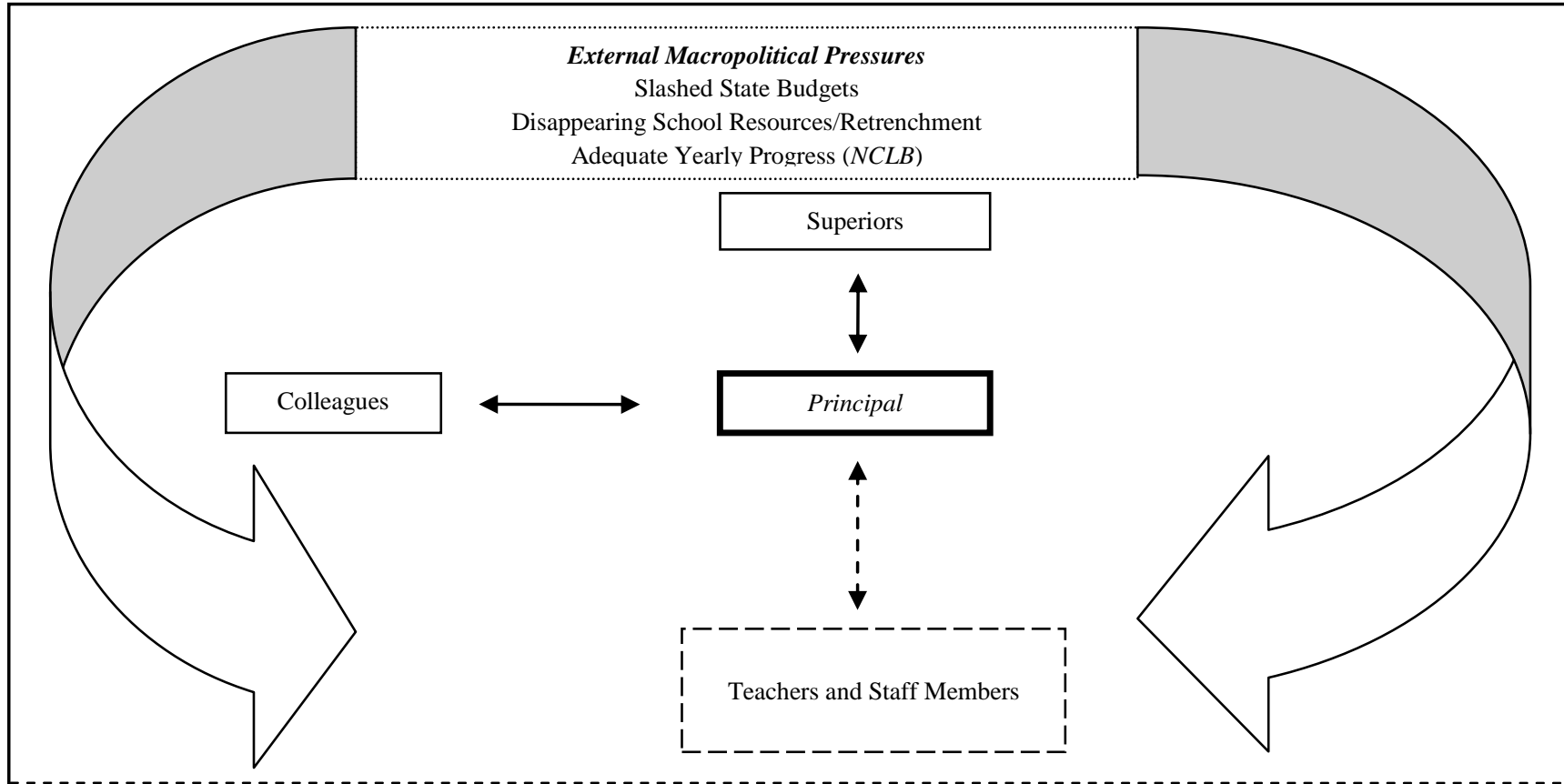

Mandates

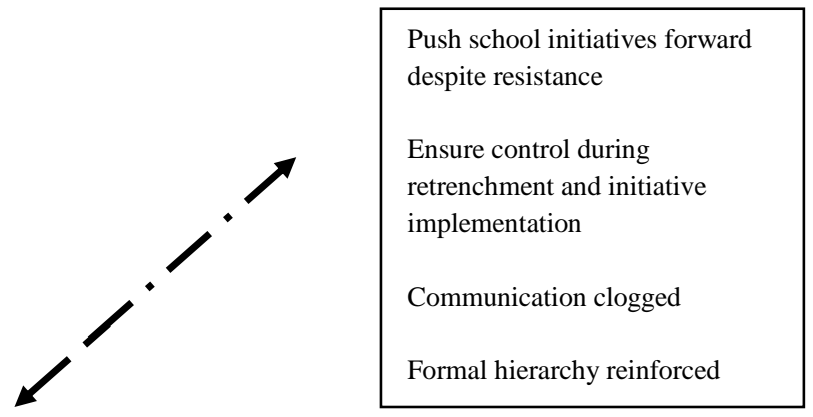

Conflictive or Closed Approaches through Rewards/Sanctions

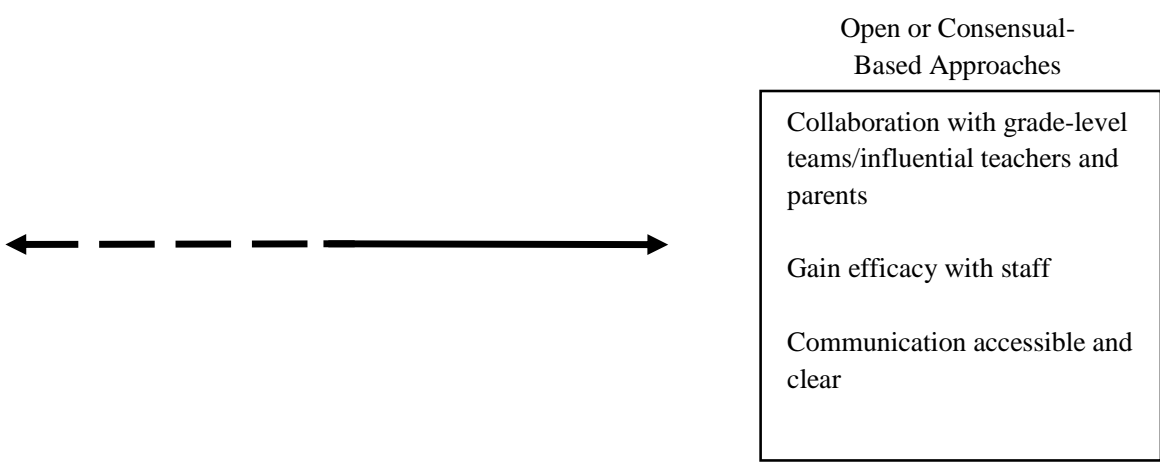

Use of rewards/sanctions to gain compliance

Task oriented

Alleviate turf battles

Communication congested

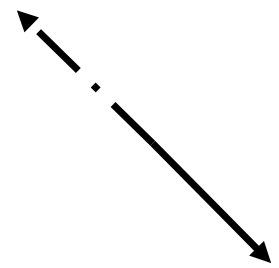

Open or Consensual-

Collaboration with grade-level teams/influential teachers and

Gain efficacy with staff

Communication accessible and

Figure 3. 
The success or failure of the principals' ability to create holistic educational change amid decline was influenced by district administrators. The districts' efforts to facilitate change and protect their schools from macropolitical interference were important to achieve successful implementation of educational change (Bjork \& Blase, 2009; Blase \& Bjork, 2009). Although the politics of decline severely impeded district administrators' abilities to suppress micropolitical fallout and consequences, central-office administrators had the ability to build a system-wide framework and infrastructure to support discussions and decision making surrounding educational change (Fullan, 2007). Superintendents' abilities to build capacity, commitment and trust amongst teachers and administrators were instrumental in building political support to advance change initiatives (Bjork \& Blase, 2009; Blase \& Bjork, 2009; Cosner, 2009; Fullan, 2007). Traditionally, trying to mandate what matters most, without building capacity for new practice, leads to certain failure (Darling-Hammond, 1993). However, during typical periods of decline, superintendents are faced with scaling back organizational resources and doing less, while consuming fewer resources (Boyd, 1983). In Miller's and Wilson's cases, district administrators expected their school and district initiatives to remain unchanged despite the dismissal of critical support staff and teachers.

Since 2007, Central School District employed a strategic action plan to "develop high expectations for all students" (p. 2). The plan mandated their building principals to "develop professional development opportunities to support district values and initiatives, guarantee curricular and academic standards through vertical coordination, and implement assessments to guide instruction and establish programs to assist and inform parents" (District Strategic Planning, 2008, pp. 22-23). Additionally, superiors grew concerned that their middle schools did not make AYP for two consecutive years, and pressured their principals to identify and track 
students who scored below proficiency on state assessments. These expectations remained unchanged during decline. Furthermore, the methods and procedures for assisting teachers and principals in reaching each goal were ambiguous and lacked detail about what curricular and instructional change would look like, as central office administrators took a passive role in reform (Blase \& Bjork, 2009). This stance left Miller wondering if her interventions were moving teachers and students forward. Subsequently, Miller relied on her autonomy in order to implement her own methods and procedures that would bring about educational change, which led to varied interventions and results.

District administrators communicated some information regarding initiatives to their principals, expecting them to carry the message or vertically articulate to their teachers during grade-level team meetings. However, teachers were often unaware of information that would guide their teaching practices or help them monitor the implementation of initiatives (Fullan, 2007). Furthermore, Miller's micropolitical landscape was flooded with the uncertainty and conflict surrounding decline and retrenchment. Her district also imposed unclear expectations and roles for their principals concerning district initiatives and educational changes. Miller thought central office administrators "did a good job of laying out the problem;" however, their absence amidst reform left Miller asking in October, "now what?"

Tensions escalated between Miller and her superiors. As Miller and the district's Assistant Director of Special Education developed a remedial reading program to help increase student proficiency on state assessments in isolation, they also planned to implement a computerbased mathematics program. The plan, to increase student proficiency in mathematics, required teachers to use the computer program once a week with their students. However, the Assistant Director of Mathematics did not support the intervention since "she did not have time to review 
the program, teachers were not trained to use it and students were taken out of their regular math class once a week." Miller felt like she was "in the middle;" however, she failed to navigate organizational structures to negotiate the methods in which educational change would be attained. Instead, she felt pressure to be viewed by her superiors as "doing something" to address the need for improving student proficiency (Bjork \& Blase, 1999).

Miller was directed by her superiors to "pull back" on the computer-based mathematics intervention and investigate more strategies for long term change. Miller underestimated the politics surrounding her decisions and the formal hierarchy in her district, which put her in an “awkward position" and professionally isolated her from her colleagues and superiors (Stephenson \& Bauer, 2010). She "felt judged for trying to do something right," but realized that she "should have consulted" her superiors before implementing new remedial programs. Miller assumed that the Assistant Director of Special Education would discuss the changes with the Assistant Director of Mathematics. However, Miller was obligated to communicate with both parties. Consequently, Miller's inability to understand or engage in the politics of power-sharing with her colleagues and superiors during decline jeopardized her effectiveness as an organizational leader, the confidence of her superiors and her position as a principal (Blase \& Bjork, 2009; Boyd, 1983).

Alternatively, Northern School District administrators assumed an active role, even during decline, to support their building principals through implementation of new math and scheduling initiatives. The district's superintendent created opportunities for lateral communication in order to bring administrators and teachers together to build capacity, conceptualize curricular approaches and provide training for educational change (Fullan, 2007). These structures were created through the Math Curriculum and Middle School Restructuring 
Committees. While support and capacity were built for the new math curriculum, the district did not build enough capacity for the language arts curriculum, as teachers did not receive curricular materials or understand how to implement them in their classrooms.

Overall, central office support for teacher training through consensual-based approaches influenced decentralized decision making and facilitated initiative implementation (Blase \& Anderson, 1995; Blase \& Bjork, 2009; Bolman \& Deal, 2003). Wilson’s superiors also ensured the adoption and alignment of homogenous district-wide curricula, assessment standards, master schedules and teaching materials between both middle schools (Fullan, 2007). On a district level, there was a climate of teamwork and trust; however, lateral social structures disappeared, as Wilson utilized vertical social networks inconsistently to communicate with his staff members.

As an insider, Wilson had already formed positive and fruitful relationships with his superintendent and superiors through his experiences as an assistant principal. He received social support from his colleagues and superiors as he implemented complex and substantial changes (Stephenson \& Bauer, 2010). Wilson's ability to negotiate with them for critical resources to push and implement new initiatives as a principal strengthened existing trust and autonomy from central office administrators (Wolcott, 1984). Unlike Miller, Wilson understood curricular and scheduling needs in his school. Subsequently, Wilson presented himself as an expert on his micropolitical landscape with superiors. However, Wilson was isolated from teachers' sentiments and complaints. Although superiors often publicly complimented Wilson on his ability to enact educational change, his teachers were exhausted and frustrated during a fastpaced period of initiative implementation and decline. Undoubtedly, Wilson was proud "to be a role model" for "taking risks," as he led teachers through a "huge shift in a student centered approach to teaching math." However, some teachers related his confidence to a "no one works 
harder than me" mentality, which upset teachers especially since "there were many teachers who put in countless hours in their work" to help enact change. Like Miller, Wilson alienated his teachers by accentuating his formal authority and dictating from the top (Boyd, 1983). Although Wilson was not at risk of losing his position since he was tenured, he was at risk of losing the trust of his staff members, as he devalued their contributions. Teachers like Christine and Samantha noted that teachers "rallied" together to support one another "with really no guidance" from Wilson. While Wilson established a passive, non-contact and non-communicative climate with his staff, he placed value with superiors and colleagues (Kanter, 1983).

Typically, educational change involves serious personal and collective experiences amid ambivalence and uncertainty (Fullan, 2007). However, during the politics of decline, real educational change seemed like a Herculean task amid acrimonious conflict (Boyd, 1983). The likelihood of initiating mobilization, adoption, implementation and institutionalization of the change process seemed unlikely as teacher morale plummeted, staff members battled over job security and the likelihood of burnout increased (Boyd, 1983; Fullan, 2007). Consequently, teacher disengagement from district or school initiatives coupled with centralized decision making from administrators during retrenchment significantly inhibited communication networks (Boyd, 1983). In both cases, Miller and Wilson never relinquished conflictive and closed leadership practices, even after retrenchment. They often used mandates, sanctions and rewards to enact educational change (Blase \& Anderson, 1995). Their leadership roles and actions were not geared towards a communal focus, but emphasized and valued the importance of expediency, structural management and efficiency (Bolman \& Deal, 2003; Foster, 2004). Although Miller and Wilson were efficient decision makers, they were not effective communicators. Their unwillingness to lead through open approaches alienated teachers from the decision-making 
process. As cultures in Central and Northern Middle School became segmented, staff members were apathetic to administrative decisions and requests (Kanter, 1983).

During periods of retrenchment and politics of decline, shrinking or lost resources may not be restored in the near future (Boyd, 1983). At the beginning stages of decline, most people will believe that resources will reappear in a year or two; however, in this political environment, novice and experienced principals need to understand the implications and reality of macropolitical pressures like slashed state public school funding, waning confidence in public schools and federal mandates to increase student proficiency (Boyd, 1983). Subsequently, principals' abilities to understand, balance and manage these pressures will prove valuable, as they attempt to sustain consensual-based leadership practices to provide staff members access to micropolitical social structures and networks and create a participative decision-making process to decide who gets what, when and how, even amid decline (Blase \& Anderson, 1995; Rhodes \& Marsh, 1992). In all, this strategy will help novice middle school principals understand their micropolitical landscapes through grapevine structures lead within their environments, through distinct leadership styles and negotiate with school community members to enact holistic educational change. 


\section{CHAPTER VII}

\section{DISCUSSION}

This year-long qualitative study described the journey and processes of two novice middle school principals as they navigated their micropolitical landscapes to negotiate for holistic educational change. One of the more abstract challenges that faced both middle school principals was their quest to successfully understand and manage the relationships between macropolitical pressures and their micropolitical environments (Mawhinney, 1999). In both cases, the principals' micro initiatives were at odds with their macro realities. As the principals' micropolitcal landscapes were subsumed in local budget crises and federal student proficiency mandates, the principals quickly learned that all politics are not local. As federal and state agencies attempted to impose logics of actions, schools in the past had time to adapt or be buffered from pressures. However, the budgetary crises that Miller and Wilson were exposed to left them, and their colleagues, with little time and protection to understand and respond to fiscal mandates from the state (Bacharach \& Mundell, 1993).

Subsequently, the principals' abilities to navigate their micropolitical landscapes were crucial to their professional survival. By understanding their micropolitical landscapes, Lisa Miller and Robert Wilson were able to form grapevine structures and relationships with colleagues and superiors, and identify key personnel, resources and programs to preserve during retrenchment (Boyd, 1982; Licata \& Hack, 1980). As they led within their landscapes, Miller and Wilson forged their own distinct administrative cultures, which included closed and conflictbased approaches through rewards, sanctions and mandates (Blase \& Anderson, 1995). Their control systems allowed them to exert their formal authority and jurisdiction over the ideologies, 
content and implementation of school and district initiatives (Anderson, 1966; Bridges, 1965; Weber, 1946).

During periods of decline and retrenchment, the principals' reliance on vertical coordination, while enforcing mandates, rewards and sanctions, ensured the completion of tasks; however, these approaches alienated staff members from vital communication networks and eroded morale (Bolman \& Deal, 2003; Boyd, 1982; Hickcox \& Ryan, 1979; Scribner, Hager, \& Warne, 2002). The principals progression within the politics of educational change unveiled that they were novice principals who were expected to negotiate with teachers, colleagues, superiors and parents to create holistic curricular and instructional changes. Their survival within a culture of shock depended on their ability to enact change amidst crises (Bjork \& Blase, 2009; Marshall, 1984; Wolcott, 1984). Subsequently, it is essential to revisit the guiding questions to describe, in detail, this process.

\section{Revisiting Research Questions}

Research Question \#1: How do new middle school principals identify key micropolitical power structures and individual power brokers in their school communities?

During the first two months of data collection, the focus of this study was on novice principals and how they identified and navigated micropolitical structures in their school communities. Subsequently, Lisa Miller and Robert Wilson participated in routine formal and informal "getting to know each other" activities and a verbal culture (Wolcott, 1984). They learned existing school values, norms, content of policy making, and decision-making processes by attending grade-level team meetings (Anderson, 1991; Erickson, 1987; Marshall \& Scribner, 1991; Schein, 1985). Grade-level team meetings were opportunities for the principals to ascertain teachers' concerns and hold informal conversations about topics, such as curricular integration, 
building management and communication. Lateral communication between teachers and their principals created an open and comfortable climate where Miller and Wilson frequently visited classrooms or just "checked in" with teachers to see how curricula and instruction were implemented (Bolman \& Deal, 2003).

In both cases, each principal replaced a principal who exhibited closed or conflictive approaches (Blase \& Anderson, 1995). Accordingly, Miller built a culture of collaboration and openness where teachers freely discussed ideas, participated in shared decision making and voiced concerns and perspectives. As an external hire, Miller understood importance of establishing positive relationships with parents and teachers to enact holistic educational change. By contrast, Wilson was a known commodity in his district, since he was hired internally. As a former assistant principal, he relied on previously established relationships with teachers, colleagues and superiors to enact change.

Both principals entered their micropolitical environments expecting to create holistic educational change through district-sponsored initiatives. Miller and Wilson implemented challenging goals that created holistic educational changes through instructional and curricular changes to improve student learning. They stressed the importance of staying calm and cool while working in a culture of shock; however, they also relied on the support of their colleagues and central office administrators to be successful while understanding their schools' micropolitical landscapes (Marshall, 1985). To manage this enormous pressure, the principals created guild or clan-like relationships with their colleagues (Licata \& Hack, 1980). Throughout the study, Miller's and Wilson's experiences were affected by central office personnel, as these members represented the formal authority of the hierarchy, peer group influence and support. 
These relationships would help them identify key players, while surviving their micropolitical processes.

Miller exhibited guild-like relationships with her colleagues, as she reached out to trusted colleagues to identify and create relationships within her school (Licata \& Hack, 1980). When interacting with her colleagues, they collaborated to help her perform, survive and succeed within her professional setting (Licata \& Hack, 1980). Although Miller mostly viewed her superiors as helpful and supportive, she was reminded that the result of her interactions with parents, teachers and students had to holistically create a school culture that stressed the district's message that failure was not an option.

By contrast, Robert Wilson exhibited clan-like relationships with his colleagues and superiors (Licata \& Hack, 1980). His previously established relationships with colleagues and central office administrators were evident since he was an insider at Northern Middle School. Wilson pointed out that he quickly gained trust from his superiors, since he had an established identity as an administrator in the district. He also co-chaired the district level math committee and was a member of the Middle School Restructuring Committee, which helped him gain efficacy and respect amongst his superiors. Wilson was seen as an expert on his school. Subsequently, his well established existing relationships with colleagues and superiors helped Wilson secure valuable resources during the macropolitical budget crisis.

The focus of the study unexpectedly shifted, however, three months into data collection as macropolitics dominated the principals' micropolitical landscapes. Public school state-aid funding was slashed while Miller and Wilson were already working within a culture of shock where events were unpredictable and individuals and coalitions were challenging existing norms and boundaries (Achinstein, 2002; Marshall, 1985). The demands of their jobs ranging from 
implementing school and district goals to supporting teachers in the classroom to addressing parental concerns to accommodating central office requests were difficult to fulfill (Marshall, 1985). As novice principals, Miller and Wilson were not adequately prepared to deal with the management or implications of an unprecedented macropolitical budgetary crisis, which included retrenchment through personnel and program cutbacks (Boyd, 1982).

Consequently, the budget crisis significantly inhibited lateral communication between teachers and their principals. Teachers found it difficult to see colleagues lose their jobs. Trust and morale deteriorated. Miller and Wilson, however, continued to have clear and open communication with their superiors and colleagues to secure valuable resources to ensure successful implementation of school initiatives even during decline. As macro factors greatly influenced school-based social and micropolitical structures, Miller and Wilson were still expected to understand their micropolitical environments by getting to know teachers, support staff and parents. However, the macropolitical environment impeded this process because Miller and Wilson were working within an escalating climate of distrust.

Research Question \#2: How do new middle school principals situate themselves within the micropolitical structures of their schools?

Although Miller and Wilson seemingly collaborated with teachers, colleagues, superiors and parents through open social structures and interactions early in their principalships, their leadership styles drastically shifted to coercive, closed and conflictive approaches once the macropolitical budget crisis took hold (Blase, 1990, 1991). During this period of decline, both principals relied on bureaucratic or hierarchical structural approaches, where decisions were made with little or no consultation from school community members (Boyd, 1982, 1983). 
However, in order to push school initiatives and control ideological discussions about teaching and learning, Miller and Wilson exhibited instructional competency and efficacy.

Subsequently, Lisa Miller relied on her previous experiences as a district language arts supervisor. Since Central Middle School was in the midst of changing the language arts curriculum, Miller felt more than qualified to support those changes. Her previous experiences also allowed her to become comfortable with giving feedback to veteran staff members. Similarly, Wilson strove to be viewed as a "math person" by his teachers, colleagues and superiors. His leadership roles on his district's Middle School Restructuring and Math Curriculum Committees gave him immediate access to holistic educational decisions, such as the purchasing of specific math curricular materials and the formation of a master schedule to promote effective student-centered instruction.

As Miller and Wilson exerted their formal authority to implement initiatives, teachers' resistance and anxiety filled both landscapes, which led to clashes and turf battles. In Central Middle School, teachers viewed the initiative of failure was not an option as "unrealistic" and interpreted that statement to mean figure out a way to pass students. By May, teachers were distracted by budget woes, as they wondered which programs and teaching positions would get eliminated amidst retrenchment. Consequently, Miller relied on authoritative and autocratic approaches to implement initiatives (Eagly, Karau, \& Johnson, 1992).

Similarly, Wilson met resistance from staff members, as Northern Middle School was undergoing massive and holistic educational changes. As a second year principal, he recognized "the fine line in terms of dealing" and compromising certain procedures, rules and norms. However, procedures and expectations regarding the implementation of new curricular and master scheduling changes were not debatable. Turf battles over "minutes of teaching and 
student contact time, what the curricular and instructional changes would look like" and how they were going to affect teachers' practice, consumed Wilson's time. Staff members battled over "who had more teaching time versus who had less teaching time; who was getting books and who was getting training." As teachers scrounged for resources, Wilson continued to lead through vertical, top-down structural approaches, causing teachers to keep their concerns away from him to side-step hierarchical control and protect their autonomy of classroom activities (Bolman \& Deal, 2003; Brooks, 2005; Lortie, 1975).

While communication all but stopped between teachers and their principals in both middle schools, Miller and Wilson still engaged in open conversations with parents and superiors. Many times, Miller and Wilson leaned on their superiors for help during escalating parent concerns. Miller and Wilson, however, wanted to prove to their superintendents that they were calm and in control, while implementing school and district initiatives in the wake of a constraining macropolitical budget crisis. They also wanted to showcase that they were achieving holistic educational change through the work of committees and grade-level teams. That said, the principals did not want a dissatisfied school community member or faction in the community to gain their superiors' attention (Wolcott, 1984).

Miller and Wilson strove to run efficient middle schools and satisfy concerned parents and teachers who were jockeying for scarce and increasingly disappearing school resources. Subsequently, both principals watched for signs of any mounting level of discontent and attempted to prevent volatile situations that would catch their superiors' attention. Miller and Wilson both engaged in open and positive relationships with their superiors; however, they did not want to receive a phone call from their superintendents asking or telling them what was wrong in their schools. They understood complaints to their superiors left them with little 
potential for remaining in their positions (Wolcott, 1984). Instead, Miller and Wilson quickly "put out fires" and intervened when parents or teachers became vocal. Subsequently, Miller and Wilson were cognizant of the most influential members in their schools. Miller understood that eighth grade teachers carried the most informal authority in Central Middle School because they were veteran and experienced teachers. Wilson made agreements behind closed doors with influential Liaison Committee members because they possessed formal authority and represented staff members who belonged to the union. The principals' ability to handle complaints "inhouse" within their micropolitical landscapes preserved their autonomy, since superiors were not involved. However, Miller and Wilson were making "big changes" within their initiatives. Subsequently, Miller and Wilson were careful not to get caught in the "crossfire" when complaints emerged. Miller and Wilson risked being viewed by their teachers as protecting their own turf, mending their own fences and concentrating on pleasing their superiors and parents (Kanter, 1983).

As Miller and Wilson transitioned into second and third year principals in September, 2010, they continued to exert control over their micropolitical landscapes primarily through mandates, rewards and sanctions (Blase, 1990). The principals' conscious decisions to rely on these tactics ensured that they would "get things done," but did not guarantee that teachers would adopt any change in their instructional practices (Blase \& Anderson, 1995; Darling-Hammond, 1995; Fullan, 2007). Wilson was in complete control of his micropolitical environment as a Stage Two principal who achieved tenure status (Parkay, Currie, \& Rhodes, 1992). As an insider, Wilson achieved stability in his micropolitical environment since he was eligible for tenure after only two years in the principalship, and he enjoyed previously established relationships and networks with superiors and colleagues (Licata \& Hack, 1980). Through his relationships and 
"insider status," Wilson gained the capacity to influence district and school values and goals (Hoy \& Hannum, 1997; Johnson, 2001). By contrast, Miller still struggled to understand her micropolitical landscape, as she grappled with federally-mandated expectations for student proficiency. As an external hire, she was not eligible for tenure until three years into her principalship and she did not have any previously established trusting relationships with teachers, colleagues or superiors to help her manage macropolitical shock. Miller's inability to bring people together and navigate micropolitical structures jeopardized her effectiveness as an organizational leader, the confidence of her superiors and her position as a principal.

Nevertheless, even through decline, parents and superiors still expected Miller and Wilson to provide instructional and curricular changes that improved student achievement. The macropolitical crisis threatened the educational outcomes that Miller and Wilson were striving to achieve. Once Miller and Wilson were confronted with that reality, they entered their micropolitical arenas where they relied on their negotiating skills to preserve programs and staff members to deliver holistic educational change.

Research Question \#3: How do new middle school principals navigate micropolitical structures and conflicts in schools to create educational change?

In both middle schools, educational change came in the form of improving student achievement, as well as restructuring their schools to support student learning and instruction. These changes typically involved anxiety, stress and struggle within micropolitical landscapes, as school community members decided to resist or accept change (Fullan, 2007). As the principals transitioned from a devastating macropolitical budget crisis in August, 2010, I anticipated that they would alter their leadership styles and preserve open approaches that were 
employed earlier in the study. However, Miller's and Wilson's reliance on conflictive and authoritative approaches remained unchanged. Consequently, their dependence on vertical coordination, while enforcing mandates, rewards and sanctions, ensured the completion of tasks; however, these approaches alienated staff members from vital communication networks and school-wide micropolitical social structures, which impeded change (Bolman \& Deal, 2003; Hickcox \& Ryan, 1979; Scribner, Hager, \& Warne, 2002).

The processes both principals experienced were identical whether they were navigating micropolitical structures to create educational change during or after the time in which macropolitical crises penetrated their schools. Miller's and Wilson's management of decline, through the norm of impersonality and minimizing personal relationships, eroded trust and morale as teachers in both middle schools lost their motivation to implement change (Boyd, 1982). As a result, Miller and Wilson did not risk losing control over expectations, policies and procedures surrounding their changes and relied on their formal authority to push through staff resistance and implement educational change (Blase \& Anderson, 1995).

Subsequently, teachers did not have access to key micropolitical social and decisionmaking structures that decided who got what, when and how during an overbearing macropolitical crisis (Lasswell, 1959). Communication was pivotal, as Miller and Wilson navigated their micropolitical landscapes to create holistic educational change. Although Miller and Wilson were efficient decision makers, they were not effective communicators. Their unwillingness to lead through open approaches alienated teachers from the decision-making process. As cultures in Central and Northern Middle School became segmented, staff members were apathetic to administrative decisions and requests (Kanter, 1983). 
The lack of communication between the principals and their teachers left me with additional and unanswered questions. How would Miller's and Wilson's micropolitical landscapes alter if they employed research-based best practices to enact change? How would the results differ if they utilized collaborative structures and capacity building, and allowed teachers time to make sense of curricular and instructional changes? How would Miller and Wilson lead within their micropolital landscapes if the state budget crisis never happened? Undoubtedly, Miller's and Wilson's decisions to lead through conflictive and closed approaches were influenced by the fact that they were novice principals. They were both working within hierarchies that expected district initiatives to remain intact and fully implemented, especially since community members voted to pass their school budgets (Bjork \& Blase, 2009). However, Wilson's standing as an insider and known commodity in his school and district allowed him to work within a supportive network with superiors and colleagues (Stephenson \& Bauer, 2010). In part, this influenced Wilson's ability to successfully identify and navigate his micropolitical landscape and negotiate for educational change amid crises. By contrast, Miller's inability to understand her micropolitical landscape or engage in the politics of power-sharing with her colleagues and superiors jeopardized her effectiveness as an organizational leader, the confidence of her superiors and her position as a principal (Blase \& Bjork, 2009; Boyd, 1983). However, both principals faced a constraining micropolitical environment since they did not engender collaborative structures, negotiate macropolitical pressures with the needs of staff members or facilitate inclusive discussions on teaching and learning in their schools (Fullan, 2007; Miskel, Meisner, \& St. Clair, 1971).

Instead, the success or failure of the principals' abilities to create holistic educational change--during decline--was influenced by district administrators. Central office efforts to 
facilitate the implementation of initiatives were important to achieve educational change (Bjork \& Blase, 2009; Blase \& Bjork, 2009). The politics of decline, however, severely impeded district administrators' abilities to buffer or suppress macropolitical and micropolitical fallout and consequences. Central office administrators had the ability to build a system-wide framework and infrastructure to support discussions and decision making surrounding educational change (Fullan, 2007). Specifically, superintendents' abilities to build capacity amongst teachers and administrators were instrumental in building political support to advance change initiatives (Bjork \& Blase, 2009; Blase \& Bjork, 2009; Fullan, 2007). Lisa Miller’s central office administrators mandated that their building principals implement goals from the district's strategic action plan. Miller was expected to administer her own methods and procedures that would stimulate educational change, which led to varied interventions and results. Since the district did not build capacity from the ground up, Miller felt pressured to "try every single thing" she could do to enact change.

Alternatively, Wilson's district administrators assumed an active role, even during decline, to support their building principals through implementation of new initiatives. Although the district's ability to develop capacity was distributed unevenly, the superintendent's reliance on collaborative opportunities to bring administrators and teachers together to conceptualize curricular approaches and provide training in mathematics promoted educational change (Fullan, 2007). Subsequently, central office support to provide training in mathematics through consensual approaches influenced decentralized decision making and facilitated initiative implementation (Blase \& Anderson, 1995; Blase \& Bjork, 2009; Bolman \& Deal, 2003). Findings in Light of Existing Research 
The purpose of this study was to identify the micropolitics that novice principals faced as they interacted with teachers, parents, colleagues and superiors to create holistic educational change. Researchers have defined micropolitics in many different ways. Iannaccone (1975) defined micropolitics as "the interaction and political ideologies of social systems of teachers, administrators, and pupils within school buildings" (p. 43). Ball (1987) proposed that the realm of micropolitics included struggles over control of organizations, goals and the ideological content of policy making and decision making in schools. Blase (1991) noted that micropolitics refers to the use of formal and informal power by individuals and groups to achieve their goals in organizations. Bacharach and Mundell (1993) added that much of the political action that occurs in organizations takes place in groups. Individuals have neither political personalities nor access to power and need protection afforded by groups to engage in any political activity (Bacharach \& Mundell, 1993). This current year-long qualitative study of first and second year principals, during a period of decline in public education, revealed that micropolitics entailed disputes and clashes between individuals and groups who used their formal and informal authority to gain access to key social structures and decision-making processes to control and allocate diminishing resources surrounding educational change.

Ball (1987) noted that schools are at times run through participative and democratic processes, while at other times they are bureaucratic as decisions exclude teacher involvement or consultation. While Miller and Wilson did use open approaches at times, their reliance on conflictive and closed approaches constrained their micropolitical landscapes. They did not bring people and organizations together to politically negotiate order in their organizations (Bacharach \& Mundell, 1993; Ball, 1987). Contrary to Ball's (1987) recommendations, Miller and Wilson did rely on their formal authority to make final decisions to enact school initiatives - all of the 
time (Bacharach \& Mundell, 1993). Lisa Miller's leadership style matched Blase and Anderson's (1995) description of adversarial leadership in which principals rarely shared power and cast the appearance of being open while aggressively achieving their goals. Robert Wilson exemplified authoritarian leadership where teachers were ignored, dialogue suppressed, and negotiation, surrounding school initiatives, remained minimal and achieved behind closed doors (Blase \& Anderson, 1995). These types of principals also played by the "rules of the game" and routinely enforced policies and rules.

Consequently, teachers' perceptions of both principals mimicked the case studies of Blase and Anderson (1995) on closed and control-oriented leaders, as clashes and turf battles erupted, while trust and morale diminished. Staff members' reactions also reflected Kanter's (1983) description of top-heavy and controlling managers who created stifling environments through centralized decision making. Subsequently, mandating too much from the top devalued and ignored teachers' contributions to their schools (Friedman, Galligan, Albano \& O'Conner, 2009). In turn, the principals assumed bureaucratic roles and received constant pressure from teachers to gain access to communicative networks, while receiving pressure from superiors to enact district initiatives (Bridge, 1965; Weber, 1946). Miller's and Wilson's actions closely resembled traditional leadership theories, as Miskel, Meisner and St. Clair (1971) noted that organizational power tends to be distributed unevenly among members. Other researchers (Anderson, 1966; Bridges, 1965; Weber, 1946) described leaders utilizing control systems to exert their formal authority and jurisdiction over the ideologies, content and implementation of school and district initiatives. Principals, leading as bureaucrats, was similar to Boyd's (1982, 1983) findings during the politics of decline. Subsequently, this study confirmed and expanded 
previous research on principals and their management of retrenchment during the politics of decline.

Boyd (1983) described the macropolitical implications and realities of slashed budgets and declining confidence in public education, which impacted policy-making and management in schools. As school officials found themselves managing fiscal strain and declining enrollments, teachers lost their jobs; enrichment programs, extra-curricular activities and social services were reduced or eliminated. Consequently, resource allocation decisions became difficult and micropolitical interactions intensified (Boyd, 1982). Since retrenchment designated clear winners and losers, organizational members jockeyed for access to decisions and morale plummeted. Incentives for performance were no longer evident within the organization and members abandoned the organization for "greener pastures." During retrenchment, decisions became centralized (Boyd, 1983).

The macropolitical budgetary crisis that Miller and Wilson faced could have easily been supplanted in the period of decline in the 1970s. Similarly to Boyd's conclusion, the principals were not prepared to manage decline (Boyd, 1983). They were still expected to educate the whole child in their middle schools while resources dwindled. The principals worked laterally with superiors and colleagues to negotiate personnel decisions. They openly communicated with parents. However, communication between the principals and their teachers all but stopped, and teachers were less involved in decision making. Amidst and after this decline, Miller and Wilson reinforced formal organizational structures and hierarchies to ensure the completion of tasks. In 1983, Boyd noted the importance for government policies to strike a balance between policy mandates and infringement upon local control and the burdens these efforts have produced in terms of excessive regulations. Existing research describing the macro-micro relationships in 
conjunction with producing holistic educational change, within a domineering macropolitical climate, is lacking.

Mawhinney (1999) noted there is little consensus regarding what is uniquely micropolitical versus what is distinctly macropolitical. Bjork and Blase (2009) highlighted a competition between policy rhetoric and policy implementation at the local level. The treatment of macropolitics, in the form of local or federal government intervention, has provided an abstract and often unclear relationship between macro-micro interactions and processes. Undoubtedly, one does not exist without the other, and the two processes cannot be seen as separate and distinct entities. However, macropolitical realities vary in compatibility to micropolitical implications.

Numerous studies and researchers (Cosner, 2009; Darling-Hammond, 2005; Fullan, 2007) have espoused educational change through the use of building trust, capacity, and bottomup approaches for school community members to make sense of policy. These researchers often demand that local and federal policymakers delegate decisions about teaching and learning to schools. However, school districts are still facing enormous pressures from local and federal mandates through declining budgets and $N C L B$ student proficiency requirements. Consequently, these penetrating pressures leave principals little discretion or time to successfully implement mandates, while protecting and managing key micropolitical structures and networks from macropolitical realities.

This study provides a more concrete perspective on the relationships between macropolitical pressures driving and intensifying micropolitical interactions. The macropolitical realities provided first and second year principals little time to employ capacity building, grow as professionals and redesign the organization for ground-up collaborative structures. The 
unexpected, overwhelming and penetrating macropolitical conditions teachers and principals faced, from March, 2010 to June, 2010, made it difficult for any educational change to be adopted.

Implications for Future Research and Current Practices

This qualitative study of first and second year middle school principals illustrated how important it is for new principals to understand their micropolitical landscapes. The formal position holds many responsibilities ranging from school management, to supervision of teachers, to establishing community and professional relationships, to upholding organizational stability, to creating holistic educational change, which makes it difficult for a novice principal to devote time to understand micropolitics. However, the decisions surrounding who gets what, when and how creates a political working environment (Marshall \& Scribner, 1991; Marshall, 1984). Subsequently, every decision a principal makes will impact and, at times, disrupt key micropolitical structures and decision-making processes. Novice principals must know the effect of their decisions on existing micropolitical structures in their schools. They also must be aware of how their leadership styles directly influence social interactions and networks.

Administrators are living within a new Age of Decline where national pressures are becoming educationalized (Cuban, 2010). Public school districts are expected to respond to the country's problems of losing economic ground to global competitors. Principals must be in tune with how these pressures will present themselves in their schools through state or federal policy mandates and reforms. They must also be much more sophisticated at conceptual thinking, and transforming the organization through people and teams (Fullan, 2007). Subsequently, principals must employ consensual-based leadership approaches to include teachers in decision-making processes and communication structures (Blase \& Anderson, 1995). This strategy will help build 
and maintain a cohesive and collegial environment and empower teachers throughout the change process. How today's principals lead and manage relationships, during an age of decline, will influence their ability to create and engender holistic educational change.

Subsequently, it is imperative that new principals understand the change process. Since public confidence in public education is waning, principals must be prepared to combat and manage further erosion of valuable resources and personnel as decline persists. Principals' consequential actions during retrenchment could mean long periods of decline (Boyd, 1983). School officials will need to seek a delicate balance between discovering the best educational and programmatic solutions during decline, securing staff understanding, maintaining legitimacy for the policymaking process and moving rapidly on retrenchment decisions to avoid opposition and conflict over time (Boyd, 1982).

More broadly, concerns about the effectiveness of public schools have prompted increasing media criticism and public attention. National reformers and policymakers have embraced private education in the form of charter schools, and have pushed for higher academic standards. Moreover, federal and state government officials have called for school leaders to make real changes and promote organizational efficiency through sensible cuts. However, schools leaders must remain cognizant that retrenchment policies coupled with fiscal uncertainty increases the likelihood for disorder and inefficiencies in schools. Consequently, educational change during decline and retrenchment seems unlikely as staff members grow anxious over their professional worth and survivability within their roles. Additionally, public school principals face the possibility of declining enrollments in their schools, as Boyd's $(1982,1983)$ studies outlined in the late 1970s and early 1980s. Public school principals may also be forced to implement teacher pay for student performance mandates which would significantly and perhaps 
adversely influence micropolitical interactions in public schools (Lugg, 2001). Whether national rhetoric will manifest into public education policy throughout the country remains uncertain. However, future research determining how public education policy will reshape principals' roles and responsibilities during decline is needed.

Finally, this study captured the ideologies and values of subsystems between teachers and administrators, negotiations of boundaries and turf between administrators and teachers and how principals asserted bureaucratic leadership approaches for political ends. This study did not capture, however, how teachers revised or remade policy, during periods of decline, to fit their classrooms. Further research is needed to fully understand the effects of decline and retrenchment on teachers and their practices in the classroom. Further research is also needed to describe how principals continue to lead as macropolitical pressures, through slashed local and state budgets, continue to threaten public schools.

\section{Limitations}

This qualitative study explored the lived experiences of two novice public middle school principals. Both principals contributed a unique perspective to the study; however, it is difficult to generalize and transfer experiences of two novice principals, since each school setting represented a limited perspective of various micropolitical landscapes. The findings of this study were realized within two public middle schools in a specific socio-economic demographic that passed their school budgets. The macropolitical budgetary climate clearly amplified micropolitical interactions in each school landscape (Anderson, 1999). However, novice principals living the effects of a defeated school budget vote may have faced different micropolitical implications. The study also did not examine urban or lower socioeconomic suburban settings, which may contain differing micropolitical landscapes. 
The study depended on each participant's realistic view of his or her work performance and micropolitical interactions. The question persisted, throughout the study, whether all significant micropolitical events and realities were revealed. The political uncertainty made participants hesitant about sharing complete accounts of their micropolitical realities. They may have withheld mentioning a negative experience or conflict. What this sample also lacked was breadth, since each principal was followed for one year, which spanned two academic years. The study did not document subsequent years, which could have provided a wider perspective of micropolitics in contrast to macropolitical realities.

Finally, both principals had to manage their obligations to me during stressful periods. They completed bi-monthly email logs and in-depth interviews. My presence, as a researcher during field visits, served as yet another audience the novice principals instinctively felt compelled to manage. Consequently, time demands posed a concern, which could have affected the amount of information each principal shared during each email log or interview. The principals also could have felt a heightened sense of anxiety since they were being observed in the midst of a tumultuous macropolitical environment.

\section{Conclusion}

Every public school displays its own life, social climate, organizational culture, and subsystems (Iannaccone, 1991). First or second year middle school principals often find themselves contributing to and navigating through one element of these social systems known as the micropolitics of education. Consequently, novice public middle school principals face the challenge of identifying key micropolitical structures and landscapes within their public schools, and have the daunting task of navigating internal micropolitical structures and interactions in relationship to external macropolitical structures, while negotiating educational change 
(Bacharach \& Mundell, 1993; Hargreaves \& Goodson, 2006; Willower, 1991). This year-long qualitative study detailed the lived experiences of two suburban novice middle school principals and documented their attempts to identify their micropolitical landscapes through seemingly open approaches, and lead within their environments to negotiate holistic educational change (Blase \& Anderson, 1995).

However, both novice middle school principals were unprepared to manage a period of decline in public education (Boyd, 1982). The principals relied on closed and conflictive leadership approaches, as typically peripheral macropolitical elements became central actors in their micropolitical landscapes (Marshall, Mitchell \& Wirt, 1989). Consequently, formal hierarchies and structural vertical leadership styles were enforced through mandates, rewards and sanctions to ensure efficiency and compliance during implementation of school and district initiatives (Bolman \& Deal, 2003; Scribner, Hager, \& Warne, 2002). During periods of macropolitical ambiguity and uncertainty, each principal relied on coercive tactics to limit and control teachers' social interactions during grade-level team meetings, and access to micropolitical structures, which decided who got what, when and how. As communicative networks became inaccessible, teachers grew apathetic and disengaged from administrative decisions and requests to promote holistic educational change.

During current budgetary and economic decline, suburban novice middle school principals need to understand how their decisions impact existing micropolitical social structures. Novice principals also must be much more attuned to macropolitical policies and mandates, and be more sophisticated at conceptual thinking, and transforming the organization through people and teams (Fullan, 2007). 


\section{References}

Achinstein, B. (2002). Conflict amid community: The micropolitics of teacher collaboration. Teachers College Record, 104(3), 421-455.

Anderson, G. L. (1991). Cognitive politics of principals and teachers: Ideological control in an elementary school. In J. Blase (ed.) The politics of life in schools: Power, conflict and cooperation, (pp. 120-38). Newbury Park, CA: Sage.

Anderson, G. L. (1999). The politics of participatory reforms in education. Theory into Practice, 38(4), 190-195.

Anderson, J. G. (1966). Bureaucratic rules: Bearers of organizational authority. Educational Administration Quarterly, 2(1), 7-34.

Bacharach, S. B., \& Mundell, B. L. (1993). Organizational politics in schools: Micro, macro and logics of action. Educational Administration Quarterly, 29(4), 423-452.

Bailey, B. (2000). “The impact of mandated change on teachers.” In N. Bascia \& A. Hargreaves (Eds.), The Sharp Edge of Educational Change. New York: Routledge/Falmer.

Ball, S. J. (1987). The micro-politics of a school: Towards a theory of school organization. London: Methuen.

Bjork, L. G., \& Blase, J. (2009). The micropolitics of school decentralization. Educational Assessment, Evaluation and Accountability, 21(3), 195-208.

Blase, J., \& Anderson, G. (1995). The micropolitics of educational leadership: From control to empowerment, Cassell, London.

Blase, J. (1987). The politics of teaching: The teacher-parent relationship and the dynamics of diplomacy. Journal of Teacher Education, 38(2), 53-60. 
Blase, J. (1989). The micropolitics of the school: The everyday political orientation of teachers towards open school principals. Educational Administration Quarterly, 25(4), 377-407.

Blase, J. (1990). Some negative effects of principals' control oriented and protective political behavior. American Educational Research Journal, 27(4), 727-753.

Blase, J. (1991). The Politics of Life in Schools: Power, conflict and cooperation. Newbury Park, CA: Sage.

Blase, J. (1991). The micropolitical orientation of teachers towards closed school principals. Education and Urban Society, 23(4), 356-378.

Blase, J. (1993). The micropolitics of effective school-based leadership: Teachers' perspectives. Educational Administration Quarterly, 29(2), 142-163.

Blase, J. (1998). The micropolitics of educational change. In A. Hargreaves, A. Lieberman, M. Fullan \& D. Hopkins (Eds.), International Handbook of Educational Change (pp. 544557). Dordrecht, Netherlands: Kluwer.

Blase, J., \& Bjork, L. (2009). The micropolitics of educational change and reform: Cracking open the black box. In A. Hargreaves (Eds.), Second International Handbook of Educational Change (pp. 237-258). Netherlands: Springer.

Blase, J., \& Blase, J. (1994). Empowering Teachers: What Successful Principals Do. Newbury Park, CA: Corwin.

Blase, J., \& Blase, J. (1999). Principal's instructional leadership and teacher development: Teachers' perspectives. Educational Administration Quarterly, 35(3), 349-378.

Blase, J., \& Blase, J. (2002). The micropolitics of instructional supervision: A call for research. Educational Administration Quarterly, 38(1), 6-44. 
Bolman, L. G., \& Deal, T. (2003). Reframing organizations: Artistry, choice and leadership ( $^{\text {rd }}$ edition). San Francisco: Jossey-Bass.

Boyd, W. (1982). School governance in an era of retrenchment. University Park: Division of Education Policy Studies Institute for Public Policy and Management. (ERIC Document Reproduction Service No. ED236810)

Boyd, W. (1983). Political science and educational administration. Geelong, Victoria, Australia: Deakin University Press. (ERIC Document Reproduction Service No. ED295316)

Bridges, E. M. (1965). Bureaucratic role and socialization: The influence of experience on the elementary principal. Educational Administration Quarterly, 1(2), 19-28.

Brooks, J. S. (2005). The dark side of school reform: Teaching in the space between reality and utopia. Lanham, MD: Rowman \& Littlefield Education.

Bryk, A. S., \& Driscoll, M. E. (1988). The School as community: Theoretical foundations, contextual influences, and consequences for students and teachers. Madison: National center of Effective Secondary Schools, University of Wisconsin.

Central Middle School. (2008). District Strategic Planning: 2007 and Beyond. September 25, 2010.

Central Middle School. (2010). Common Planning Time Protocol. September 17, 2010.

Central Middle School. (2010). Strategic Action Plan 2009-2010. August 6, 2010.

Cosner, S. (2009). Building organizational capacity through trust. Educational Administration Quarterly, 45(2), 248-291.

Creswell, J. W. (1998). Qualitative inquiry and research design: Choosing among five traditions $\left(2^{\text {nd }}\right.$ Ed.). Thousand Oaks, CA: Sage. 
Creswell, J. W., \& Miller, D. L. (2000). Determining validity in qualitative inquiry. Theory into Practice, 39(3), 124-130.

Cuban, L. (2010). Professional learning communities: A popular reform of little consequence? Retrieved October 6, 2010, from http://larrycuban.wordpress.com

Darling-Hammond, L. (1992). Reframing the school reform agenda: Developing capacity for school transformation. Phi Beta Kappan, 74(10), 752-761.

Darling-Hammond, L. (2005). Policy and change: Getting beyond bureaucracy. In A. Hargreaves, (Ed.), Extending Educational Change (pp. 362-387). Dordrecht, Netherlands: Springer.

Duke, D. L., Isaacson, N. S., Sagor, R., \& Schmuck, P. A. (1984). Transition to leadership: An investigation of the first year principalship. Portland, OR: Lewis and Clark College, Educational Administration Program.

Eagly, A. H., Karau, S. J., \& Johnson, B. T. (1992). Gender and leadership style among school principals: A meta-analysis. Educational Administration Quarterly, 28(1), 76-102.

Erickson, F. (1987). Conceptions of school culture: An overview. Educational Administration Quarterly, 23(4), 11-24.

Foster, W. P. (2004). The decline of the local: A challenge to educational leadership. Educational Administration Quarterly, 40(2), 176-191.

Friedman, A., Galligan, H., Albano, C., \& O’Conner, K. (2009). Teacher subcultures of democratic practice admist the oppression of educational reform. Journal of Educational Change, 10(4), 249-276.

Fullan, M. (2007). The new meaning of educational change. $4^{\text {th }}$ edition. New York: Teachers College. 
Gordon, J., \& Patterson, J. (2008). "It's what we've always been doing." Exploring tensions between school culture and change. Journal of Educational Change, 9(1), 17-35.

Griffith, J. (1999). The school leadership/school climate relation: Identification of school configurations associated with change in principals. Educational Administration Quarterly, 35(2), 267-291.

Hanson, E. M. (1979). Educational administration and organizational behavior. Boston: Allyn \& Bacon.

Hargreaves, A. (1998). Pushing the boundaries of educational change. In A. Hargreaves et al. (Eds.) International Handbook of Educational Change. London: Kluwer, 281-294.

Hargreaves, A., \& Goodson, I. (2006). Educational change over time? The sustainability of nonsustainability of three decades of secondary school change and continuity. Educational Administration Quarterly, 42(1), 3-41.

Hess, F. M., \& Leal, D. L. (2001). The opportunity to engage: How race, class and institutions structure access to educational deliberation. Educational Policy, 15(3), 474-490.

Hickcox, E., \& Doris, R. (1979). Governance and administration in a period of declining enrollments. Curriculum Inquiry, 9(4), 305-320.

Hoy, W. K., \& Hannum, J. W. (1997). Middle school climate: An empirical assessment of organizational health and student achievement. Educational Administration Quarterly, 33(3), 290-311.

Hoy, W. K., \& Sweetland, S. R. (2001). Designing better schools: The meaning and measure of enabling school structures. Educational Administration Quarterly, 37(3), 296-321.

Iannaccone, L. (1975). Educational policy systems. Fort Lauderdale, FL: Nova University Press. 
Iannaccone, L. (1991). Micropolitics of education: What and why. Education and Urban Society, 23(4), 465-471.

Johnson, B. L. (2001). Micropoltical dynamics of education interests: A view from within. Educational policy, 15(1), 115-134.

Kanter, R. M. (1983). The change masters: Innovation for productivity in the American corporation. New York: Simon and Schuster, 1983, Ch. 3.

Kardos, S. M., Johnson, S. M., Peske, H. G., Kauffman, D., \& Liu, E. (2001). Counting on colleagues: New teachers encounter the professional cultures of their schools. Educational Administration Quarterly, 37(2), 250-290.

Lasswell, H. D. (1959). Political constitution and character. Psychoanalysis and the Psychoanalytic Review, 46(4), p. 3-18.

Licata, J. W., \& Hack, W. G. (1980). School administrator grapevine structure. Educational Administration Quarterly, 16(3), 82-89.

Lindle, J., \& Mawhinney, H. (2003). Introduction: School leadership and the politics of education. Educational Administration Quarterly, 39(1), 3-9.

Lortie, D. C. (1975). Schoolteacher: A sociological study. Chicago: The University of Chicago Press.

Lugg, C. A. (2001). Congress, teachers and the peril of merit pay. A report for the Center for Educational Research, Analysis and Innovation. Milwaukee, WI: University of Wisconsin, Milwaukee.

Marshall, C. (1985). Professional shock: The enculturation of the assistant principal. Education and Urban Society, 18(1), 28-58. 
Marshall, C., Mitchell, D., \& Wirt, F. (1989). Culture and education policy in the American states. London: Falmer Press.

Marshall, C., \& Scribner, J. (1991). It's all political: Inquiry into the micropolitics of education. Education and Urban Society, 23(4), 347-355.

Marshall, C., \& Rossman, G. B. (1998). Designing qualitative research: $3^{\text {rd }}$ Edition. London: Sage Publications.

Mawhinney, H. B. (1999). Reappraisal: The problems and prospects of studying the micropolitics of leadership in reforming schools. School Leadership and Management, 19(2), 159-170.

McGregor, D. M. (1957). The human side of enterprise. In J.M. Shafritz \& J.S. Ott (Eds.), Classics of Organization Theory (pp. 174-180). Belmont, CA: Wadsworth Publishing Company.

Miskel, C., Meisner, R., \& St. Clair, K. (1971). An investigation of the politics of education using two theories of social organization as a conceptual guide. Educational Administration Quarterly, 7(3), 64-77.

New Jersey Department of Education. (2009). No Child Left Behind Report. Retrieved September 14, 2010, from http://education.state.nj.us/rc/nclb09/index.html

New Jersey Department of Education (2010). 2010-2011 School Accountability and AYP. Retrieved November 5, 2010, from http://education.state.nj.us/education/title1/accountability/ayp/1011

New Jersey Department of Education: Division of Finance. (2010). Projected SFRA state school aid 2010-2011 and projected total school aid 2010-2011. Retrieved July 22, 2010, from www.state.nj.us/stateaid 
Parkay, F. W., Currie, G. D., \& Rhodes, J. W. (1992). Professional socialization: A longitudinal study of first-time high school principals. Educational Administration Quarterly, 28(1), 43-75.

Patton, M. Q. (1987). Field work and observation. In How to use qualitative methods in evaluation. Thousand Oaks: CA: Sage.

Patton, M. Q. (1990). Qualitative evaluation and research methods. Newbury Park: Sage.

Rhodes, R., \& Marsh, D. (Eds.) (1992). Policy networks in British government. Oxford: Clarendon Press.

Schein, E. H. (1985). Defining organizational culture. Organizational Culture and Leadership. San Francisco: Jossey-Bass.

Scott, R. W. (2002). The subject is organizations. Organizations: Rational, Natural and Open Systems. Englewood Cliffs: Prentice Hall.

Scribner, J. P., \& Donaldson, J. F. (2001). The dynamics of group learning in a cohort: From non-learning to transformative learning. Educational Administration Quarterly, 35(5), 605-636.

Scribner, J. P., Hager, D. R., \& Warne, T. R. (2002). The paradox of professional community: Tales from two high schools. Educational Administration Quarterly, 38(1), 45-76.

Sergiovanni, T. J. (1994). Organizations or communities? Changing the metaphor changes the theory. Educational Administration Quarterly, 30(2), 214-226.

Smircich, L., \& Morgan, G. (1982). Leadership: the management of meaning. The Journal of Applied Behavioral Science, 18(3), 257-73.

Stephenson, L. E., \& Bauer, S. C. (2010). The role of isolation in predicting new principals' burnout. International Journal of Education Policy and Leadership, 9(5), 1-17. 
Tooms, A. K., Kretovics, M. A., \& Smialek, C. A. (2007). Principals' perceptions of politics. International Journal of Leadership in Education, 10(1), 89-100.

Tyack, D., \& Cuban, L. (1995). Tinkering toward utopia: A century of public school reform. Cambridge: Harvard University Press.

Wahlstrom, K. L., \& Louis, K. S. (2008). How teachers experience principal leadership: The roles of professional community, trust, efficacy, and shared responsibility. Educational Administration Quarterly, 44(4), 458-495.

Weber, M. (1946). Bureaucracy. Essays in Sociology. Oxford University Press, Inc.

Willower, D. (1991). Micropolitics and the sociology of school organizations. Education and Urban Society, 23(4), 442-454.

Wolcott, H. F. (1984). The man in the principal's office: An ethnography. New York: Holt, Rinehart \& Winson.

Yin, R. K. (2009). Case study research: Design and methods ( ${ }^{\text {th }}$ Ed.). Thousand Oaks, CA: Sage Publishing. 


\section{APPENDICES}

Appendix A: Data Collection Instruments for Principals

Interview Topics

All interviews will follow a mixed general guide approach and standardized open-ended interview format, in which I will ask the principals to share with me learning experiences that will relate to the following topics:

- Student Management

- Parents

- Teachers

- Board of Education Members

- School Management

- Paperwork/Procedures

- Politics

- Hidden Politics

- Time Management/Stress

- Union Issues

- Parent-Teacher Association

- Special Interest Groups

- Public Relations

- Special Assignments/Mandates

- Regional/State/Federal Expectations

- Superiors

- Daily Tasks 
- Control 
Time of interview:

Date:

Place:

Interviewer:

Interviewee:

Interview \#1: January 2010 Principal Interview Questions

1. What do you expect in your new role?

2. What do you expect to be your highest priority issues this year?

3. How are you planning to tackle daily tasks, while addressing high priority concerns?

4. What, in your position, are you feeling good about?

5. If you were truly stumped by a situation, what would you do? Who would you turn to, or how might you work the problem?

6. What do you wish you had more guidance or preparation on?

7. How will you identify school community expectations for this year?

8. What do you perceive as school community expectations for this year?

9. How do you expect to fit into the school community given your new role? 
Time of interview:

Date:

Place:

Interviewer:

Interviewee:

Interviews \#2 through \#6: March through October 2010 Principal Interview Questions

1. How has this year gone so far for you?

2. What, in your position, are you feeling confident about?

3. Can you tell me about something difficult or challenging you faced this year, and how you worked through that?

4. Can you tell me about any conflicts you have had with individuals or groups? What role did you play if any in the conflict or handling it?

5. Do you think you have had too much support/advice/pressure to conform?

6. Has there been anything you felt pressured to do that conflicted with your own preferences, or any compromises you have had to make?

7. What experiences have you had with groups within the school like departments, grade level teams, committees, community groups?

8. What are you planning and expecting for upcoming weeks?

9. Can you tell me your experiences this year with:

○ Parents

○ Teachers

○ Board of education members

- School culture

○ Time management/stress

- Superiors 
- Public relations

○ Politics

○ Hidden politics

- School/District/State Mandates 
Time of interview:

Date:

Place:

Interviewer:

Interviewee:

Interview \#7: December 2010 Principal Interview Questions

1. What have you had to do to be accepted as a principal in your school community? Was there a process for full membership? Can you describe it? What priorities does your school community seem to have for a new principal?

2. Can you tell me a success story from this year?

3. What will you did you do differently in your second year? What is something you want to do "better"?

4. Can you recall a specific moment that taught you something about the principalship?

5. Can you recall a specific conversation or learning experience with a colleague that taught you something about the principalship?

6. How did your interactions with your colleagues influence your transition into the school community?

7. How did you identify and navigate all of the school community members and their interests this year?

8. Can you recall a specific moment that taught you about your school environment?

9. In what areas of school life did you try to exercise control, and in what areas did you cede control to others?

10. Can you describe your most significant encounters this year?

11. Why were they so significant? 
12. Can you tell me your experiences this year with:
○ Parents
○ Teachers
- Board of education members
○ School culture
○ Time management/stress
○ Superiors
○ Public Relations
○ Politics
○ Hidden Politics
- School/District/State Mandates 
January 2010 through December 2010 Bi-monthly Email Log Questions

Each member will provide an overview of the following bi-monthly:

1. How did your past two weeks go?

2. What formal and informal encounters did you have with school community members?

3. Can you describe your most significant encounter during the past two weeks?

4. What made the encounter so significant?

5. What events or encounters do you think were successful?

6. What would you do differently if you could?

7. What are you planning and expecting for upcoming weeks? 
January 2010 through December 2010 Phone Check Questions

In the event a subject does not supply an e-mail log for a given period of time, I will follow up with a brief phone check:

1. How did your past two weeks go?

2. What formal and informal encounters did you have with school community members?

3. Can you describe your most significant encounter during the past two weeks?

4. What made the encounter so significant?

5. What events or encounters do you think were successful?

6. What would you do differently if you could?

7. What are you planning and expecting for upcoming weeks? 
Appendix B: Data Collection Instruments for School Community Voices

All interviews will follow a standardized open-ended interview format, in which I will ask the lead teachers or facilitators, school-based union representatives and the president of the parentteacher association to share with me learning experiences that will relate to the following topics:

Time of interview:

Date:

Place:

Interviewer:

Interviewee:

Position of interviewee:

Interview \#1: January 2010 School Community Voices Interview Questions

1. What is your role within the school or district?

2. What issues are currently important to you?

3. How do you perceive your role within the school?

4. Which groups do you see as being most influential in the school or district?

5. How are your concerns currently being addressed?

6. What do you perceive as the needs of the district and school?

7. What do you hope to see for the rest of the year? 
Time of interview:

Date:

Place:

Interviewer:

Interviewee:

Position of interviewee:

Interview \#2 June 2010 School Community Voices Interview Questions

1. How do you perceive the year going for the school or community?

2. What issues are currently important to you?

3. What issues do you see being addressed?

4. How are school and community issues being addressed?

5. How are your concerns currently being addressed?

6. Which groups do you currently see as being the most influential in the school or community?

7. What do you hope to see next year? 
Time of interview:

Date:

Place:

Interviewer:

Interviewee:

Position of interviewee:

Interview \#3: December 2010 School Community Voices Interview Questions

1. How do you perceive the year going for the school or community?

2. What major issues were addressed in the school or community?

3. Which groups are currently the most influential in the school or community?

4. How were school and community issues addressed over the past year?

5. How were your concerns addressed over the past year?

6. What do you hope to see for the rest of the year? 


\title{
Appendix C: IRB Review Approval Notice
}

\author{
RUTGERS UNIVERSITY \\ Office of Research and Sponsored Programs \\ ASB III, 3 Rutgers Plaza, Cook Campus
}

New Brunswick, NJ 08901

November 19, 2009

P.I. Name: Caruso

Protocol \#: E10-121

Louis F. Caruso

54 Alexandria Way

Basking Ridge NJ 07920

Dear Louis Caruso:

\section{$\underline{\text { Notice of Exemption from IRB Review }}$}

Protocol Title: "The Micropolitics of Educational Change Experienced by Novice Public Middle School Principals"

The project identified above has been approved for exemption under one of the six categories noted in 45 CFR 46, and as noted below:

Exemption Date: 10/25/2009 Exempt Category: 2

This exemption is based on the following assumptions:

- This Approval - The research will be conducted according to the most recent version of the protocol that was submitted.

- Reporting - ORSP must be immediately informed of any injuries to subjects that occur and/or problems that arise, in the course of your research;

- Modifications - Any proposed changes MUST be submitted to the IRB as an amendment for review and approval prior to implementation;

- Consent Form (s) - Each person who signs a consent document will be given a copy of that document, if you are using such documents in your research. The Principal Investigator must retain all signed documents for at least three years after the conclusion of the research;

Additional Condition: Authorization from the following research site must be forwarded to the IRB prior to commencement of study procedures at the site(s): All Participating School Districts.

Additional Notes: None

Failure to comply with these conditions will result in withdrawal of this approval.

The Federalwide Assurance (FWA) number for Rutgers University IRB is FWA00003913; this number may be requested on funding applications or by collaborators.

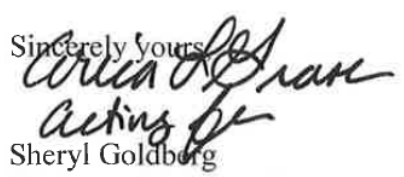

Director of Office of Research and Sponsored Programs

egraser@grants.rutgers.edu

cc: Catherine Lugg 